\title{
Meeting abstracts
}

\section{3rd European Workshop for Rheumatology Research}

\author{
Marseille, France \\ 27 February - 2 March 2003
}

Received: 14 January 2003 Published: 24 February 2003

(c) 2003 BioMed Central Ltd (Print ISSN 1478-6354; Online ISSN 1478-6362)

\section{Autoantibodies and antigens}

1

\section{Rheumatoid arthritis - class prediction by autoreactivity profiles}

R Bergholz1, F Schumann1, S Behrens', U Ungethüm1, G Valet², WA Schmidt ${ }^{3}$, GR Burmester ${ }^{1}$, JM Engel ${ }^{4}$, WJ van Venrooij ${ }^{5}$, G Steiner6 ${ }^{6}$ S Bläß1

${ }^{1}$ Department of Rheumatology \& Clinical Immunology, Charité University Clinic, Berlin, Germany

2MPI Biochemistry, Munich, Germany

${ }^{3}$ Clinic for Rheumatology Berlin Buch, Berlin, Germany

${ }^{4}$ Rheumaklinik, Bad Liebenwerda, Germany

${ }^{5}$ Department of Biochemistry, University of Nijmegen,

The Netherlands

${ }^{6}$ Divison of Rhematology, Department Internal Medicine III, Vienna

General Hospital, Austria

Arthritis Res Ther 2003, 5 (suppl 1):1

Heterogeneity and multifactoriality complicate diagnostics and our understanding of pathogenesis of rheumatoid arthritis (RA). The only accepted serologic parameter (rheumatoid factor [RF]) is not disease specific, nor are any of several novel RA autoantibodies. We aimed at identifying profiles instead of individual autoreactivities allowing for unambiguous prediction of RA.

Selected RA autoantigens were tested by ELISA (RF and anti-cyclic citrullinated peptide [anti-CCP]) or Western blot (heavy-chain-binding protein $[\mathrm{BiP}]$, heterogeneous ribonucleoprotein particle A2 [RA33/ hnRNP A2], calpastatin and calreticulin). Antibody reactivities were assayed from serum samples of 149 RA patients and 132 patients with other rheumatic diseases and from synovial fluids (SF) (58 RA, 65 non-RA).

No single autoreactivity was sufficient for unambiguous prediction of RA. Frequencies of multiparameter profiles consisting of $3,4,5$ and 6 autoreactivites were determined. Fifteen six-parameter serum profiles were exclusively expressed in RA patients, representing a cumulative sensitivity of $59 \%$. Twelve SF profiles were exclusively expressed in $64 \%$ of RA patients. The self-learning classification algorithm CLASSIF1 was capable of accurately predicting RA when these profiles were present. Data profile analysis of $\mathrm{RF} / \mathrm{CCP} / \mathrm{BiP} /$ calpastatin/calreticulin/RA33 provided specific discrimination of $64 \%$ of RA. Most importantly, RA specific profiles were observed in $64 \%$ of patients with early disease ( $<12$ months).

For the first time, the accurate prediction of the class RA has been achieved by the use of multiparametric autoreactivity profiles. Because of early expression in disease, these profiles make it possible to start a disease-modifying therapy long before irreversible bone and joint destruction may develop. Additional RA-specific profiles are required to cover the entire group of RA patients.
2

Investigation of the reactivity patterns of antifilaggrin antibodies in sera and synovial fluids from patients with rheumatoid arthritis using citrullinated synthetic peptides

M Brózik', J Szakonyi², A Magyar ${ }^{3}$, B Rojkovich', R Tobi ${ }^{3}$, F Hudecz ${ }^{3}$, P Gergely ${ }^{2}$, K Merétey ${ }^{1}$

${ }^{1}$ National Institute of Rheumatology, Frankel Leo u 25, Budapest, Hungary

${ }^{2}$ Central Laboratory of Immunology, Faculty of Medicine, Semmelweiss Medical University, Budapest, Hungary

${ }^{3}$ Peptide Chemistry Research Group, Eötvös Lóránd University, Budapest, Hungary

Arthritis Res Ther 2003, 5 (suppl 1):2

Antifilaggrin antibodies comprise a heterogeneous population of antibodies directed to citrullinated proteins.

Recent studies have shown that their production is highly specific for rheumatoid arthritis (RA) and the initial antigenic trigger for these autoantibodies can be localised to the inflammed synovial tissue.

The aim of our study was to compare the reactivity and specificity of antibodies in sera and synovial fluids towards citrullinated epitopes. Peptide sequence corresponding to human profilaggrin (amino acid residues 306-324) and sequences with citrulline substitution at different positions were synthetised by mutipin peptide synthesis on solid supports. Shortened versions of the peptide were also produced by removal of amino acid residues from its $\mathrm{N}$ and $\mathrm{C}$ terminals. Completely citrullinated variant of the 14-mer peptide was also prepared. Peptide with no citrulline replacement was used as a control antigen. We found significant differences in the sensitivity for RA of 19 individual peptides tested (from $5 \%$ to $68 \%$ ), reflecting previous results that the surrounding amino acids play an important role in creation of an autoantigenic epitope. Further, we tested the reactivities of paired serum and synovial fluids and found very similar peptide recognition patterns in serum and synovial IgG from the same individuals. Studies on larger number of samples are in progress to evaluate the results statistically that may support further evidence of the synovial origin of antifilaggrin autoantibodies.

Acknowledgement: This work was supported by the Hungarian grant OTKA T037876.

\section{3}

Analysis of the peptidylarginine deiminase $\mathbf{V}$ gene in rheumatoid arthritis

L Caponi', E Petit-Teixeira ${ }^{3}$, M Sebbag' ${ }^{2}$ F Bongiorni', S Moscato', F Pratesi', J Osorio', M Guerrin-Weber ${ }^{3}$, F Cornelis ${ }^{3}$, G Serre ${ }^{2}$, P Migliorini for European Consortium for Rheumatoid Arthritis Families (ECRAF)

${ }^{1}$ Clinical Immunology Unit, University of Pisa, Pisa, Italy

2INSERM U563, Toulouse, France

${ }^{3} E C R A F$ and Genople EVRY, France

Arthritis Res Ther 2003, 5 (suppl 1):3

A number of rheumatoid arthritis (RA) sera contain antibodies specific for peptides in which arginine is substituted by the deiminated form cit- 
rulline (AKA). These antibodies are a marker of RA, as they are absent in other disorders. The enzyme responsible for the generation of citrulline residues, peptidylarginine deiminase (PAD), has different isoforms, with a specific tissue distribution. PADV, expressed in monocytes, might be responsible for the deimination of arginine residues of synovial proteins and thus be involved in the generation of epitopes for RA-specific antibodies. The ECRAF genome scan showed suggestive linkage evidence at PADV locus on chromosome 1 $(P<0.005)$. We decided to analyze $P A D V$ as a candidate gene for RA, studying a cohort of 100 RA patients (tested for AKA) and their unaffected parents. Investigation (by single-strand conformation polymorphism [SSCP] analysis and sequencing) of the 16 exons, $5^{\prime}$ and $3^{\prime}$ regions of the PAD V gene provided polymorphisms in the $5^{\prime}$, exons 3,4 , and 7 and $3^{\prime}$ regions. Analysis used the transmission disequilibrium test and the haplotype relative risk for alleles and haplotypes with Analyze and Genhunter2 programs.

We found an association between RA and one PAD V haplotype (38\% in RA versus $17 \%$ in controls) $(P<0.007)$. The association was also observed in the AKA+ RA subgroup $(41 \%)(P<0.03)$.

In conclusion, the PAD V gene may be considered one of the genetic factors that confer susceptibility to RA. Studies are in progress to clarify the relationship between the PADV haplotypes, the enzyme activity and the production of anticitrulline antibodies.

\section{4}

\section{Subclass distribution of IgG autoantibodies to deiminated fibrinogen in rheumatoid arthritis S Chapuy-Regaud, L Nogueira, C Clavel, M Sebbag, C Vincent, G Serre}

Department of Epidermis Differentiation and Rheumatoid Autoimmunity, INSERM U563, Toulouse, France Arthritis Res Ther 2003, 5 (suppl 1):4

Background: Antifilaggrin autoantibodies, previously known as 'antikeratin' antibodies or antiperinuclear factor, are serum IgG that constitute the most specific diagnostic markers of rheumatoid arthritis (RA). We showed that they specifically recognise deiminated forms of the $\alpha$ and $\beta$ chains of fibrin in the rheumatoid synovium. Subsequently, we developed a new ELISA for these autoantibodies, using in vitro deiminated human fibrinogen as immunosorbent (AhFibA-ELISA). We evaluated its diagnostic performance in a cohort of 617 patients with well-characterised rheumatic diseases, including 181 patients with established RA: at a diagnostic specificity of $98.5 \%$, the ELISA presents a diagnostic sensitivity of $76 \%$. It is to date the most efficient test for the diagnosis of RA.

Objective: On the basis of this test, we undertook to determine the subclass distribution of AhFibA.

Methods: From the AhFibA-ELISA, four ELISAs using monoclonal antibodies to each IgG subclass (IgG1, IgG2, IgG3 and IgG4) were developed. The ELISAs were adjusted to allow the respective proportions of each AhFibA subclass to be determined in each serum sample tested. 141 RA patients positive for AhFibA were analysed.

Results: For each IgG subclass, the titres (optical density [OD] values) in the whole population of patients were found to be significantly correlated with those obtained with the AhFibA-ELISA. IgG1 AhFibA reached the highest $O D$ values (range 0.137-3.028, median: 1.125), followed by lgG4 AhFibA (range 0-2.846, median 0.043), IgG3 AhFibA (range 0-1.448, median 0.034) and lastly lgG2 AhFibA (range $0-0.695$, median 0.040). The predominance of IgG1 AhFibA was also observed at the individual level since, among the 141 AhFibA-positive sera, all but one contained at least $40 \%$ of IgG1 AhFibA. In $39.7 \%$ of the sera, one or several other subclasses accounted for more than $10 \%$ of total AhFibA. IgG4 AhFibA was the most frequently associated subclass, $25 \%$ of the sera containing more than $10 \%$ of these antibodies. Only 10.7 and $7.9 \%$ of the sera contained more than $10 \%$ of $\lg$ 22 and IgG3 AhFibA, respectively.

Conclusion: These results confirm and extend those previously
The predominance of $\lg \mathrm{G} 1 \mathrm{AhFibA}$, and their frequent association with IgG4 AhFibA, raises the question of the Th1/Th2 balance in RA. Moreover, the predominance of IgG1 AhFibA is compatible with effector mechanisms involving complement activation and/or the engagement of Fc gamma receptors.

5

\section{Peptidylarginine deiminase isoforms expressed in the synovial membrane of rheumatoid arthritis patients}

S Chapuy-Regaud', M Sebbag', R Nachat ${ }^{1}$, D Baeten'2, V Foulquier1, M Simon'1, T Senshu ${ }^{3}$, M Yamada ${ }^{3}$, H Takahara4, F De Keyser' ${ }^{2}$, G Serre ${ }^{1}$

${ }^{1}$ Department of Epidermis Differentiation and Rheumatoid Autoimmunity, INSERM U563, Toulouse, France

2Department of Rheumatology, Ghent University Hospital, Ghent, Belgium

3Yokohama City University, Yokohama, Japan

4Ibaraki University, Ibaraki, Japan

Arthritis Res Ther 2003, 5 (suppl 1):5

Background: Antifilaggrin autoantibodies (AFAs) are highly specific for rheumatoid arthritis and are probably involved in its pathophysiology. We showed that they are synthesised in the rheumatoid synovial membrane and that their target antigens in the tissue correspond to variants of the $\alpha$ and $\beta$ chains of fibrin. The variants are generated by deimination, i.e. transformation of their arginine into citrulline residues. Deimination, mediated by a peptidylarginine deiminase (PAD) activity, generates the epitopes recognised by AFA/antifibrin autoantibodies. Four PAD isoforms (or types), have been identified and cloned in humans and rodents (mouse and rat). Expression of one or several of these isoforms has been reported in numerous tissues, but their targets are still poorly known.

Objective: Since fibrin deimination occurs in the rheumatoid synovial tissue, we undertook to identify which PAD types are expressed in the tissue.

Methods: By immunising rabbits with peptides situated in the most variable regions of the otherwise highly conserved PAD type sequences (three synthetic peptides per PAD), we produced antisera specific for each of the four PAD isoforms. The antisera were affinity-purified on the corresponding peptides. Each set of anti-peptide antibodies was confirmed to be specific for one isoform by immunoblotting on recombinant or purified PADs. Additional antisera or purified antibodies to whole human PADs II, III and V were used to confirm the results obtained with the anti-peptide antibodies.

The synovial tissue from seven patients with rheumatoid arthritis was analysed. In all the tissues, the presence of deiminated proteins and particularly of deiminated fibrin was demonstrated by immunoblotting and/or immunohistology. Then low-salt extracts of the tissues were analysed by immunoblotting with all the immunological tools to PADs. Results: Expression of PAD type $V$ was clearly detected in all seven patients. Expression of PAD type II was observed in six patients. No reactivities were observed with antibodies specific for PAD types I and III.

Conclusion: Of the four PAD isoforms, only the types II and V are significantly expressed in the synovial tissue of patients with rheumatoid arthritis. Their respective roles in deimination of fibrin in the tissue remain to be determined.

\section{6}

\section{Paratope diversity of anti-prothrombin antibodies S Cucnik, T Kveder, B Bozic}

Department of Rheumatology, University Medical Centre, Ljubljana, Slovenia Arthritis Res Ther 2003, 5 (suppl 1):6

To ascertain the heterogeneity of anti-prothrombin antibodies (aPT), we compared three in-house aPT ELISAs: A) medium binding plates, phosphatidylserine, prothrombin, Tris-buffered saline, calcium; B) high binding plates, prothrombin, Tris-buffered saline; and C) high binding 
plates, prothrombin, PBS. One serum, exhibiting high positive aPT in all three ELISAs, was selected as the calibrator. Sera from 47 patients (41 with SLE, 4 with pAPS, 2 with arterial thromboses) were tested for $\lg \mathrm{G}$ and $\lg \mathrm{M}$ aPT.

The results showed six different patterns: 1) similar results were obtained with $A, B$ and $C$ (similar analytical sensitivity); 2) similar results were obtained with $A$ and $B$ while $C$ showed lower analitycal sensitivity; 3) $B$ and $C$ seemed analytically less sensitive than $A$; 4) $A$ and $B$ were analytically less sensitive than $C$; 5 ) A showed very low analytical sensitivity; 6) A and C showed lower analytical sensitivity than B.

The analysis of all the presented patterns showed noncomparable results of the three ELISAs. In our experiments, prothrombin was recognized by relevant antibodies when the protein was bound to phosphatidylserine-coated microtiter plates using calcium ions or when it was bound to high binding plates with or without calcium ions. Nevertheless, detected aPT values were not of the same fine specificity. Different binding conditions for prothrombin exposed different epitopes, resulting in the detection of various subgroups of aPT.

\section{7}

\section{High-affinity antibodies against $\beta_{2}$-glycoprotein I S Cucnik, T Kveder, A Ambrozic, B Borut}

Department of Rheumatology, University Medical Centre, Ljubljana, Slovenia

Arthritis Res Ther 2003, 5 (suppl 1):7

Background: Antibodies against $\beta_{2}$-glycoprotein I (anti- $\beta 2 \mathrm{GPI}$ ) are believed to be of low affinity and thus unable to bind to the free antigen in a solution.

Objective: The aim of our study was to determine the affinity of IgG anti- $\beta 2 \mathrm{GPI}$, isolated by affinity chromatography.

Methods: A $\beta 2 \mathrm{GPI}$ affinity column was prepared by $\mathrm{CNBr}$-activated agarose without spacer arms and human purified unnicked $\beta 2 \mathrm{GPI}$. The IgG fraction from the protein $G$ column was applied to the column and bound antibodies were eluted with various solutions: A) $0.1 \mathrm{M}$ glycine / $0.5 \mathrm{M} \mathrm{NaCl} / 0.1 \%$ Tween $20 \mathrm{pH} 2.5$; B) $0.1 \mathrm{M}$ glycine / $4 \mathrm{M} \mathrm{NaCl} /$ $0.1 \%$ Tween $20 \mathrm{pH} 2.5$; C) $0.1 \mathrm{M}$ sodium borate $\mathrm{pH} 10$ and D) $25 \%$ ethylene glycol. Eluted fractions containing anti- $\beta 2 \mathrm{GPI}$ antibodies were neutralised and analysed by ELISA using various binding buffers. The level of anti- $\beta 2$ GPI antibodies in each sample was derived from the standard curve according to the defined dilutions of monoclonal antibodies (AUG are arbitrary units of $\lg G$ monoclonals).

Results: Increased concentrations of sodium ions in the binding solution from $0.15,0.25,0.50,1.11,2.07$ and $4.0 \mathrm{M} \mathrm{NaCl}$ did not completely prevent the binding between isolated antibodies and $\beta_{2}$-GPI (79.8, 65.3, 36.1, 19.9, 12.0 and 8.1 AUG, respectively).

Conclusion: In contrast to the common opinion that all anti- $\beta 2 \mathrm{GPI}$ autoantibodies are of low affinity, we clearly showed that at least one subset among them was of high affinity.

\section{8}

\section{Anti-Ro/SSA antibodies in rheumatoid arthritis (RA) F Franceschini, I Cavazzana, F Malacarne, P Airò, R Cattaneo, N Del Papa, A Radice, RA Sinico}

\section{Piazzale Spedali Civili, Brescia, Italy}

Arthritis Res Ther 2003, 5 (suppl 1):8

Background: AntiRo are found in $5-15 \%$ of RA. Significant associations were reported with sicca, vasculitis, hypergammaglobulins, ANA, high-titer RF, toxicity to D-penicillamine and gold salts treatment. Aim of the study: to evaluate clinical features, radiologic progression and response to disease-modifying antirheumatic drugs (DMARDs) in antiRo-RA patients.

Patients and methods: We studied 210 patients with RA: antiRo were determined by $\mathrm{CIE}$, with human spleen extract, and by ELISA with recombinant Ro proteins (Pharmacia). Cutoff values for ELISA were determined testing 177 sera from routine.
Results: AntiRo were detected in 27 patients (F:M 12.5:1). Two groups (antiRo ${ }^{+}$and antiRo-) did not show any difference with regard to disease duration, arthritis onset and articular erosions. AntiRo were associated with xerophthalmia $(P<0.0000001)$, xerostomia $(P=0.0012)$, oral ulcers $(P=0.0067)$, scleritis $(P=0.0067)$ and amyloidosis $(P=0.042)$. Rheumatoid factor, antiperinuclear factor and anticitrulline were recorded in 70\% in both groups; hypergammaglobulinemia, ANA, anti-dsDNA and AMA were frequently detected in antiRo ${ }^{+}$patients. Patients were given a mean of 3.93 DMARDs, with no statistical difference between antiRo+ and antiRo-: hydroxychloroquine, methotrexate and gold salts are the most frequently used. Patients who were antiRo- were more frequently treated with hydroxychloroquine and infliximab, while D-penicillamine was used more frequently in those who were antiRo+. DMARD toxicity was detected in $9.3 \%$ of antiRo+, with no statistically significant difference between the two groups.

Conclusion: AntiRo, found in $12.8 \%$ of patients with RA, is associated with extra-articular features and with an autoantibody profile unusual for RA. No difference with respect to DMARD toxicity was found in anti$\mathrm{Ro}^{+}$patients.

\section{9}

Presence of anti-RNP-A and anti-RNP-C antibodies is inversely associated with renal symptoms of systemic lupus erythematosus

I Hoffman', I Peene', L Meheus², K De Bosschere'2, F Hulstaert', TWJ Huizinga ${ }^{3}$, L Cebecauer ${ }^{4}$, D Isenberg ${ }^{5}$, EM Veys ${ }^{1}$, F De Keyser ${ }^{1}$

${ }^{1}$ UZG, Ghent, Belgium

2Innogenetics, Ghent, Belgium

${ }^{3}$ Leiden University Medical Center, Leiden, The Netherlands

${ }^{4}$ Research Institute for Rheumatic Diseases, Piestany, Slovakia

${ }^{5}$ University College London, London, UK

Arthritis Res Ther 2003, 5 (suppl 1):9

Background: Systemic lupus erythematosus (SLE) is an autoimmune rheumatic disease characterised by the production of autoantibodies. The most common serious feature of SLE is renal involvement. An association with anti-RNP antibodies remains controversial.

Aim: To identify associations of autoantibodies and renal symptoms in a consecutive cohort of SLE patients.

Methods: Sera and clinical data from 235 consecutive SLE patients, fulfilling the ACR criteria for SLE, were collected in four centres. The presence of renal disease was defined as the presence of cellular casts in the urine, proteinuria $(>0.5 \mathrm{~g} /$ day), or glomerulonephritis during the course of the disease. Autoantibody profiles were determined by the INNO-LIA ${ }^{\mathrm{TM}}$ ANA Update (a line immunoassay with recombinant and/or native antigens, including SmB, SmD, RNP-70, RNP-A, RNP-C, Ro52, Ro60, SSB, and ribosomal P) and anti-dsDNA antibodies by indirect immunofluorescence on Crithidia luciliae. Odds ratios (ORs) and their $95 \%$ confidence intervals $(\mathrm{Cl})$ were computed to determine the associations between antibodies and renal symptoms. No correction was made for multiple testing.

Results: The presence of anti-RNP-A and anti-RNP-C appeared to be protective against renal involvement $(\mathrm{OR}=0.445, \mathrm{Cl}=0.210-0.942$ and $\mathrm{OR}=0.484, \mathrm{Cl}=0.243-0.964$, respectively). Concerning the individual symptoms, anti-RNP-C was associated with a lower occurrence of proteinuria $(\mathrm{OR}=0.470, \mathrm{Cl}=0.236-0.938)$, cellular casts $(\mathrm{OR}=0.324, \mathrm{Cl}=0.150-0.696)$ and glomerulonephritis $(\mathrm{OR}=0.460$, $\mathrm{Cl}=0.226-0.934)$, whereas anti-RNP-A was only significantly associated with a lower occurrence of cellular casts $(O R=0.303$, $\mathrm{Cl}=0.129-0.716)$. In contrast, antibodies to dsDNA were associated with a higher risk for cellular casts $(\mathrm{OR}=2.014, \mathrm{Cl}=1.057-3.839)$. We found no associations between renal symptoms and other specific antinuclear reactivities. More specifically, for anti-RNP-70 a trend was only detected for the association with the presence of cellular casts (OR=0.411, $\mathrm{Cl}=0.153-1.106)$.

Conclusion: Anti-RNP-A and anti-RNP-C antibodies appear to be associated with a lower risk for renal disease. 
10

\section{Cultured salivary gland epithelial cells release exosomes that contain the Sjögren's-syndrome- associated autoantigenic ribonucleoproteins Ro/SSA and La/SSB \\ EK Kapsogeorgou, ID Dimitriou, RF Abu-Helu, HM Moutsopoulos, MN Manoussakis}

Department of Pathophysiology, National University of Athens, 75 Mikras Asias Street, Athens, Greece Arthritis Res Ther 2003, 5 (suppl 1):10

Sjögren's syndrome (SS) is characterized by exocrine gland destruction associated with lymphocytic infiltrations and chronic autoimmune antigen-driven responses against the intracellular Ro/SSA and La/SSB ribonucleoproteins. Epithelial cells, which are the main targets of autoimmune responses, appear to have a central role in the pathogenesis of SS. In recent years we have presented evidence indicating that salivary gland epithelial cells (SGECs) of SS patients are inherently capable of functioning as antigen-presenting cells. Recently, a novel, cell-free mechanism of antigen presentation has been identified. This mechanism involves exosomes, which are small $(30-200 \mathrm{~nm}) \mathrm{mem}$ brane vesicles of endosomal origin secreted by a variety of cell types, such as reticulocytes, $B$ lymphocytes and dendritic cells. In the present study we investigated the capacity of cultured SGEC lines established from SS patients and disease controls to release exosomal vesicles that contain intracellular ribonucleoproteins. Membrane vesicles were isolated by differential centrifugation from SGEC culture supernatants and their nature was confirmed by electron microscopy. Cultured SGECs from patients and controls secreted significant amounts of exosomal vesicles, in a manner largely indistinguishable from other exosomesecreting cells. Exosome release was not associated with apoptosis or other cellular destruction processes. SGEC-derived exosomes were found by Western blot analysis to contain Ro/SSA, La/SSB, and Sm ribonucleoproteins. Our results indicate that SGECs are capable of secreting exosomes. This mechanism may represent a pathway through which intracellular epithelial antigens are exported and subsequently presented to the immune system. In this context, exosomes produced by epithelial cells may have a role in the pathogenesis of SS.

\section{1}

\section{Low frequency of phosphatidylserine/prothrombin complex antibodies in a cohort of patients with anticardiolipin antibodies and recent thrombosis \\ H Locht}

Department of Autoimmunology, Statens Serum Institut, Copenhagen, Denmark

Arthritis Res Ther 2003, 5 (suppl 1):11

Objective: Clinical data from patients who were positive for anticardiolipin antibodies (ACAs), tested on a routine basis in an autoimmune laboratory, were obtained by questionnaires from the referring physicians. One hundred and sixty-two individuals had experienced a recent (within $<6$ months) thromboembolic event. All sera were tested for lgG and $\lg \mathrm{M}$ antibodies against cardiolipin, $\beta_{2}$-glycoprotein $1 \quad\left(\beta_{2}\right.$-glp 1$)$, and the complex of phosphatidylserine/prothrombin (PPC) by in-house ELISA methods.

Results: Among the 162 ACA-positive patients, 31 (19\%) were also positive for antibodies against PPC. In the group with ACA only, $73 \%$ of the patients had no pre-existing rheumatic condition, compared with $32 \%$ in the PPC group $(P=0.00002)$. Thirty-two percent in the PPC group had SLE, vs $12 \%$ in the ACA group $(P=0.016)$. The fractions of patients with deep venous thrombosis (DVT), pulmonary embolism $(\mathrm{PE})$, or myocardial infarction (MI) were equal, whereas cerebrovascular incidents (CVI) were more frequent among ACA patients; $51 \%$ vs $26 \%$ $(P=0.02)$. Antibodies against $\beta_{2}$-glp 1 were also more frequent in the PPC group $61 \%$ vs $30 \%(P=0.002)$.
Conclusion: Antibodies against both ACA and PPC seem to define a subset of patients with autoimmune thrombophilia. More patients with PPC antibodies had SLE and also tested positive for antibodies against $\beta_{2}$-glp 1. The distribution of thrombotic manifestations differed between the two populations in that $\mathrm{CVI}$ was more frequent in the ACA-only group, whereas the fractions with DVT, PE, and MI were equal.

\section{2}

\section{Anticardiolipin antibodies of IgG and IgM isotypes reflect different forms of recent thromboembolic events}

\section{H Locht, A Wiik}

Department of Autoimmunology, Statens Serum Institut, Copenhagen, Denmark

Arthritis Res Ther 2003, 5 (suppl 1):12

Objective: To correlate the distribution and levels of anticardiolipin (ACA) and anti- $\beta_{2}$-glycoprotein 1 (a- $\beta_{2}$-glp 1$)$ antibodies of $\operatorname{lgG}$ and IgM isotypes to the clinical spectrum of recent (within $<6$ months) thromboembolic events.

Method: During one year, all sera positive for IgG or IgM ACA submitted on a routine basis from hospitals or primary-care physicians from all parts of Denmark were recorded. Information about thromboembolic events and any underlying rheumatic disease was obtained by questionnaires from the referring physicians. Sera were analysed for lgG/lgM ACA and a- $\beta_{2}$-glp 1 antibodies by in-house ELISA assays, and the results were expressed in arbitrary units.

Results: One hundred and sixty-two patients fulfilled criteria for recent thromboembolic disease. Cerebrovascular infarction (CVI) was present in 82 patients, deep venous thrombosis (DVT) in 34, pulmonary embolism (PE) in 14, myocardial infarction (MI) in 4, and other thromboses in 28 patients. Isolated IgG ACA was found in 31 of 48 patients with DVT+PE $(65 \%)$, but in only 21 of 82 patients with CVI $(26 \%)$ $(P=0.00002)$. In contrast, isolated IgM ACA was found in $9(19 \%)$ of patients with DVT+PE, but in $46(56 \%) \mathrm{CVI}$ patients $(P=0.00007)$. $\operatorname{lgG}$ a- $\beta_{2}$-glp 1 antibodies were found in $13(16 \%) \mathrm{CVI}$ patients and $23(48 \%)$ DVT+PE patients $(P=0.0002)$.

Conclusion: IgG and IgM ACA isotypes seem to define different clinical subsets of patients with recent thromboembolic events, with IgG ACA being most prevalent in the group having DVT+PE whereas IgM ACA is found primarily among CVI patients. There was a linear correlation between levels of $\lg G$ a- $\beta_{2}$-glp 1 antibodies and $\lg G$ ACA.

\section{3}

\section{Autoantibodies in osteoarthritis}

J Menard', J Neidel'2, C Perka², M Sparmann³ ${ }^{3}$ B Mueller'

${ }^{1}$ Deutsches RheumaForschungs-Zentrum, Berlin, Germany

${ }^{2}$ Charité, Humboldt-University, Berlin, Germany

3/mmanuelkrankenhaus, Berlin, Germany

Arthritis Res Ther 2003, 5 (suppl 1):13

Objective: We have previously shown that inflammatory cytokines are up-regulated in chondrocytes of osteoarthritis (OA) patients. However, the inflammatory responses associated with OA are still ill defined. To investigate in more detail the involvement of the immune system in the pathogenesis of $O A$, we here analyzed patients for the presence of autoantibodies.

Methods: Both sera and synovial fluids obtained from 85 OA patients at the time of joint replacement were tested for autoreactivity. Autoantibodies reacting against synovial membranes were detected performing immunofluorescence on cryosections. Autoantibodies recognizing lysate components of various cell lines (B-cell, T-cell, monocyte, fibroblast and chondrosarcoma) were shown by the use of Western blot analyses. In preparation for the identification of the respective autoantigens, we started to immunoprecipitate the proteins of interest.

Results: Sera from the OA patients reacted strongly with cells in the synovial membranes whereas sera obtained from healthy donors did 
Figure 1

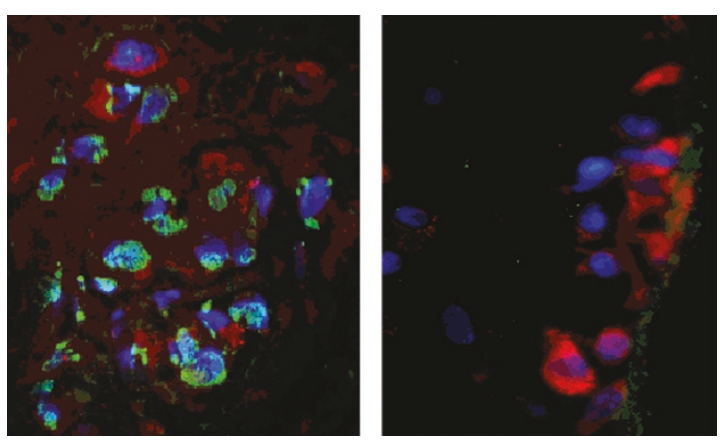

Immunofluorescence reveals the presence of autoantibodies in $\mathrm{OA}$ sera. Cryosections of synovial membranes were incubated with control (A) or OA (B) sera. The binding of autoantibodies was detected via FITC-labeled anti human IgG antibodies (green). Fibroblasts were stained with the specific antibody (5B5) and developed via SArhodamine (red). Nuclei are counterstained using DAPI (blue). The full colour version of this figure can be viewed online at http://arthritis-research.com/supplements/5/S1/13

not (Fig. 1). Furthermore, about 50\% of the OA sera and none of the control or RA sera reacted very strongly against lysate components of the different cell lines tested. The corresponding synovial fluids reacted against the same lysate components, but the signals obtained were of reduced intensity.

Conclusion: Our results demonstrate the presence of autoantibodies in sera and synovial fluid in about half the OA patients. The specificities of these autoantibodies are not restricted to the joints, as reactivity was detected towards any cell line tested. Hoping to design new diagnostic tools and to shed light on the role of autoantibodies in the development and progression of $\mathrm{OA}$, we are in the process of identifying the corresponding autoantigens.

\section{4}

\section{The infectious origin of the antiphospholipid syndrome: induction by passive transfer of anti- $\beta 2 \mathrm{GPI}$ antibodies induced by common bacteria}

\section{Blank, I Krause', M Fridkin², N Keller'1, J Kopolovic',} I Goldberg', A Tobar', Y Shoenfeld1

${ }^{1}$ Center for of Autoimmune Diseases, Department of Internal Medicine ' $B$ ', The Weizmann Institute of Science, Rehovot, Israel

${ }^{2}$ Department of Organic Chemistry, The Weizmann Institute of Science, Rehovot, Israel

Arthritis Res Ther 2003, 5 (suppl 1):14

The antiphospholipid syndrome (APS) is characterized by the presence of pathogenic autoantibodies against $\beta_{2}$-glycoprotein I ( $\beta 2 \mathrm{GPI}$ ). The factors causing production of anti- $\beta 2 \mathrm{GPI}$ remain unidentified, but an association with infectious agents has been reported. We recently identified a hexapeptide (TLRVYK) that is recognized specifically by a pathogenic anti- $\beta_{2}$ GPI monoclonal antibody. In the present study we evaluated the APS-related pathogenic potential of microbial pathogens, which share structural homology with the this hexapeptide. Mice were immunized with a panel of TLRVYK-related microbial particles and were studied for the development of mouse anti- $\beta 2 \mathrm{GPI}$ autoantibodies. Mouse $\operatorname{lgG}$ specific to the TLRVYK peptide were affinity purified from the immunized mice and passively infused i.v. into naive mice at day 0 of pregnancy. APS parameters were evaluated in the infused mice on day 15 of pregnancy. Following immunization, high titers of anti-peptide, anti- $\beta_{2}$ GPI antibodies were observed in mice immunized with Haemophilus influenzae, Neisseria gonorrhoeae or tetanus toxoid. Naive mice infused with the affinity-purified anti-peptide antibodies had a significant thrombocy- topenia, prolonged aPTT and elevated percentage of fetal loss, similar to the findings in a control group of mice immunized with a pathogenic anti$\beta 2 \mathrm{GPI}$ monoclonal antibody. Our study establishes a mechanism of molecular mimicry in experimental APS, demonstrating that bacteria homologous with $\beta 2 \mathrm{GPI}$ structure are able to induce the generation of pathogenic anti- $\beta 2 \mathrm{GPI}$ antibodies along with APS manifestations.

\section{5}

\section{FcyRI up-regulation induced by local adenoviral- mediated IFN- $\gamma$ production aggravates chondrocyte death during immune-complex-mediated arthritis}

K Nabbe1, PL van Lent', AE Holthuysen ${ }^{1}$, AW Sloetjes', J Kolls ${ }^{2}$, JS Verbeek ${ }^{3}$, WB van den Berg ${ }^{1}$

${ }^{1}$ Department of Experimental Rheumatology and Advanced Therapeutics, University Medical Center Nijmegen, The Netherlands ${ }^{2}$ Louisiana State University Health Science Center, New Orleans, LA, USA ${ }^{3}$ Department of Human and Clinical Genetics, University Medical Center, Leiden, The Netherlands

Arthritis Res Ther 2003, 5 (suppl 1):15

Using various FcyR-deficient mice, we have obtained suggestive evidence that FcyRl on macrophages is responsible for severe cartilage destruction during arthritis mediated by immune complexes (ICs) and Th1 cells. In contrast, in arthritis mediated solely by ICs, FcyRIII seems more important. This suggests that T-cell-mediated Fc $\gamma \mathrm{RI}$ up-regulation promotes pronounced cartilage destruction. A likely Th1-cell-derived cytokine mediating Fc $\gamma \mathrm{RI}$ expression is interferon- $\gamma$ (IFN- $\gamma$ ).

In the present study we investigated whether IFN- $\gamma$ is able to up-regulate cartilage destruction during experimental immune complex-mediated arthritis (ICA) and, if so, whether this mechanism is indeed regulated by FcyRI. IFN- $\gamma$ was locally overexpressed in the murine knee joint prior to ICA induction by the use of adenoviral vectors. This had no significant effect on joint inflammation as studied by histology. However, irreversible cartilage destruction as studied by the degree of chondrocyte death was markedly enhanced. IFN- $\gamma$ overexpression resulted in a fivefold increase in chondrocyte death, in comparison with the control group, which had received a control adenoviral vector expressing GFP (AdGFP).

To study whether this effect of IFN- $\gamma$ was related to the presence of ICs, IFN- $\gamma$ was also overexpressed in a naive joint and during zymosaninduced arthritis, which is an IC-independent arthritis model. No severe cartilage destruction was found, implying a crucial role for ICs and their receptors (Fc $\gamma \mathrm{Rs})$ in the IFN- $\gamma$ effect.

When IFN- $\gamma$ was overexpressed in murine knee joints, Fc $\gamma R$ I mRNA expression was up-regulated in synovial cells. To prove that the aggravation of chondrocyte death by IFN- $\gamma$ is indeed Fc $\gamma \mathrm{RI}$-mediated, ICA was raised in $\mathrm{Fc}_{\mathrm{C}} \mathrm{RI}^{-1-}$. IFN- $\gamma$ overexpression did not result in significant elevation of joint inflammation either in $\mathrm{Fc}_{\mathrm{R}} \mathrm{Rl}^{-/}$or their wild-type controls. Interestingly, although IFN- $\gamma$ was overexpressed, chondrocyte death remained absent in $\mathrm{Fc}_{\mathrm{CPI}}{ }^{-/}$, whereas in wild-type controls chondrocyte death was highly increased after IFN- $\gamma$ overexpression.

These results indicate that IFN- $\gamma$ can aggravate cartilage destruction in an IC-dependent fashion, mediated by FcyRI.

\section{6}

\section{The diagnostic significance of autoantibodies in patients with very early rheumatoid arthritis}

V Nell, K Machold, W Hueber, G Eberl, H Hiesberger, E Hoefler, J Smolen, G Steiner

Division of Rheumatology, University Hospital of Vienna, Lainz

Hospital, Vienna, Austria

Arthritis Res Ther 2003, 5 (suppl 1):16

In the past few years, several novel autoantibodies (autoAbs) have been described in patients with rheumatoid arthritis (RA), including an autoAb to citrullinated antigens (anti-CCP) and anti-RA33 autoAb. It was our aim to assess the value of these two autoAbs in relation to rheumatoid factor (RF) in discriminating RA from non-RA in a cohort of patients with very early arthritis. 
Ninety-four patients with arthritis of less than 3 months' duration were included in this prospective study. Follow-up was for at least 1 year. Sixty-one patients had a final diagnosis of RA and 33 had other arthritides. Among the RA patients, RF was present in 34 (56\%), anti-CCP in $18(30 \%)$, and anti-RA33 in $15(25 \%)$ at their first visit. Among the 33 non-RA patients, 6 were RF-positive, 3 had anti-RA33, and 1 had anti-CCP. Thus, anti-CCP was very specific for RA with a positive predictive value (PPV) of 95\%, while RF and anti-RA33 were somewhat less specific, with PPVs of $85 \%$ and $83 \%$, respectively. However, the co-occurrence of anti-RA33 and RF was observed exclusively in RA patients and thus had a PPV of $100 \%$ in this relatively small cohort of patients. In conclusion, these data suggest that the determination of autoantibodies such as anti-CCP and anti-A2/RA33 in addition to RF may be quite helpful in the early diagnosis of RA.

\section{7}

\section{A rapid ELISA based method to determine peptidyl- arginine deiminase activity in biological samples \\ S Nijenhuis, AJW Zendman, JMH Raats, GJM Pruijn, WJ van Venrooij}

Department of Biochemistry, University of Nijmegen, Nijmegen, The Netherlands

Arthritis Res Ther 2003, 5 (suppl 1):17

Peptidylarginine deiminases (PADs; EC 3.5.3.15) are a family of calcium-dependent enzymes that convert peptidylarginine into peptidylcitrulline. The recent finding that patients with rheumatoid arthritis (RA) produce autoantibodies against citrulline-containing epitopes greatly increased the interest in the PAD enzymes and their activities. It is not yet known whether there is a causative relationship between the generation of antibodies targeting citrullinated epitopes and the development of the disease. Characterisation of the structure and function of PADs may help to understand the production process of citrullinated antigens and possibly also the aetiology of RA.

Several assays are known to monitor PAD activity in biological samples. However, these assays either have a low sensitivity or are laborious. Here, we describe the development of a simple, rapid method for the simultaneous analysis of many PAD-containing samples. This new method is based on the binding of an antibody specifically recognising a citrulline-containing epitope in a defined peptide. We show that this method is very sensitive and can be applied to monitor PAD activity in many types of biological samples, such as bacterial lysates, mammalian cell extracts and tissue extracts.

\section{8}

\section{Autoantibodies to deiminated fibrinogen are the most efficient serological criterion for early rheumatoid arthritis diagnosis}

L Nogueira', S Chapuy-Regaud', A Constantin', C Clavel'1, M Sebbag', A Cantagrel' ${ }^{2}$, C Vincent ${ }^{1}$, G Serre' 1

${ }^{1}$ Department of Epidermis Differentiation and Rheumatoid Autoimmunity, INSERM U 563, Toulouse, France

2Department of Rheumatology, Rangueil Hospital, Toulouse, France Arthritis Res Ther 2003, 5 (suppl 1):18

Background and objectives: Autoantibodies to deiminated proteins are known to be the most specific serological marker for the diagnosis of rheumatoid arthritis (RA). We recently showed that deiminated fibrin is the major target of this family of autoantibodies in rheumatoid synovial tissue. We subsequently developed, and validated on a large series of patients with established rheumatic diseases, an ELISA for the detection of circulating autoantibodies to deiminated human fibrinogen (AhFibA). The test was shown to be the most efficient (specific and sensitive) serological criterion for the diagnosis of RA.

Methods: We collected 352 sera from patients with arthritides of recent onset (disease duration $<1$ year). The diagnosis was established after at least 2 years' follow-up. The patients were then classified rheumatic diseases. The previously developed ELISA, using in vitro deiminated human fibrinogen as immunosorbent, was used for detection and titration of AhFibA. Antibodies to cyclic citrullinated peptide (CCP) were sought in accordance with the manufacturer's procedure (Immunoscan RA, Euro-diagnostica). Rheumatoid factor (RF) was titrated by nephelometry (RF-reagent for Image, Beckman Coulter).

Results: The diagnostic sensitivity of AhFibA was found to be significantly higher than those of CCP $(P<0.05)$ and RF $(P<0.001)$ (Table 1). The positive predictive values (PPV) of the three tests were all found to be very high and were not significantly different. The negative predictive values (NPV) were too low to be diagnostically useful. Among the AhFibA-positive RA sera $83 \%$ were RF-positive, while among the AhFibA-negative, only $13 \%$ were RF-positive.

Table 1

Diagnostic indices computed at thresholds allowing 0.985 specificity to be reached

\begin{tabular}{lll}
\hline Antibodies to & Se & PPV \\
\hline AhFibA & 0.646 & 0.974 \\
CCP & 0.543 & 0.969 \\
RF & 0.274 & 0.941
\end{tabular}

PPV, positive predictive value.

Conclusion: Unlike the case with RF, autoantibodies to deiminated proteins are confirmed to be of diagnostic value in early arthritides. The detection of these autoantibodies by ELISA using their synovial target (deiminated fibrin) appears the most efficient method for the diagnosis of early RA.

\section{9}

\section{Anti-BIP antibodies in rheumatoid arthritis} GS Panayi, M Bodman-Smith, V Corrigall

GKT School of Medicine, Guy's Hospital, London, UK Arthritis Res Ther 2003, 5 (suppl 1):19

Background: We have implicated the human chaperone protein BiP in the pathogenesis of rheumatoid arthritis (RA). Increased immunoglobulin binding of RA sera to BiP is seen on Western blot analysis.

Methods: We now describe an ELISA developed to enable rapid screening of sera for antibody reactivity to BiP.

Results: Specificity of the assay has been shown by free ligand competition and extensive correlations with other immunological parameters. We show no correlation between anti-BiP and rheumatoid factor or with cyclic citrullinated peptide. We confirm the increased binding of immunoglobulin to BiP in the sera of a group of patients with RA $(n=96)$ in comparison with controls $(n=96)$. Our data show a specificity of $71 \%$ and a sensitivity of $73 \%$ for RA. Furthermore, these data show that antibody will bind to a nonglycosylated form of BiP, since the protein is produced in an Escherichia coli expression system.

Conclusion: We have developed a robust protocol for the detection of antibodies to the human chaperone molecule BiP. Our data show an elevated antibody response to BiP in RA patients and hence support a role for this molecule in the disease.

\section{0}

Antineutrophil cytoplasmic antibodies in synovial fluid from patients with early rheumatoid arthritis

M Puszczewicz, I Zimmermann-Górska, G Bialkowska-Puszczewicz, E Tatarkiewicz

University of Medical Sciences, Poznañ, Poland Arthritis Res Ther 2003, 5 (suppl 1):20

Background: Antineutrophil cytoplasmic antibodies (ANCAs) occur in vasculitides, including Wegener's granulomatosis and Churg-Strauss 
syndrome. Their presence in sera of patients with some other rheumatic diseases has been well documented. ANCAs have also been detected in synovial fluid (SF) of patients with RA; however, their presence and potential role in early stages of the disease is not known. Objective: The aim of the study was to evaluate the prevalence and specificity of ANCAs in SF in early RA.

Methods: SF samples were obtained from 114 patients with early RA. Control SF were taken from 76 patients with knee osteoarthritis (OA). ANCAs were detected by indirect immunofluorescence and by ELISA. Proteinase 3, myeloperoxidase, elastase, lactoferrin and lysozyme, as well as cathepsin G, were used as antigens in ELISA method. At the same time antinuclear antibodies (ANAs) and rheumatoid factor (RA) were detected in SF samples under study.

Results: ANCAs were found by indirect immunofluorescence in SF of 26/114 (22.8\%) patients with early RA and 2/76 (2.6\%) patients with OA. A perinuclear pattern ( $p$-ANCA) was detected in $22 / 26$ cases (84.6\%), and atypical pattern (a-ANCA) in 4/26 (15.3\%). In patients with OA, p-ANCAs only were observed. We did not observe a cytoplasmic pattern (c-ANCA) in indirect immunofluorescence or in the reactivity against proteinase 3 in ELISA. p-ANCAs yielded reactivity against lactoferrin in SF from 15/26 (57\%) and against myeloperoxidase in 5/26 (19.2\%) SF samples from RA patients. a-ANCAs indicated reactivity against cathepsin $G$ in $3 / 26$ cases $(11.5 \%)$ and against lysozyme in $1 / 26$ (3.8\%). RF was present in 18/26 (69.2\%) and ANA in 14/114 (12.2\%) SF samples from patients with RA.

Conclusion: ANCAs are present in SF of over $20 \%$ of patients with early RA We think that these antibodies in SF could be one of the early RA markers. Their role in this stage of synovitis should be clarified.

21

\section{Biphasic decline/increase for anticitrulline and monophasic decline in anti-type II collagen antibody levels in recently diagnosed RA patients}

J Rönnelid 1,2, S Rogberg', B Nordmark', J Lampa', I Dahlbom³, T Hansson ${ }^{1,3}$, L Klareskog ${ }^{1}$

1 Unit of Rheumatology, Karolinska Hospital, Stockholm

2 Unit of Clinical Immunology, Uppsala University, Uppsala, Sweden

${ }^{3}$ Pharmacia Diagnostics, Uppsala

Arthritis Res Ther 2003, 5 (suppl 1):21

Objective: Antibodies against both type II collagen and citrulline residue containing peptides can be found in rheumatoid arthritis (RA) patients. We have noted that serum levels of both anticollagen and anticitrulline antibodies show significant decline after inclusion in an early arthritis clinic (EAC) cohort, and wanted to compare their kinetic patterns of disappearance.

Methods: Two hundred and fifty-five EAC patients and 80 RA patients were followed for 1 and 5 years, respectively, from the time of initial referral. Anticollagen and anticitrulline antibodies were determined with ELISA at inclusion and after 3 months and 1, 2, 3 and 5 years.

Results: At the patients' inclusion, anticollagen and anticitrulline antibodies were found in $6.3 \%$ and $48.2 \%$, respectively, of EAC patients and in $11.5 \%$ and $61.0 \%$ of the patients with definite RA. Serum levels of antibodies against type II collagen declined continously for the entire study period in both groups, being significant already at 3 months after inclusion. Serum levels of anticitrulline antibodies, on the other hand, showed a biphasic pattern. A significant decline from inclusion (for EAC patients at 1 year, and for RA patients at 3 months and at 1 and 2 years) was followed by increased serum levels (significant for RA patients between 2 and 5 years). No correlation was found between changes in serum levels of anticollagen and anticitrulline antibodies at any time.

Conclusion: These findings suggest that different immunological events predispose to immunity against collagen type II and against citrulline-containing peptides in RA.
Zinc finger domain of Ro60kD autoantigen is essential for binding of Ro52kD and autoantibodies

JG Routsias, A Makri, C Sakarellos, M Sakarellos-Daitsiotis, A Kosmopoulou, HM Moutsopoulos, AG Tzioufas

Department of Pathophysiology, School of Medicine, University of Athens, Athens, Greece

Arthritis Res Ther 2003, 5 (suppl 1):22

The Ro60kD polypeptide is associated with both RNA and the Ro52kD protein. The specific protein-RNA and protein-protein interactions are thought to occur through the RNP and zinc-finger secondary structure elements located on the 92-161 and 301-327 regions of Ro60kD protein, respectively. The zinc finger domain of Ro60kD is a good candidate to hold a conformational epitope, because both the binding of zinc and the redox conditions can induce specific conformational changes. In this study, we investigated the presence of antibodies against synthetic peptides corresponding to the zinc finger domain of Ro60kD protein (Zif-1b), to a truncated form possessing zinc-binding regions but lacking the intermediate loop (Zif-2b) and to the intermediate loop (310-319) of the zinc finger domain (Zif-3b). We found that the peptide Zif-1b, corresponding to the native sequence (301-327 aa) of Ro60kD, is recognized by antibodies from the majority (83\%) of anti-Ro/La-positive patients with primary Sjögren's syndrome (pSS), in the absence of zinc ions. The same sera failed to react with Zif- $1 \mathrm{~b}$ in the presence of $\mathrm{Zn}^{2+}(2.5 \%)$. Its truncated form (Zif- $2 b$ ) did not react against the same sera, while the peptide corresponding to loop 310-319 (Zif-3b) exhibited high reactivity (85\%). The presence of zinc ions was necessary for binding of Zif- $1 \mathrm{~b}$ to recombinant Ro52kD, indicating that discrete conformational states of the Ro60kD zinc finger domain are employed in interaction with Ro52kD protein and autoantibodies. The two different states of the zinc finger domain of Ro60kD may reflect the existence of the Ro60kD autoantigen in different redox environments (e.g. in the interior of the cell and cell membrane), where the Cys residues have different capacities to coordinate zinc ions.

\section{3}

\section{Differential expression of IgVH mRNAs in human RA} synovium detected by single-cell RT-PCR

S Ruzickova1,3, Z Cimburek', J Niederlova1, O Horvath², O Krystufkova', T Dörner ${ }^{2}$, J Vencovsky ${ }^{1}$

1/nstitute of Rheumatology and Laboratory of Gene Expression, Czech Academy of Sciences, Prague, Czech Republic

2Institute of Microbiology, Czech Academy of Sciences, Prague, Czech Republic

${ }^{3}$ Department of Rheumatology/Immunology, Medical Faculty, Charité, Humboldt University, Berlin, Germany

Arthritis Res Ther 2003, 5 (suppl 1):23

Introduction: In rheumatoid arthritis (RA), the synovial membranes contain lymphocytic infiltrates sometimes resembling germinal centres. The production of clonally related immunoglobulin (lg) transcripts, the presence of plasma cells within RA synovial tissue, somatic mutations and isotype switching in RF-specific synovial B lymphocytes have been observed. In addition, the expression of recombination-activating genes 1 and 2 (Rag1 and 2) has been detected in RA synovial B cells. Objective: Analysis of the presence of plasma cells, mutational frequencies of their Ig heavy-chain transcripts, the signs of isotype switching and expression of Rag1 and 2 genes in inflamed RA synovial tissue. Methods: Synovial tissue sections were labeled with anti-CD19, antiCD138 and anti-CD38 antibodies and visualized using the alkaline phosphatase technique. Individual $\mathrm{CD}_{19}{ }^{+} \mathrm{CD} 38^{+}$plasma cells were isolated from digested synovium of two caucasian RA patients using single-cell deposition. The cDNA from each single B cell was generated, and nested polymerase chain reaction specific for $\mathrm{VH}$ genes and Rag1 and Rag2 genes was performed. After sequencing, the VBASE database was used to assign $\mathrm{VH}, \mathrm{DH}$ and $\mathrm{JH}$ gene segments and somatic mutations. 
Results: Three different subsets of CD19+ $\mathrm{CD} 38^{+}$plasma cells were detected. The first subset represents cells expressing only IgM transcripts $\left(\operatorname{lgM}^{+}, 13.5 \%\right)$, the second expressed only lgG transcripts $(\operatorname{lgG}+, 48.7 \%)$ and the third produced both $\operatorname{lgM}$ and $\lg G$ mRNAs $\left(\operatorname{lgM}^{+}\right.$ $\left.\mathrm{lgG}^{+}, 37.8 \%\right)$. All of these detected IgVH mRNAs contained mutated sequences, indicating their memory cell origin. However, the differences of mutational frequencies between these subsets were statistically significant $\left(\operatorname{lgM}^{+}\right.$plasma cells $3.8 \%$, IgG ${ }^{+}$plasma cells $11.2 \%$ and $\mathrm{IgM}^{+} \operatorname{lgG}{ }^{+}$cells $\left.6.3 \%\right)$. Interestingly, either Rag1 or Rag2 mRNA was observed in $83.3 \%$ of all analyzed CD19+CD38+ plasma cells, with the highest frequency in the $\operatorname{lgM}^{+} \operatorname{lgG}{ }^{+}$subset of plasma cells (71.4\%). Conclusion: The population of $\mathrm{CD} 19^{+} \mathrm{CD}^{+} 8^{+}$plasma cells differentially expressing mutated IgVH mRNAs and reinducing Rag 1 and 2 genes was observed in $\mathrm{RA}$ synovium. The $\operatorname{lgM}^{+} \operatorname{lgG} \mathrm{G}^{+}$cells might represent cells switching from $\operatorname{lgM}$ to $\operatorname{lgG}$ isotype and $\operatorname{lgG}+$ plasma cells might correspond to post-switched cells producing high-affinity (auto)antibodies.

\section{4}

\section{Ability of second-generation anti-cyclic citrullinated peptide (CCP) to predict rheumatoid arthritis in patients with early arthritis}

\section{A Saraux, JM Berthelot, P Le Goff, P Youinou}

Department of Rheumatology, Centre Hospital Universitaire, Brest, France Arthritis Res Ther 2003, 5 (suppl 1):24

Objective: We previously studied the diagnostic value of biological tests in $\mathrm{RA}$ and found that IgG-AKA, first generation of anti-CCP, IgM-RF by ELISA, and the latex test is the best combination in diagnosing RA. The goal of the present study was 1 ) to study the diagnostic value of the second generation of anti-CCP and 2) to determine the diagnostic value of second-generation anti-CCP used in combination in the same population. Methods: A cohort of 270 patients with early arthritis underwent a standardized examination, laboratory tests and radiographs in 1995-1997. The final diagnosis was evaluated by a panel of five rheumatologists between June and December, 1999. The respective diagnostic values of antiperinuclear factor, antikeratin antibody, and anti-CCP (commercial kits: Eurodiagnostica first generation [EFG], Eurodiagnostica second generation [ESG], and Axis-Shield [AS]) carried out on sera taken at the patients' first visit in discriminating between patients who did (98/270; $36 \%$ ) and did not have RA at the last visit was evaluated using receiving-operator characteristic curves. To evaluate the combination of antiCCP with other laboratory tests in discriminating between patients with and without RA, a multiple logistic regression with backward selection using the likelihood ratio test was applied.

Results: 1) Anti-CCP, APF and IgG AKA were not perfectly correlated with each other. For anti-CCP EFG (cutoff 53 UI), ESG (cutoff $0.120 \mathrm{OD}$ ), and AS (cutoff $0.320 \mathrm{OD}$ ), sensitivity and specificity were $47 \%-93 \%, 57 \%-94 \%$ and $58 \%-94 \%$, respectively. 2) By the use of a multiple logistic regression, second generation anti-CCP, IgG-AKA, the latex test and IgM-RF ELISA were selected.

Conclusion: ESG and AS are the best tests for predicting RA. Combining one of these tests with IgG-AKA, IgM-RF, and the latex test slightly increases the diagnostic value.

\section{5}

\section{Autoantibodies to hnRNP-A2 in SLE: identification of disease-specific linear epitopes and correlation with disease activity and clinical features}

G Schett ${ }^{1}, \mathrm{~F}$ Monneaux ${ }^{2}$, E Hoefler ${ }^{3}$, R Fritsch ${ }^{1}$, M Tohidast-Akrad $^{3}$, J Smolen 1,3, S Muller', G Steiner ${ }^{1,3}$

${ }^{1}$ Division of Rheumatology, University of Vienna, Austria

2 Institut de Biologie Moléculaire et Cellulaire, CNRS, Strasbourg, France

${ }^{3}$ Ludwig-Boltzmann-Institute for Rheumatology, Vienna, Austria

Arthritis Res Ther 2003, 5 (suppl 1):25

The autoantigen hnRNP-A2 (RA33) is targeted by autoantibodies erythematosus (SLE) and mixed connective tissue disease (MCTD). To define the humoral autoimmune response in more detail, a series of overlapping peptides covering the N-terminal part hnRNP-A2 known to harbour the major epitopes was studied by ELISA in sera from patients with SLE $(n=40)$, RA $(n=50)$, MCTD $(n=11)$ and other rheumatic diseases $(n=86)$ and from healthy subjects $(n=29)$. Antipeptide reactivities were detected in $25 \%$ of SLE sera but only rarely in patients with RA or MCTD. Since most of the SLE patients investigated had inactive disease, we next studied sequential sera of 15 individual patients. Of those, only three patients were completely negative for hnRNP-A2 antibodies, while all the other patients showed at least one positive reaction during the observation period. These were directed to the full-length protein and/or to 4 of the 13 peptides used: p35-55, p50-70, p90-116 and p155-175. Interestingly, autoreactivities to the first three peptides were significantly associated with each other but not with reactivity to p155-175 or to the complete protein. This cluster of reactivity was also not linked to any clinical marker of disease. In contrast, p155-175 was strongly correlated with reactivity to the complete protein $(P<0.001)$ and both reactivities were associated with autoAb to dsDNA and correlated significantly with clinical disease activity, skin involvement and proteinuria $(P<0.01)$. Remarkably, immunohistochemical analysis revealed overexpression of hnRNP-A2 in affected skin of SLE patients. These data, together with previously published findings in murine SLE models, are suggestive of an involvement of hnRNP-A2 autoimmunity in the pathogenesis of SLE.

\section{6}

Fcy receptors complement interaction: new aspects in pathogenesis and treatment of vasculititis

\section{RE Schmidt}

Clinical Immunology, Hannover Medical School, Hannover, Germany Arthritis Res Ther 2003, 5 (suppl 1):26

For a long time, detailed mechanisms of immune-complex-mediated vasculitis have been unknown. The advent of gene knockout technology and the characterization of the various Fc and complement receptors as well as cytokines now allows the various pathogenetic elements in vasculitic inflammation to be distinguished.

Using various murine knockout models, in particular Fc $\gamma$-receptor-deficient animals, mast-cell-defective animals, and complement-deficient animals in recent years, we have shown that FcyRIII and C5a receptor are critical for induction of immune-complex-mediated vasculitis. In several studies, it became clear that mast cells have a critical role in the initiation of the inflammatory process. On these mast cells, again the FcyRIII is a critical activating receptor used by immune complexes. When examining the effects of immune complexes in glomerular mesangial cells and GBM nephritis, we showed that IgG immune com-

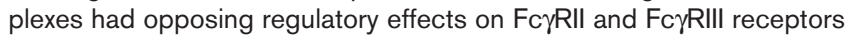
in glomerular mesangial cells. Whereas activation by TNF- $\alpha / \mathrm{LL}-1 \beta$ induces substantial Fc $\gamma \mathrm{RII}$ expression, IFN- $\gamma$ showed a complete downregulation of FcyRII. At the same time, IFN- $\gamma$ induced the Fc receptor $\gamma$-chain as well as the low-affinity IgG receptor FcyRlll. Triggering of FcyRIII again induced chemoattractant protein 1, MCP-1, MCP-5 and RANTES.

Examining the regulatory role in the cooperation of $\mathrm{Fc} \gamma$ receptors and complement, we showed that $\mathrm{C} 5 \mathrm{a}$ is critical in amplifying the inflammatory response to $\lg \mathrm{G}$. $\mathrm{C} 5 \mathrm{a}$ is important on the one hand in downregulating Fc $\gamma \mathrm{R} I \mathrm{ll}$, and on the other hand in inducing the activating FcyRlII.

Altogether, distinguishing the various components of vasculitis pathogenesis allows for new strategies to intervene in this inflammatory process. 
27 Linear epitopes of two different autoantigens (La/SSB
and myelin basic protein) with a high degree of
molecular similarity cause different humoral responses

A Terzoglou, JG Routsias, C Sakarellos, M SakarellosDaitsiotis, HM Moutsopoulos, AG Tzioufas

Department of Pathophysiology, School of Medicine, University of Athens, Athens, Greece

Arthritis Res Ther 2003, 5 (suppl 1):27

Backgkround: Sequences 147-154aa of La/SSB and 139-146aa of human myelin basic protein (MBP) present $83 \%$ sequence similarity.

Objective: We investigated the immune response of both epitopes in rabbits and in sera from patients with autoimmune diseases.

Methods: Peptides 147-154aa of La/SSB and 139-146aa of MBP were used for immunizations of New Zealand White rabbits. Spreading to the other epitopes of La/SSB (289-308aa, 349-364aa) as well as the recombinant human MBP (hMBP) and La/SSB (recLa) was identified using ELISA assays. Sera from 49 patients with systemic lupus erythematosus (SLE), 44 patients with Sjögren's syndrome (pSS), and 18 with rheumatoid arthritis (RA) with anti-RolLa reactivity were tested against the two peptides and the hMBP.

Results: Rabbits immunized with the La epitope developed early antibodies against all three La/SSB peptides, hMBP, and recLa. In contrast, rabbits immunized with the MBP peptide developed a late immune response to other La epitopes, hMBP, and recLa. Inhibition experiments using the MBP peptide as inhibitor against the hMBP showed that the $79 \%$ of reactivity was abolished, indicating that this peptide is the major antibody target in MBP. Twenty percent of pSS, $27 \%$ of SLE, and none from RA patients reacted with the 147-154aa La epitope; $28 \%$ of pSS, $22 \%$ of SLE, and $17 \%$ of RA sera reacted with the MBP peptide. Finally, $17 \%$ of pSS, $37 \%$ of SLE, and $30 \%$ of RA sera reacted with the hMBP.

Conclusion: La 147-154aa peptide when used for animal immunizations can induce immediate epitope spreading while the mimicking epitope MBP 139-146aa induces a delayed response against the other La epitopes. A significant proportion of human sera reacted with both peptides and hMBP. Thus, despite the fact that these two peptides present molecular similarity, they induce different immune responses.

\section{8}

\section{Autoantibodies predict progression to rheumatoid arthritis in undifferentiated arthritis: a prospective cohort study}

FA van Gaalen, SP Linn-Rasker, WJ van Venrooij, BA de Jong, FC Breedveld, CL Verweij, REM Toes, TWJ Huizinga

Department of Rheumatology, Leiden University Medical Center, Leiden, The Netherlands

Arthritis Res Ther 2003, 5 (suppl 1):28

Background: Early intervention in rheumatoid arthritis (RA) reduces long-term disability. However, early diagnosis of RA can be difficult, as the disease may initially be indistinguishable from other forms of arthritis. Recent studies indicate that autoantibodies can be detected years before clinical symptoms develop. In a cohort with recent-onset arthritis, we aimed to assess the value of autoantibodies in predicting the development of RA in patients with undifferentiated arthritis (UA).

Methods: IgM rheumatoid factors (IgM-RF) and anti-cyclic citrullinated peptide (CCP) antibody tests were performed at baseline in 936 consecutive, newly referred patients with recent-onset arthritis. Two weeks after inclusion arthritis, patients who could not be properly classified were categorized as UA. Patients with UA were followed for 3 years and evaluated for progression to RA.

Results: At 2 weeks, 346 of 936 patients (37\%) with recent-onset arthritis were classified as having UA. After 3 years of follow-up, 127 UA patients (40\%) had progressed to RA. However, RA had developed in 64 of 69 UA patients with a positive anti-CCP test, giving a positive predictive value (PPV) of $93 \%$ and a negative predictive value (NPV) of 74\%. Progression to RA was observed in 51 of 68 UA patients with IgM-RF antibodies at baseline (PPV 75\%, NPV 70\%).

Conclusion: Up to 3 years before a diagnosis of RA was made, autoantibodies were detected in patients with UA. Detection of antiCCP antibodies had a high predictive value for the progression to RA. Thus, screening for anti-CCP antibodies in UA allows physicians to predict progression to RA.

\section{9}

Autoantibodies to GPI are predominantly present in extra-articular complications of human rheumatoid arthritis

FA van Gaalen, REM Toes, HJ Ditzel, M Schaller, CL Verweij, TWJ Huizinga

Department of Rheumatology, Leiden University Medical Center, Leiden, The Netherlands

Arthritis Res Ther 2003, 5 (suppl 1):29

Several years ago, Benoist et al. described in Cell a T-cell transgenic mouse that spontaneously developed severe arthritis (KRN model). Subsequent reports demonstrated that in this model, disease is caused by antibodies against glucose-6-phosphate isomerase (GPI).

A link between this mouse model and human disease was made when Schaller et al. reported that antibodies against GPI are present in $64 \%$ of human rheumatoid arthritis (RA) (Nat Immunol 2001). However, this finding remains controversial, since several other groups could not reproduce these results. Given these apparently conflicting findings, we hypothesized that GPI antibodies are present in a specific subset of RA patients and set out to determine at what point autoantibodies to GPI occur in RA. GPI antibodies were detected in only few sera of of uncomplicated RA (2\%)and healthy controls (3\%). However, in RA patients with disease manifestation outside their joints, GPI antibodies were more common. $18 \%$ of RA patients with skin inflammation (rheumatoid nodules) and 45\% of RA patients with vascular inflammation had anti-GPI antibodies. Yet, in RA patients with arthritis complicated by decreased numbers of circulating granulocytes (Felty's syndrome) $92 \%$ had GPI antibodies. But, since the GPI antigen was not detected on RA granulocytes, we propose that GPI antibodies are not likely to be directly involved in granulocyte destruction.

In summary, we conclude that anti-GPI antibodies that cause disease in the KRN mouse model are common in human RA complicated by inflammation outside the joint, demonstrating the relevance of the mouse model to human disease.

\section{0}

\section{Citrullination of synovial proteins in murine models of rheumatoid arthritis}

E Vossenaar, S Nijenhuis, MM van Helsen, A van der Heijden, WB van den Berg, WJ van Venrooij, L Joosten

Department of Biochemistry, University of Nijmegen, Nijmegen, The Netherlands

Arthritis Res Ther 2003, 5 (suppl 1):30

Antibodies directed to citrulline-containing proteins are highly specific for rheumatoid arthritis (RA) and can be detected in up to $80 \%$ of RA patients. Citrulline is an unnatural amino acid that can be incorporated into proteins only by post-translational modification of arginine by peptidylarginine deiminase (PAD) enzymes. We investigated the presence of anticitrulline antibodies, PAD enzymes and citrullinated antigens in an acute and a chronic destructive mouse model for arthritis: streptococcal-cell-wall arthritis and collagen-induced arthritis. In both mouse models, PAD2 mRNA is present in the synovium but not translated into PAD2 protein. In contrast, PAD4 mRNA, although absent from healthy synovia, is readily transcribed and translated by polymorphonuclear neutrophils infiltrating the synovial tissue during inflammation. As a consequence, several synovial proteins are subjected to citrullination. One of these proteins was identified as fibrin, which has been reported to 
be citrullinated also in the synovia of RA patients. Although the generation of citrullinated antigens during synovial inflammation in the mice was eminent, no anticitrullinated protein antibodies could be detected. In conclusion, the citrullination of synovial antigens is an active process during joint inflammation both in mouse and man, but the induction of autoantibodies directed against these proteins is a more specific phenomenon detectable only in RA patients.

\section{1}

\section{Fibrinogen-specific T cells in rheumatoid arthritis}

E Vossenaar ${ }^{1}$, R Bergholz², F Schumann ${ }^{2}$, GR Burmester ${ }^{2}$, JM Engel ${ }^{3}$, WJ van Venrooij ${ }^{1}$, S Bläß ${ }^{2}$

${ }^{1}$ Department of Biochemistry, University of Nijmegen, The Netherlands ${ }^{2}$ Department of Rheumatology \& Clinical Immunology, Charité

University Clinic, Berlin, Germany

${ }^{3}$ Rheumaklinik, Bad Liebenwerda, Germany

Arthritis Res Ther 2003, 5 (suppl 1):31

Rheumatoid arthritis (RA) is characterized by the occurence of autoreactive antibodies and T cells. The family of antibodies directed to citrulline-containing antigens (anti-filaggrin, anti-CCP and anti-Sa) have the highest specificity $(>98 \%)$ for RA. To investigate the presence of citrulline-specific T cells in RA patients, we analyzed T-cell reactivity to unmodified and citrullinated filaggrin and fibrinogen in modified T-cell proliferation assays.

No T-cell responses were observed when either unmodified or citrullinated filaggrin was used as the stimulating antigen in serum-free T-cell proliferation assays. With unmodified fibrinogen, however, T-cell proliferation was observed in $8 / 15(53 \%)$ of RA patients, while only $1 / 14$ control patients (SLE, SSc, PsoA, Sjö) displayed clearly positive T-cell proliferation. The difference was highly significant $(P<0.0001)$. These findings were even more pronounced when using citrullinated fibrinogen as stimulating antigen: 10/15 (67\%) RA patients were positive for T-cell proliferation and again only $1 / 14$ control patients was clearly positive $(P<0.0001)$. T-cell reactivity in RA patients was significantly $(P<0.05)$ higher against citrullinated as compared with unmodified fibrinogen. We conclude that fibrinogen (citrullinated or not) can induce proliferation of RA T cells, thereby further substantiating its pathogenic relevance.

\section{2}

\section{Elevated anti-serum amyloid P component (SAP) antibodies in SLE patients}

G Zandman-Goddard, M Blank, P Langevitz, M Pras, Y Levy, T Witte, A Doria, J Rovensky, Y Shoenfeld

Center for Autoimmune Diseases, Sheba Medical Center, Tel Hashomer, Israel

Arthritis Res Ther 2003, 5 (suppl 1):32

Background: Serum amyloid P component (SAP) binds to DNA and chromatin and plays a role in the clearance of apoptotic debris. One postulated mechanism in the dysregulation of the immune system in systemic lupus erythematosus (SLE) is the aberrant clearance of apoptotic cells. We hypothesize that binding of SAP to anti-SAP antibody may alter SAP function.

Objective: The aim of the study was to determine the presence of antiSAP antibodies in SLE patients and investigate the correlation with clinical disease.

Methods: Samples from 481 subjects (357 SLE patients, 124 normal controls) were screened for the presence of elevated anti-SAP antibody titers by the ELISA method (optical density $405 \mathrm{~nm}$ above $3 \mathrm{SD}$ were considered elevated). Clinical parameters and SLEDAI scores were assessed from the review of files.

Results: Elevated anti-SAP antibody titers were detected in $47 \%$ of SLE samples, versus $2 \%$ of the control group. In a representative group ( $n=112$ ), $62 \%$ of patients had elevated anti-SAP antibodies and anti-dsDNA antibody titers. SLEDAl scores were assessed in 83 patients, of whom 54\% had elevated anti-SAP antibody titers: $59 \%$ had a SLEDAI score of at least 8 , an indication of severe disease. The vated anti-SAP antibody titers did not reveal a specific pattern. Serial sampling of two representative SLE patients revealed a decrease in anti-SAP antibody titers after treatment with IVIg that correlated with a decrease in anti-dsDNA antibody titers and with clinical improvement.

Conclusion: Elevated anti-SAP antibody titers were detected in SLE patients and correlated with disease activity. In SLE patients, elevated anti-SAP antibody titers may serve as an additional diagnostic and prognostic marker.

\section{Cytokines}

\section{3}

Clinical and immunological effects of anti-TNF therapy in systemic lupus erythematosus (SLE) M Aringer, G Steiner, WB Graninger, E Höfler, H Hiesberger, C-W Steiner, J Smolen

Rheumatology, Internal Medicine III, University of Vienna, Austria Arthritis Res Ther 2003, 5 (suppl 1):33

Background: Tumor necrosis factor (TNF) is increased in the sera of patients with SLE and in lupus glomerulonephritis and is associated with disease activity. We investigated clinical and immunological outcomes in a pilot trial of TNF blockade in SLE.

Methods: Within an open safety study, SLE patients with nephritis or arthritis receive the humanized chimeric anti-TNF antibody infliximab plus azathioprine or methotrexate. Serum TNF (sTNF)was measured by ELISA, the percentages of TNF-positive lymphocytes by fluorocytometry. Results: In the first two lupus nephritis patients treated with infliximab, proteinuria fell from 1.2 to $0.3 \mathrm{~g} / 24 \mathrm{~h}$ and from 5.7 to $1.1 \mathrm{~g} / 24 \mathrm{~h}$, respectively, within 3 months after the start of therapy; the (normal) creatinine serum levels remained stable. Arthritis in a third SLE patient remitted under therapy but relapsed 8 weeks after the last infusion. Anti-dsDNA IgG antibodies increased transiently in all three patients at around week 10 of therapy. An increase in anti-histone antibodies (as well as anti-chromatin antibodies in two of the three patients) predated the increase in anti-dsDNA, which was not associated with increased disease activity. Interestingly, even the increase in anti-histone antibodies was predated by an increase in sTNF (mean \pm SD of peak value $168 \pm 114 \mathrm{pg} / \mathrm{ml}$ ), while the percentage of lymphocytes carrying TNF decreased at the same time.

Conclusion: Anti-TNF therapy improves SLE glomerulonephritis and arthritis but leads to a transient increase in autoantibodies, which was not associated with flares in our patients. The observation that antidsDNA antibodies are predated by anti-histone antibodies and that this increase follows the changes in TNF suggests that TNF-blocking therapy is directly associated with an increase in anti-histone and a subsequent transient increase in anti-dsDNA antibodies.

\section{4}

Therapy with soluble TNF receptor (etanercept) induces apoptosis in rheumatoid arthritis (RA) synovium

Al Catrina, C Trollmo, J Lampa, E af Klint, Y Hermansson, L Klareskog, A-K Ulfgren

Rheumatology Unit, Department of Medicine, Karolinska Hospital/Institutet, Stockholm, Sweden

Arthritis Res Ther 2003, 5 (suppl 1):34

Objectives: This study evaluates modulation of rheumatoid arthritis (RA) synovial apoptosis by therapy with the soluble tumor necrosis factor (TNF) alpha receptor (etanercept).

Methods: Apoptosis (TUNEL [transferase-mediated UTP end labeling] combined with morphology), cell-surface markers (CD3, CD68, CD163, Fas), FLIP and granzyme B were evaluated by immunohistochemistry in synovial biopsies from 12 RA patients before and after 8 weeks of treatment with etanercept. Moreover, the in vitro effect of etanercept on FLIP expression and on the death of mononuclear cells (MNCs) derived from synovial fluid (SF) was determined in five RA patients by flow cytometry. 
Results: Etanercept treatment increased synovial apoptosis and decreased the number of CD68-positive and CD163-positive monocyte/macrophages and FLIP expression $(P<0.05)$. No significant changes were observed for the expression of CD3, Fas and granzyme B. In vitro, low concentrations of etanercept (1 and $10 \mu \mathrm{g} / \mathrm{ml})$ increased cell death $(P<0.05)$ in the SF CD14-positive monocyte/ macrophage population after 24 hours' incubation, while higher concentrations $(100 \mu \mathrm{g} / \mathrm{ml})$ had no effect. FLIP expression in this population did not change after in vitro culture with either low or high doses. The in vitro culture with etanercept did not induce any changes in FLIP expression or apoptosis level in SF CD3-positive cells.

Conclusion: Therapy with etanercept at clinically relevant concentrations increased RA synovial monocyte/macrophage apoptosis, suggesting an alternate pathway to explain the decrease in synovial cellularity observed after anti-TNF therapy.

\section{5}

\section{The effect of methotrexate and mycophenolic acid on} monokine production in vitro

\section{S de Lathouder', AH Gerards'2, ER de Groot', LA Aarden'}

${ }^{1} /$ mmunopathology, Sanquin Research at CLB, Amsterdam, The Netherlands

${ }^{2}$ Rheumatology, VU medical center, Amsterdam, The Netherlands Arthritis Res Ther 2003, 5 (suppl 1):35

Methotrexate (MTX) and mycophenolic acid (MPA) are used clinically for their immunosuppressive properties. MTX is widely used for the treatment of RA. MPA is used to prevent graft rejection and is now experimentally used in SLE and RA. The precise mechanism of action is still debated. Both drugs, though in different ways, inhibit the de novo synthesis of DNA and RNA. We have analysed cytokine production in short cell cultures in whole blood and isolated cells by ELISA. We have shown before that both drugs inhibit the production of several cytokines after T-cell stimulation, and we concluded that MTX leads to irreversible elimination of activated T cells by apoptosis, whereas MPA reversibly prevents activation of resting $T$ cells.

We now show that when monocytes are stimulated by SAC or lipopolysaccharide, both MTX and MPA decrease TNF- $\alpha$, IL- 6 and IL- 8 production. However the inhibition is not as profound as after T-cell stimulation. An exception is the effect on the production of the proinflammatory cytokine IL-1 $\beta$. The production of IL-1 $\beta$ is not influenced by MTX after SAC or LPS stimulation, whereas the production is increased by MPA when cells are stimulated with LPS, but not with SAC. We have investigated the cause for this increase. The expression of IL-1 13 mRNA is not influenced by MPA. Immunoprecipitation and ELISA show that MPA leads to a decrease in the intracellular pro- form of IL-1 $\beta$. We conclude that MPA leads to enhanced cleavage of pro-IL-1 $\beta$.

\section{6}

Changes in rheumatoid factor reflect the inflammatory response (CRP and ESR) to infliximab treatment

L De Rycke, E Kruithof, N Van Damme, IEA Hoffman, F Van den Bosch, EM Veys, F De Keyser

Department of Rheumatology, Ghent University Hospital, Ghent, Belgium Arthritis Res Ther 2003, 5 (suppl 1):36

Background: We showed previously that there is a reduction in both rheumatoid factor (RF) Waaler Rose (WR) and RF latex fixation (LF) titres after infliximab treatment, but that no differences are seen for anticyclic citrullinated peptide antibodies.

Objectives: To analyze changes in C-reactive protein (CRP) and erythrocyte sedimentation rate (ESR) in relation to changes in RF.

Patients and methods: Sixty-two patients with refractory rheumatoid artritis (RA) were treated with infliximab in an early-access program. They received $3 \mathrm{mg} / \mathrm{kg}$ infliximab IV at weeks 0,2 and 6 and every 8 weeks thereafter in combination with methotrexate. Serum samples were obtained at baseline and at week 30 and tested for RF WR, RF LF, CRP and ESR. For statistical analysis, Mann-Whitney tests were used. $P$-values $\leq 0.05$ were considered significant.
Results: Patients with an increase in RF WR titre $(n=9)$ were likely to have an increase in CRP (median CRP increase of $0.59 \mathrm{mg} / \mathrm{dl}$ ) and ESR (median ESR increase of $9 \mathrm{~mm} / \mathrm{h}$ ), whereas patients with no increase in RF WR titre $(n=53)$ were more likely to have a decrease in CRP (median CRP decrease of $0.89 \mathrm{mg} / \mathrm{dl}$ ) and ESR (median ESR decrease of $5.5 \mathrm{~mm} / \mathrm{h}$ ) during infliximab treatment. The changes in CRP and ESR were significantly different when comparing patients with an increase in RF WR titre and patients with no increase in RF WR titre ( $P=0.046$ for CRP and $P=0.032$ for ESR). When additionally also the RF LF titre increased in the group of patients with an increase in RF WR titre, all patients $(n=3)$ had an increase in CRP (median CRP increase of $2.3 \mathrm{mg} / \mathrm{dl}$ ) and ESR (median ESR increase of $16 \mathrm{~mm} / \mathrm{h}$ ).

Conclusion: After infliximab treatment, RA patients with an increase in RF WR titre are more likely to have increased inflammatory parameters, in comparison with patients who had no increase in RF WR. Especially when both RF titres increased, an increase of CRP and ESR was present in all patients.

\section{7}

\section{Promoter polymorphisms in the IL-18 gene are associated with rheumatoid arthritis in two independent clinical cohorts}

JA Gracie', N Koyama², M Field'1, F McGarry'1, A Schobel ${ }^{2}$, IB Mclnnes', B Moller ${ }^{2}$

${ }^{1}$ Centre for Rheumatic Diseases, University of Glasgow, Glasgow, UK ${ }^{2}$ Rheumatology, University of Frankfurt, Frankfurt, Germany Arthritis Res Ther 2003, 5 (suppl 1):37

Introduction: IL-18 in synovial tissues of patients with rheumatoid arthritis (RA) promotes local inflammation via effects on innate and adaptive immune responses. Promoter polymorphisms may modulate IL-18 expression. Using two independent clinical cohorts, we determined the frequency of single nucleotide polymorphisms (SNPs) in the IL-18 promoter for RA patients.

Methods: DNA was extracted from peripheral blood mononuclear cells of 102 RA patients and 114 healthy donors in Frankfurt and from 153 RA patients and 187 healthy donors in Glasgow. In Frankfurt, DNA was amplified by polymerase chain reaction (PCR) and the presence of IL-18 SNP at positions -607 and -137 was determined by the restriction fragment length technique. Independently, in Glasgow, allele-specific PCR was performed for the same SNP sites.

Results: Frankfurt cohort: The $-607 \mathrm{C}$ and $-137 \mathrm{G}$ alleles were significantly more frequent in the RA population. Highly significant associations $(P<0.001)$ for RA were found for the homozygous $C$ genotype in positions -607 and -137 . Glasgow cohort: The $-137 \mathrm{C}$ allele was more frequent in RA patients $(P<0.01)$, but no effect was seen at position 607. Moreover, the $-137 \mathrm{CC}$ genotype was more frequent in RA $(P<0.01)$. However in contrast to the Frankfurt dataset, no effect was seen at the -607 site.

Conclusion: SNPs at the -137 position in the IL-18 promoter appear to contribute to the genetic background in RA pathogenesis. Importantly, this has been independently identified in two clinical cohorts, by the use of distinct methodologies, in Germany and the UK. IL-18 is a promising therapeutic target and, as such, defining factors that modulate its regulation in rheumatoid tissues is important.

\section{8}

Combination of the proinflammatory cytokines IL-1, TNF- $\alpha$ and IL-17 leads to enhanced expression and additional recruitment of AP-1 family members, Egr-1 and NF-KB in osteoblast-like cells

\section{Granet, P Miossec}

INSERM U403, Department of Immunology and Rheumatology, Hôpital E Hérriot, Lyon, France Arthritis Res Ther 2003, 5 (suppl 1):38

Objectives: To determine the contribution of IL-1, TNF- $\alpha$ and IL-17 on $\mathrm{AP}-1, \mathrm{NF}-\mathrm{KB}$ and Egr-1 activation in cytokine-induced bone destruction 
as in rheumatoid arthritis, we investigated the effect of these proinflammatory cytokines on transcription factor activation in osteoblasts.

Methods: Osteoblast-like ROS $17 / 2.8$ cells were cultured with IL-1, TNF- $\alpha$ and IL-17 alone and in combination. Effects of each cytokine were explored by RT-PCR and immunocytochemistry.

Results: IL-1 and TNF- $\alpha$ induced most of these transcription factors while IL-1 7 had a weak effect. IL-1 induced egr-1 and all AP-1 member expression, except fosB and junD. TNF- $\alpha$ also induced AP-1 member expression, with a longer expression for fra- 1 and fra-2. These two cytokines individually induced nuclear translocation at $30 \mathrm{~min}$, except for JunB. IL-17 enhanced fra-2 and egr-1 mRNA between T30-T120 with a peak at T90, while nuclear localisation was noticed at T30 for Fra-1, JunD and NF-kB. More importantly, when these cytokines were used at low concentrations with no effect when used alone, their combinations showed a synergistic effect on transcription and nuclear translocation of AP-1 members, Egr-1 and NF-KB. Moreover, cytokine combinations allowed an enhanced recruitment of factors not express by cytokines used alone.

Conclusion: AP-1, Egr-1 and NF- $\mathrm{KB}$ pathways in osteoblast cells are very sensitive to the combined effect of proinflammatory cytokines through additive or synergistic mechanisms.

\section{9}

\section{Expression of chemokines and their receptors in synovial tissue of patients with rheumatoid arthritis, osteoarthritis and reactive arthritis}

\section{JJ Haringman, TJM Smeets, MC Kraan, PP Tak}

Clinical Immunology and Rheumatology, Academic Medical Center/University of Amsterdam, Amsterdam, The Netherlands Arthritis Res Ther 2003, 5 (suppl 1):39

Background: Chemokine receptors and their ligands play a crucial role in the recruitment of leukocyte subsets into inflamed tissue. Their exact expression in synovial tissue (ST) of patients with various forms of arthritis has yet to be determined.

Objective: The objective of this study was to determine the expression of an extensive number of chemokines and their receptors in patients with rheumatoid arthritis (RA) and other forms of arthritis.

Methods: Synovial biopsies were obtained with a Parker-Pearson needle from patients with RA ( $n=23)$, osteoarthritis (OA) $(n=16)$, and reactive arthritis $(\operatorname{ReA})(n=8)$. ST was studied in patients with both early and late stages of disease. Sections were analyzed by immunohistochemistry using monoclonal antibodies against CD3 (T-cells), CD68 (macrophages), CD13 (aminopeptidase N), CCR1, CCR2b, CCR5, CXCR4, CCL2 (MCP-1), CCL8 (MCP-2), CCL7 (MCP-3), CCL14 (hCC-1), CCL15 (hCC-2), CCL16 (hCC-4), and CCL5 (RANTES). Digital image analysis was used to quantify the staining and for statistical analysis the Kruskal-Wallis $H$ test and the Mann-Whitney $U$ test were used.

Results: All chemokines and chemokine receptors were detected in inflamed synovium. There was abundant expression of especially CD13, CCR1, CXCR4, CCR5, CCL7, and CCL8 in all forms of arthritis. The ligands CCL7, CCL8, CCL14, CCL15, and CCL16, which have not previously been described in ST, were all expressed in inflamed ST. The expression of CCL5 (RA, $11182 \pm 2239$ (mean integrated optical density \pm SEM); OA, $8759 \pm 2930$; ReA, $2081 \pm 1181$; $P=0.010$ ) and CCL15 (RA, 4993 \pm 1601 (mean integrated optical density \pm SEM); OA, 1738 \pm 573 ; ReA, $1252 \pm 1919 ; P=0.043$ ) was significantly higher in rheumatoid ST compared with disease controls. Conclusion: These results suggest a potentially important role for a variety of chemokines and their receptors in the migration of inflammatory cells towards the synovial compartment. Disruption of the chemokine network might represent a novel therapeutic approach in RA, but also in other arthritides.
40

\section{Osteoprotegerin protects from generalized bone loss} in TNF-transgenic mice

S Hayer', K Redlich1, J Zwerina1, B Bolon'2, C Dunstan2, B Görtz', H Bergmeister ${ }^{3}$, G Kollias ${ }^{4}$, G Steiner ${ }^{1}$, J Smolen ${ }^{1}$, G Schett ${ }^{1}$

${ }^{1}$ Division of Rheumatology, Department of Internal Medicine III, University of Vienna, Vienna, Austria

${ }^{2}$ Department of Pathology, Amgen, Inc., Thousand Oaks, CA, USA

${ }^{3}$ Center for Biomedical Research, University of Vienna, Vienna, Austria

${ }^{4}$ Institute of Immunology, Alexander Fleming Biomedical Sciences

Research Center, Vari, Greece

Arthritis Res Ther 2003, 5 (suppl 1):40

Background: Chronic inflammatory conditions, such as rheumatoid arthritis, are characterized by generalized loss of bone mass. Proinflammatory cytokines, such as TNF, are believed to play a central role in this process by increasing bone resorption.

Objective: We have investigated systemic bone changes in human TNF-transgenic (hTNFtg) mice, which spontaneously develop severe inflammatory arthritis.

Results: Osteodensitometry revealed a significant decrease of trabecular bone mineral density (BMD) (-37\%) in hTNFtg mice, and histomorphometry revealed a dramatic loss of bone volume $(-85 \%)$ in comparison with wild-type controls. Osteoclast-covered bone surface and serum levels of deoxypyridinolin crosslinks were significantly elevated, suggesting increased osteoclast-mediated bone resorption in hTNFtg mice. Osteoprotegerin (OPG) completely blocked TNF-mediated bone loss by increasing BMD (+89\%) and bone volume (+647\%). Most strikingly, formation of primary spongiosa was dramatically increased $(+563 \%)$ in hTNFtg mice after OPG treatment. Osteoclastcovered bone surface and serum levels of deoxypyridinolin crosslinks were significantly decreased by OPG, suggesting effective blockade of osteoclast-mediated bone resorption. OPG did not influence levels of hTNF, TNF-receptor-1, IL-1 $\beta$ and IL-6. However, OPG decreased bone formation parameters, which were elevated in hTNFtg mice. In contrast to OPG, bisphosphonates and anti-TNF treatment did not affect generalized bone loss in hTNFtg mice.

Conclusion: These data indicate that TNF-mediated generalized bone loss is primarily dependent on RANKL/RANK signaling and can be blocked by OPG. Thus, OPG may represent a potent tool to prevent generalized loss of bone mass in chronic inflammatory disorders, especially rheumatoid arthritis.

\section{1}

\section{Influence of anti-TNF therapy on monocyte gene expression in rheumatoid arthritis}

M Hernandez, L Martinez, O Kiesslich, N Tandon, M Janitz, H Lehrach, F Wagner, T Häupl, GR Burmester, B Stuhlmüller

Department of Rheumatology, Charité, Berlin, Germany Arthritis Res Ther 2003, 5 (suppl 1):41

Background and objective: The joint in rheumatoid arthritis (RA) is characterized by pannus formation and cartilage/bone destruction. In RA, not only tissue macrophages but also blood monocytes (MO) are known to be activated and spontaneously release inflammatory mediators. However, genes and functional pathways involved in RA monocyte activation are recognized and characterized only in part.

Of all techniques for differential mRNA expression analysis, DNA arrays raise most expectations and are applied for drug discovery and compound testing in preclinical or clinical studies. This technique may also enable the identification of genes and expression patterns associated with the type of disease, stage of activation, disease progression and molecular therapeutic mechanisms. For functional interpretation, the experimental concept is important. Considering drawbacks and benefits, analysis of defined cell populations is advantageous for functional interpretation.

Methods: Therefore, we analyzed the expression profile of untouched negatively separated MO using the Affymetrix U133A/B array system. $\mathrm{MO}$ were obtained from normal donors, patients with active RA before 
and after several months of anti-TNF antibody therapy. Bioinformatic analysis of gene expression included background correction, normalization, comparative statistics and cluster analysis.

Results: So far, six characteristic clusters have been obtained, including genes relevant to RA and induced or decreased upon therapy. Furthermore, RA regulated genes were identified, which returned to 'normal' upon anti-TNF treatment, indicating selective molecular effects of the drug.

Conclusion: These promising results could open new avenues for the identification of novel genes for a general definition of $\mathrm{MO} / \mathrm{macrophage}$ activation patterns and for pathways activated or blocked during different stages of the disease or therapy-induced remission in RA.

\section{2}

\section{Endogenous IL-12p40 is crucial for antigen-induced arthritis and is partly involved in chronic relapsing streptococcal-cell-wall arthritis}

\section{Jacobs, L Joosten, MMA Helsen, E Lubberts, WB van den Berg}

Rheumatology Research Laboratory, University Medical Center Nijmegen, Nijmegen, The Netherlands

Arthritis Res Ther 2003, 5 (suppl 1):42

Background: Interleukin 12 (IL-12) is a proinflammatory cytokine with important immunoregulatory activities and is critical in determining the differentiation and generation of Th1 cells.

Objectives: For the present study, we investigated the role of endogenous IL-12p40, component of both IL-12 and IL-23, in the pathogenesis of antigen- and chronic relapsing streptococcal-cell-wall-(SCW-) induced arthritis. To this end we used C57BI6 (wild-type; WT) and IL-12p40-deficient (IL-12 ko) mice. Chronic SCW was induced by intraarticular (i.a.) injection of $25 \mu \mathrm{g} \mathrm{SCW}$ fragments at days $0,7,14$ and 21. Joint swelling and histology were examined at day 28 after the first injection. Antigen-induced arthritis (AIA) was initiated by i.a. injection of $60 \mu \mathrm{g} \mathrm{mBSA}$ in preimmunized mice. Joint swelling was measured at days 3,7 and 14, whereas histology was examined at days 7 and 14 .

Results: At day 28, joint swelling of the mainly macrophage-driven chronic SCW arthritis was significantly reduced in IL-12p40 ko mice in comparison with WT mice $(P=0.0008)$. Although cell influx was decreased $(P=0.0194)$, no reduction in cartilage proteoglycan depletion was found. In a predominantly T-cell-mediated process such as AIA, joint swelling was significantly suppressed at days 3 and 7 in IL-12p40 ko mice in comparison with WT $(P=0.0021$ and $P=0.0260$ respectively). Moreover, histopathology was drastically reduced in IL-12p40 ko mice; the number of inflammatory cells was strongly suppressed in IL-12p40 ko mice in comparison with WT animals (1.6 \pm 0.4 vs $0.2 \pm 0.2$ and $P<0.0001)$. In line with these findings matrix proteoglycan depletion was completely absent in $\mathrm{IL}-12 \mathrm{p} 40$ ko mice $(1.9 \pm 0.35$ vs $0.05 \pm 0.11$ and $P<0.0001)$.

Conclusion: These results indicate that IL-12p40 plays a pivotal role in antigen-induced arthritis and a minor role in chronic relapsing streptococcal-cell-wall-induced arthritis.

\section{3}

\section{IL-18 directly promotes joint inflammation and induces cartilage destruction through IL-1}

L Joosten, E Lubberts, MJM Wagenmans, MMA Helsen, FAJ van de Loo, WB van den Berg

Rheumatology Research Laboratory, University Medical Center Nijmegen, Nijmegen, Netherlands

Arthritis Res Ther 2003, 5 (suppl 1):43

Background: Interleukin-18 is a member of the IL-1 family of proteins that exerts proinflammatory effects and induces cartilage destruction in vitro.

Objective: The goal of the present study was to investigate whether IL-18 mediates joint destruction in vivo, directly or via induction of other cytokines.
Results: To this end, we performed both in vitro and in vivo kinetic studies. 35S-labeled explants of C57BI/6 mice were cultured for 24 to 72 hours in either IGF-1, IGF-1/IL-18 or IGF-1/IL-1 $\beta$ in combination with or without IL-1 receptor antagonist (IL-1Ra) or an ICE inhibitor. Wild-type, TNF $\alpha$-deficient and IL- $1 \alpha, \beta$-deficient mice were used for in vivo IL-18 exposure studies. Mice were injected intra-articularly with $10^{7} \mathrm{pfu} \mathrm{mlL}-18$ adenovirus at day 0 , and histopathology was examined at days 4,7 and 14 . In vitro IL-18 exposure for 24 or 48 hours did not induce cartilage degradation, determined as release of prelabeled proteoglycans. Cartilage degradation by IL-18 was only found after a 72-hour culture period. Blocking of IL-1 with IL-1Ra or ICE-inhibitor resulted in almost complete protection against IL-18 mediated cartilage degradation in vitro. Application of $10^{7} \mathrm{pfu}$ AdmL-18 resulted in prolonged elevated levels of IL-18, for up to 14 days. Histology at days 4,7 , and 14 revealed that local overexpression of IL-18 resulted in increasing joint inflammation and cartilage destruction in the wild-type mice. Of high interest, IL-18 gene transfer in IL-1 $\alpha, \beta^{-/-}$mice did not show cartilage damage at the various time points, although joint inflammation was similar to that in the wild-type animals. Overexpression of IL-18 in TNF $\alpha$-deficient mice showed that TNF $\alpha$ was partly involved in IL-18-induced joint inflammation.

Conclusion: Here we showed that IL-18 induces joint inflammation independently of IL-1. In addition, we showed that IL-1 generation, due to IL-18 exposure, was essential for marked cartilage degradation both in vitro and in vivo. These findings imply that IL-18 contributes, through separate pathways, to joint inflammation and cartilage destruction.

\section{4}

\section{TNF polymorphisms are associated with the development of joint erosions in psoriatic arthritis \\ D Kane', J Balding'2, W Livingstone ${ }^{2}$, L Mynett-Johnson², B Bresnihan', O Smith², O Fitzgerald1}

${ }^{1}$ Department of Rheumatology, St Vincent's University Hospital, Dublin, Irish Republic

${ }^{2}$ Department of Genetics, Trinity College, Dublin, Irish Republic

Arthritis Res Ther 2003, 5 (suppl 1):44

Objective: To determine whether functional cytokine gene polymorphisms influence disease susceptibility and phenotype in patients with psoriatic arthritis (PsA).

Methods: DNA was obtained from 147 PsA patients (mean age of arthritis onset $=35.2 \pm 13.4$ years; oligoarticular $=43$ [29\%], polyarticu$\operatorname{lar}=104[71 \%])$ and 389 healthy Irish blood donors. Seven functional proinflammatory (IL-1 $\beta+3953$, IL-6 -174, TNF- $\alpha-308$, TNF- $\beta+252$ ) and anti-inflammatory (IL-10 -1082, IL-10 -592, IL-1Ra [intron 2, 86bp VNTR]) gene polymorphisms were detected by PCR and RFLP assays. Results: No significant difference in genotype frequencies was observed between the control population and the PsA population, and no association with ACR functional class, disease classification (polyarticular or oligoarticular), the presence of spinal involvement, or age of PsA onset was observed. Age of onset of psoriasis was significantly associated with the TNF- $\beta(P=0.0011)$ and TNF- $\alpha(P=0.01)$ polymorphisms. The TNF- $\beta$ B2/B2 and TNF- $\alpha-308$ AA genotypes were associated with the earliest mean age of psoriasis onset. Plain radiographs of the hands and feet were obtained in 114 patients (64 with joint erosions, 48 with periostitis). The presence of joint erosions was significantly associated with the TNF- $\alpha-308 \mathrm{~A}(P<0.0001)$ and TNFB1 $(P=0.0009)$ alleles. Sequential radiographs were obtained in $52 / 61$ patients who presented with early PsA ( $<2$ years' duration) with $19 / 52$ (37\%) increasing the number of joint erosions (progressors) over a median interval of 24 months. The TNF- $\alpha-308 \mathrm{~A}$ allele and the TNFB B1 allele were significantly increased in the progressor group ( $P=0.014$ and $P=0.048$ respectively).

Conclusion: The TNF- $\alpha-308$ and TNFB polymorphisms are significantly associated with the presence of joint erosions in PsA and with the progression of joint erosions in early PsA. 
45

\section{Defect of Th1 immune response of whole blood cells from active patients with rheumatoid arthritis (RA) M Kawashima, P Miossec}

Department of Immunology and Rheumatology and INSERM U-403, Hôpital Edouard Hérriot, Lyon, France

Arthritis Res Ther 2003, 5 (suppl 1):45

Background: Cases of severe tuberculosis have been reported in patients with RA during anti-TNF-alpha (TNF- $\alpha$ ) treatment. In addition to TNF- $\alpha$, IFN gamma (IFN- $\gamma$ ) and the cellular immunity are known to be important to prevent the development of tuberculosis infection.

Objective and methods: We examined mRNA expression of IFN- $\gamma$, IL-4, T-bet, GATA-3, and TNF- $\alpha$ by peripheral whole blood from RA patients $(n=28)$ and healthy controls $(n=16)$, using real-time RT-PCR. Results: IFN- $\gamma$, IL-4, and TNF- $\alpha$ expression was significantly higher in RA than in healthy blood $(P=0.0023,0.003$, and 0.0004 , respectively). In RA samples, T-bet expression correlated with that of IFN- $\gamma$ $(r=0.738, P<0.0001)$ and negatively correlated with serum CRP levels $(r=-0.516, P=0.004)$. No correlation between T-bet and IFN- $\gamma$ expression was observed in healthy blood. Next, we separated RA patients into two groups according to their serum CRP levels. In comparison with healthy or mild RA (CRP $<40 \mathrm{mg} / \mathrm{l}, n=19$ ), active RA blood (CRP $>40 \mathrm{mg} / \mathrm{l}, n=9$ ) showed significantly lower ratio of T-bet/ $\beta$-actin $(P=0.014, P=0.0009)$ or T-bet/GATA-3 $(P=0.0035$, $P=0.0085$, respectively). Active RA blood expressed significantly lower IFN- $\gamma$ mRNA in comparison with that of mild RA $(P=0.014)$. There was no difference of IFN- $\gamma$ expression between active RA and healthy blood, but active RA showed higher expression of IL-4 than that of healthy samples $(P=0.025)$. TNF- $\alpha$ expression by active RA blood was lower than that of mild RA $(P=0.013)$ and healthy blood, though not significantly so.

Conclusion: These findings demonstrate that IFN- $\gamma$, T-bet, or TNF- $\alpha$ expression by whole blood cells may be influenced by disease activity of RA, and the combination of the defect of TNF- $\alpha$ and Th1 immune response indicated by low IFN- $\gamma$ and T-bet with high IL-4 expression in the active RA blood, with the additional effect of blockade of TNF activation on T cells, may represent critical conditions for the development of tuberculosis.

\section{6}

TNF- $\alpha$ dependency of IL-17-induced joint pathology differs under naive and arthritis conditions in vivo

M Koenders, E Lubberts, L Joosten, B Oppers, L van den Bersselaar, J Kolls, WB van den Berg

University Medical Center Nijmegen, Nijmegen, The Netherlands Arthritis Res Ther 2003, 5 (suppl 1):46

Background: T-cell IL-17 is a proinflammatory cytokine present in the synovium of RA patients. IL-17 is an inducer of other cytokines, such as IL-1 and TNF. It can have both additive and synergistic effects on cytokine induction and tissue destruction with these cytokines, but may have direct pathological effects as well.

Objective and methods: In the present study, we examined the dependency of TNF- $\alpha$ in the IL-17-induced joint inflammation and cartilage damage under naive and arthritis conditions using an adenoviral vector expressing mlL-17 (AdlL-17).

Results: IL-17 overexpression in the knee joint of naive mice resulted in joint inflammation and cartilage proteoglycan depletion, which gradually increased with time. No effects were noted with the same dose of the control vector. IL-17 induced elevated expression of IL-1 mRNA levels in the synovium in comparison with the control group. However, no difference in IL-17-induced joint pathology was noted in IL-1 $\alpha / \beta$-deficient mice. Of high interest, using TNF- $\alpha$ deficient mice, the IL-17-induced joint inflammation and cartilage damage were almost completely absent. This strongly indicates that under naive conditions in vivo the IL-17-induced joint inflammation and cartilage destruction are mediated by TNF and not necessarily by IL-1.
Since it is known that in streptococcal-cell-wall (SCW) arthritis, TNF and IL-1 induction can be uncoupled, we did similar experiments in this acute SCW arthritis model. Overexpression of T-cell IL-17 in this macrophage-mediated model results in an elevation of joint inflammation and cartilage proteoglycan depletion in comparison with the control vector group. Furthermore, this T-cell cytokine turns this acute model into a more chronic one. Although knocking out TNF- $\alpha$ did have some effect on inflammation and cartilage damage, the dependency of TNF in IL-17 induced pathology was not as strong as under naive conditions. Conclusion: These data show a direct relation of IL-17 and TNF- $\alpha$ induction under naive conditions in vivo. However, the presence of IL-1 during arthritis conditions and the collaboration of IL-17 with IL-1 modulates the TNF- $\alpha$ dependency during arthritis.

\section{7}

\section{Differential effects of leflunomide and methotrexate on cytokine production in RA \\ MC Kraan', TJM Smeets', MJ van Loon', FC Breedveld², BAC Dijkmans ${ }^{3}$, PP Tak ${ }^{1}$}

${ }^{1}$ Division of Clinical Immunology and Rheumatology, Academic Medical Center/University of Amsterdam, Amsterdam, The Netherlands 2Department of Rheumatology, Leiden University Medical Center, Leiden, The Netherlands

${ }^{3}$ Department of Rheumatology, Free University, Amsterdam, The Netherlands

Arthritis Res Ther 2003, 5 (suppl 1):47

Background: T cells are considered to be pivotal cells in the pathogenesis of rheumatoid arthritis (RA) and therefore represent a potential target for treatment. The novel disease-modifying antirheumatic drug (DMARD) leflunomide inhibits pyrimidine biosynthesis. T cells are especially susceptible to inhibition of this enzyme due to increased demand for pyrimidines after activation, together with the absence of a salvage pathway.

Objective: We investigated the effects of leflunomide on cytokine profiles in vivo and in vitro to provide more insight into the mechanism of action of leflunomide in RA.

Methods: Serum samples from 100 RA patients, treated with either leflunomide $(n=50)$ or methotrexate $(n=50)$, were collected at baseline, after 12 weeks and after 1 year of treatment. In these samples, serum levels of interleukin-6 (IL-6) and interferon gamma (IFN- $\gamma$ ) were determined by ELISA. The effects of the active metabolite of leflunomide (A77-1726; 0-200 $\mu \mathrm{M}$ ) on IL-6 and IFN- $\gamma$ production by peripheral blood mononuclear cells (PBMCs) from healthy volunteers $(n=6)$ and RA patients $(n=3)$ were studied by ELISA after activation (with phytohemagglutinin, lipopolysaccharide, and $\alpha C D 3 / \alpha C D 28$ ) by ELISA. In addition, monocytes and lymphocytes were isolated from two healthy volunteers by density-gradient centrifugation methods, and effects of A77-1726 on IL-6 production after activation (with phytohemagglutinin or lipopolysaccharide) were measured by ELISA and PCR. Effects on cell proliferation ( ${ }^{3} \mathrm{H}$-thymidine incorporation), were measured as well. Results: Serum levels of IFN- $\gamma$ were significantly reduced after leflunomide treatment (baseline $43 \mathrm{pg} / \mathrm{ml} \pm 10$ [mean \pm SEM]; 1 year $29 \pm 7$ $[P=0.015])$, whereas we did not observe a change in IL- 6 concentrations in serum (baseline 158 $\pm 41,4$ months $151 \pm 48$ ). In contrast, both IFN- $\gamma$ and IL- 6 serum levels were significantly reduced after methotrexate treatment. Consistent with these data, in vitro experiments revealed a dose-dependent inhibition of IFN- $\gamma$ production by activated PBMCs in both healthy volunteers and RA patients in the presence of A77-1726, without a clear-cut effect on IL-6 production. IL- 6 production by monocytes was not inhibited (measured by ELISA and PCR). Production of IFN- $\gamma$ by lymphocytes was inhibited by A77-1726.

Conclusion: The results presented here show inhibition of IFN- $\gamma$ production by leflunomide without a clear-cut effect on IL-6 production. This differential effect supports the hypothesis that leflunomide preferentially affects activated T cells. The effects on T cells could be explained by both $\mathrm{DHODH}$ inhibition and effects on signal transduction pathways. 
48

\section{Alveolar macrophages in scleroderma lung disease are activated by TGF- $\beta$ and IL-4 but not TNF- $\alpha$ I Luzina, S Atamas, B White}

University of Maryland, Baltimore, MD, USA

Arthritis Res Ther 2003, 5 (suppl 1):48

Background: We reported previously that alveolar macrophages from scleroderma patients with lung inflammation are characterized by an activated gene expression profile.

Objective: The purpose of this study was to identify the molecular mediators that have activated alveolar macrophages in scleroderma lung disease, through an analysis of transcription factor activation.

Methods: Freshly isolated alveolar macrophages were negatively selected by depleting $\mathrm{CD}^{+}$cells from BAL cells of six patients with lung inflammation. Nuclear translocation of 55 transcription factors was evaluated using a protein/DNA array system (Panomics). Data were analyzed using hierarchical clustering.

Results and conclusion: Three distinct clusters of translocated transcription factors were notable. One cluster included Smad3/4 as well as other factors involved in or activated by TGF- $\beta$ signaling, including CREB/p300, Fast-1, the glucocorticoid receptor element, and GAS/ISRE. A second cluster included Stat5/6 and other factors activated by IL-4 signaling, including GATA, Sp1, and early-response element. The third cluster included factors that were translocated to the nucleus in low levels in only a few samples. This cluster included NF- $\mathrm{KB}$, which is critical in signaling by TNF- $\alpha$ and IL-1, and several other transcription factors activated by TNF- $\alpha$ signaling. In animal models, macrophages that are activated by TGF- $\beta$ or IL- 4 have been associated with the subsequent development of fibrosis. Thus, we directly demonstrate cellular activation by the profibrotic factors TGF- $\beta$ and IL-4 in involved tissues from scleroderma patients.

\section{9}

\section{Circulating bioactive TNF in rheumatoid arthritis patients treated with infliximab: link to clinical response \\ H Marotte, P Miossec}

Clinical Immunology Unit, Departments of Immunology and Rheumatology, Hôpital Edouard Hérriot, Lyon, France

Arthritis Res Ther 2003, 5 (suppl 1):49

Background: Infliximab is an anti-tumor-necrosis-factor (anti-TNF) antibody used for the treatment of rheumatoid arthritis.

Objective: To clarify heterogeneity in patient response, a bioassay was established to measure functional circulating tumor necrosis factor (TNF). Results: Culture of TNF activated synoviocytes with plasma samples before and after infliximab treatment showed an increased production of IL- 6 that was strongly reduced by treatment. This pattern was associated with a good clinical response, and bioactive TNF levels detected with this bioassay were correlated with TNF levels measured by ELISA. This was not observed in patients with a poor response. The functional circulating bioactive TNF was significantly $(P<0.001)$ more elevated in subset with a good biological response than bad responders. No correlation was observed with levels of soluble receptors.

Conclusion: This result suggests the importance of systemic bioactive TNF in such response.

\section{0}

\section{Shared epitope and rheumatoid arthritis severity: association with infliximab treatment in a postmarketing study}

\section{H Marotte, P Gaudin, C Alexandre, P Miossec}

Clinical Immunology Unit, Departments of Immunology and

Rheumatology, Hôpital Edouard Hérriot, Lyon, France

Arthritis Res Ther 2003, 5 (suppl 1):50

Background: Modalities of infliximab treatment for active rheumatoid arthritis (RA) have been established following randomised clinical trials.
Objective: In a postmarketing study, we compared the clinical presentation of RA patients from the same geographic area treated by infliximab or not. We checked for markers linked with selection for infliximab treatment focusing on the shared epitope (SE).

Methods: RA patients (897) from the Rhone-Alpes area, France, were enrolled. Clinical indices of disease activity and joint destruction, including age, sex, disease duration, Ritchie articular index, and right Larsen wrist index, were collected. Biological data included erythrocyte sedimentation rate, rheumatoid factor (RF), and SE status. SE determination was performed by enzyme-linked oligosorbent assay.

Results and conclusion: All patients had the typical clinical and biological features of RA. The patients were predominantly white women and $64.6 \%$ were RF-positive. The distribution of the SE was $44.74 \%$ for 0 copy, $43.33 \%$ for 1 copy, and $11.93 \%$ for 2 copies. The risk of developing joint destruction was associated with the presence of the SE, with a dose effect. SE heterozygote patients were almost twice as likely to develop erosions as SE-negative patients $(\mathrm{OR}=2.18 ; 95 \% \mathrm{Cl}$ 1.48-3.22, $P<0.001)$. Patients with two copies of the SE were more likely to develop erosions ( $\mathrm{OR}=4.73, \mathrm{Cl} 2.67-8.36, P<0.001)$. When patients treated with infliximab were isolated, RA severity parameters, such as the Ritchie and Larsen indices, RF, and the presence of the SE, were associated with infliximab treatment. The frequency of the SE in RA patients treated with infliximab was approximately twice as high for SE heterozygote carriers $(\mathrm{OR}=2.18 ; 95 \% \mathrm{Cl} 1.43-3.31, P<0.001)$, and 4 times as high for SE homozygotes $(\mathrm{OR}=3.88 ; 95 \% \mathrm{Cl} 2.25-6.68$, $P<0.001$ ). Thus RA patients with the SE were more often selected for infliximab treatment extending the link between $\mathrm{SE}$ and severity.

\section{1}

\section{High-molecular-weight PEG precipitates from synovial fluid induce more TNF- $\alpha$ than those from serum of RA patients, which is in contrast to patients with other inflammatory arthritides}

L Mathsson', N Mohammad Noor' ${ }^{1}$, G EIGhazali', O Sjöberg', L Bengtsson', K Nilsson Ekdahl', B Nilsson'1, J Rönnelid ${ }^{1,2}$

1 Unit of Clinical Immunology, Uppsala University, Stockholm, Sweden 2Unit of Rheumatology, Karolinska Institute, Stockholm, Sweden Arthritis Res Ther 2003, 5 (suppl 1):51

Background: We have earlier shown that polyethylene glycol (PEG) precipitates from sera of active SLE patients can induce monokine production, possibly through immune complexes.

Objective: We have now investigated monokine production induced by PEG precipitates from arthritis patients.

Methods: Paired synovial fluid (SF) and serum samples from 26 RA patients and 20 patients with other inflammatory arthritides were subjected to combined PEG precipitation and purification. The IgG content was determined by ELISA. Precipitates were added to peripheral blood mononuclear cell (PBMC) cultures, and supernatant levels of TNF- $\alpha$ and IL- 10 determined by ELISA after 20 hours.

Results: In both the investigated PBMC donors, the highest median values of TNF- $\alpha$ were found in SF-PEG cultures. In one of the PBMC donors, this difference was significant in paired analysis for all patients and for the RA group only, but not for non-RA patients only. The correlation between the TNF- $\alpha$ and IL-10 production was higher for RA than for non-RA patients, and higher for SF than for serum precipitates. No correlation was noted between the IgG content of the precipitates and cytokine levels.

Conclusion: In this preliminary study, PEG precipitates from RA SF induced higher production of TNF- $\alpha$ than did corresponding serum precipitates, possibly through stimulation by immune complexes in SF. Since no correlation was observed between the $\lg G$ content and cytokine induction, it is likely that immune-complex composition rather than the $\lg \mathrm{G}$ content of the precipitates determines the cytokine response. 
52

\section{A novel therapeutic approach to cytokine modulation in articular inflammation using filarial nematode derived ES-62

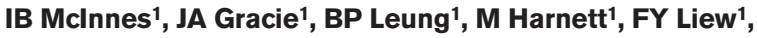 W Harnett ${ }^{2}$ \\ ${ }^{1}$ Centre for Rheumatic Diseases and Department of Immunology, University of Glasgow, Glasgow, Scotland, UK \\ ${ }^{2}$ Department of Immunology, University of Strathclyde, Glasgow, Scotland, UK \\ Arthritis Res Ther 2003, 5 (suppl 1):52}

Background: Discovering safe, novel immunomodulators that are effective in RA is currently a major therapeutic objective. Long-term immune system deviation is most striking in the host-parasite relationship, in which microbes may coexist with a human host.

Objective: We have investigated our previously discovered filarial derived ES-62 for therapeutic potential in RA.

Methods: ES-62 was administered during collagen-induced arthritis (CIA) either at immunization (prophylactic) or 24 hours after the onset of clinically evident disease (therapeutic). Cytokine and antibody responses were measured in ex vivo cultures. RA synovial cultures were also made. Results: ES-62 exhibited powerful immunomodulation of CIA, preventing initiation of inflammatory arthritis. Crucially, ES-62 suppressed even established disease. These effects were due to inhibition of cytokine release, specifically TNF- $\alpha$, and reversal of collagen specific Th1 responses associated with reduced expression of IFN- $\gamma$. The physiologic relevance of these observations was confirmed, as ES-62 down-regulated the release of proinflammatory cytokines (TNF- $\alpha$ and IL-6) from patient-derived samples. Conclusion: The host-parasite relationship has long promised therapeutic potential. Our data clearly show that ES-62, a filarial-derived moiety, can profoundly alter cytokine expression in vitro and in vivo in inflammatory arthritis. This in turn suggests an intriguing role for ES-62 in treating chronic inflammatory diseases. Finally, our data have implications for the mechanisms that might underpin previously reported epidemiologic interactions between chronic infection and autoimmunity.

\section{3}

\section{Crosstalk between synovial fibroblasts and T lymphocytes in rheumatoid arthritis: effect of methotrexate}

\section{E Miranda, A Balsa, M Benito, C de Cózar, D Pascual-Salcedo,} E Martín-Mola

Hospital La Paz, Madrid, Spain

Arthritis Res Ther 2003, 5 (suppl 1):53

Objective: Our objective was to characterize the molecules responsible for crosstalk between synovial fibroblasts (SFibs) and Tlymphocytes (TLs) in RA and test the effect of methotrexate (MTX).

Methods: SFibs were obtained from RA patients. TLs were isolated from peripheral blood of healthy controls and RA patients, and from RA synovial fluid by Ficoll-Hypaque gradient and magnetic depletion of non-T cells; purity was $99 \%$. Cocultures were established in six-well plates; adhesion molecules and surface and intracellular cytokines were determined by flow cytometry.

Results: Synovial fluid TLs (SFTLs) from RA patients $(n=10)$ and peripheral blood TLs (PBTLs) from untreated recent-onset RA $(n=10)$ induced an up-regulation of intercellular adhesion molecule (ICAM)-1, intracellular IL-8, IL-15 and surface IL-15 in SFibs. SFTLs and PBTLs showed an upregulation of IFN- $\gamma, \mathrm{IL}-17, \mathrm{CD} 25$ and CD69 when cocultured with SFibs. Freshly isolated PBTLs from healthy controls $(n=10)$ did not induce SFib cytokine production. Pretreatment of SFs with MTX $(0.1-1 \mu \mathrm{M})$ prevented the TL-stimulated increase of IL-8 and IL-15. Pretreatment of TLs with MTX $(0.1-1 \mu \mathrm{M})$ prevented the SFib-induced up-regulation of IFN- $\gamma$, IL-17, CD25 and CD69. Blocking MoAbs to IL-15, but not an isotypecontrol antibody, prevented the increased TL secretion of IFN- $\gamma$ and IL-17
TL-induced up-regulation of IL-8 and IL-15 in SFibs. Cocultures of TLs and SFibs using $0.4 \mu \mathrm{M}$ plate inserts did not induce a significant up-regulation of adhesion molecules or cytokines. Paraformaldehide-fixed TLs did up-regulate IL-8 and IL-15 in SFibs. This suggests that direct cell contact is an important contributor to the observed effects.

Conclusion: SFib production of IL-8 and IL-15 may contribute to the influx and proliferation of TL in the RA joint. In turn, TL cytokines IFN- $\gamma$ and IL- 17 stimulate the production of IL- 8 and IL-15 by Sfibs, thereby creating a feedback loop that leads to persistent synovial inflammation. MTX seems to disrupt this loop, acting at both the SFib and TL level.

\section{4}

Plasma-cell like morphotype with loss of CD3 expression by Th1 cytokine producing cells

\section{G Page', A Sattler'2, A Thiel'2, A Radbruch², P Miossec'}

${ }^{1}$ INSERM U403 and Departments of Immunology and Rheumatology, Hôpital Edouard Hérriot, Lyon, France

${ }^{2}$ Department for Humoral Immunology, German Arthritis Research Centre, Berlin, Germany

Arthritis Res Ther 2003, 5 (suppl 1):54

Background and objective: Activated T helper CD4+ T cells, by their production and secretion of cytokines, seem to have functional similarities with plasmocytes secreting immunoglobulins. The morphotype and phenotype of IL-17- and IFN- $\gamma$-producing cells in both in vitro and in vivo situations remain to be clarified. Oligoclonal activation of normal peripheral blood mononuclear cells with the superantigen SEB and polyclonal activation with PMA/PHA for 4,24 , and 48 hours were used as in vitro models. This study was extended to various in vivo situations such as RA, dermatomyositis (DM), and normal activated lymph nodes. Methods: We looked at the phenotype of IL-17 and IFN- $\gamma$-producing cells by immunohistochemistry, using the CD3 and CD4 T-cell markers, the CD20 B-cell marker, the CD38, and the kappa and lambda light-chain immunoglobulins plasmocytes markers. We also focused on the expression of two chemokine receptors, CCR6 and CCR7, involved with their associated ligands CCL20 and CC19/CCL21 in the migration of T lymphocytes. Results and conclusions: IL-17 and IFN- $\gamma$-producing cells acquire a plasma-cell-like morphotype associated with the reduced expression of CD3 and the persistence of CD4 after both polyclonal and oligoclonal activation. In RA, DM, and activated lymph nodes, IL-17- and IFN- $\gamma$-producing cells presented the same morphotype. In RA synovium, these plasmacytoid-like Th1-producing cells still express the CD4 marker but not the CD3 and are CD20-, CD38-, kappa- and lambda-. In both in vitro and in vivo conditions, some of the Th1-producing cells can produce the CCR6 and CCR7 chemokine receptors, a finding which supports the argument that CCL20/CCR6 and CCL19,21/CCR7 play a role in the homing of $\mathrm{T}$ cells.

\section{5}

\section{Effects of leflunomide on interleukin-1 receptor antagonist (IL-1Ra) synthesis in chondrocytes and synovial fibroblasts}

\section{G Palmer, D Burger, F Mezin, C Gabay, J-M Dayer, P-A Guerne}

Divisions of Rheumatology and Immunology, University Hospital, Geneva, Switzerland

Arthritis Res Ther 2003, 5 (suppl 1):55

Objectives: We analyzed the effects of the active metabolite of leflunomide, A77-1726, on IL-1Ra production by chondrocytes and synovial fibroblasts, with regards to the relevance of its use in RA and other cartilage damaging diseases.

Methods and results: Cartilage was obtained from joints replaced for osteoarthritis or broken femoral neck. Synovial membranes were obtained from joints replaced for osteoarthritis. Cells were isolated by collagenase digestion; chondrocytes were used either directly (primary cells) or between passages 1 and 5 (dedifferentiated cells). IL-1Ra concentrations in cell conditioned media (CM) or cell lysates were assessed using a sandwich ELISA. In chondrocytes and synoviocytes, A77-1726 
dose-dependently enhanced the stimulatory effects of IL-1 $\beta$ or TNF on IL1 Ra production (average 2 fold increase in primary chondrocytes, 10 fold increase in synoviocytes). A maximal response was observed at $100 \mu \mathrm{M}$. In synoviocytes, A77-1726 increased the production of soluble (s; as measured in CM) and intracellular (ic; as measured in cell lysates) IL$1 \mathrm{Ra}$; in contrast, no significant amounts of iclL-1Ra were recovered from primary chondrocytes. We next investigated putative pathways involved, first focusing on known effects of A77-1726 on uridine and prostaglandin $\mathrm{E}_{2}\left(\mathrm{PGE}_{2}\right)$ synthesis. The addition of exogenous uridine did not modify the effects of A77-1726. The addition of $\mathrm{PGE}_{2}$ partially reversed the effects of A77-1726 in chondrocytes and synoviocytes. Indomethacin also increased IL-1Ra production, although less potently than A77-1726, and its effects were completely annulled by low doses of $\mathrm{PGE}_{2}$. A77-1726 at $100 \mu \mathrm{M}$ inhibited by $95-98 \%$ the production of $\mathrm{PGE}_{2}$ induced by IL-1 $\beta$ and TNF- $\alpha$; this was not significantly different from the inhibition achieved by optimal doses of indomethacin.

Conclusion: A77-1726 may thus possess chondroprotective effects by increasing IL-1Ra release by chondrocytes and synoviocytes. The effects of A77-1726 seem to arise partially through inhibition of $\mathrm{PGE}_{2}$ synthesis, but other mechanisms likely concur to its stimulatory effect on IL-1Ra production.

\section{6}

\section{The Th2 cytokine IL-10 inhibits hyaluronan mRNA accumulation in fibroblast-like synoviocytes \\ C Pollaschek, KM Stuhlmeier}

Ludwig Boltzmann Institute for Rheumatology, Vienna, Austria Arthritis Res Ther 2003, 5 (suppl 1):56

Background: IL-10 has been shown to be beneficial in a series of ailments, inflammatory arthritis among them.

Objective: In an attempt to study possible mechanisms we investigated the effect of IL-10 on mRNA accumulation of genes encoding hyaluronan. Hyaluronan and/or its degradation products have been implicated in the many detrimental effects associated with disease progression. Here we report that IL-10 suppresses noninduced as well as induced mRNA accumulation of certain genes encoding hyaluronan.

Methods: Human fibroblast-like synovial cells (FS) were studied for their potential to synthesize hyaluronan synthase (HAS) mRNA. Expression levels of mRNA for HAS1, HAS2 and HAS3 were monitored by RT-PCR. IL-10 was added to FS cultures for 6 hours.

HAS3 is constitutively expressed in FS. We found that treating FS with IL-10 inhibited HAS3 mRNA accumulation in a dose-dependent manner. Similar to HAS3, HAS2 mRNA was readily detectable in unstimulated FS. Our experiments show that in contrast to HAS3, IL-10 has no significant effect on HAS2 mRNA. Furthermore, in contrast to HAS3 and HAS2 mRNA levels in untreated FS, HAS1 mRNA is below or close to the detection limit in unstimulated FS but can be readily induced by stimulating these cells with TGF- $\beta$ ( $1 \mathrm{ng} / \mathrm{ml}$ for 6 hours). We tested the potential of IL-10 to inhibit TGF- $\beta$-induced HAS1 mRNA synthase and found that IL-10 also inhibited TGF- $\beta$ induced HAS1 mRNA, albeit to a lesser degree.

Conclusion: IL-10 can be a potent inhibitor of induced as well as noninduced HAS activation. While $10 \mathrm{ng} / \mathrm{ml}$ of IL-10 can reduce HAS3 levels in FS by more than $90 \%$, the effect of IL-10 on TGF- $\beta$ induced HAS1 levels is less pronounced. Taken together, it is tempting to speculate that the observed beneficial effects of IL-10 in rheumatoid arthritis are at least in part due to its inhibitory effect on HAS mRNA activation.

\section{7}

\section{Adjustment in anti-TNF therapy after initial response: long-term follow-up in patients with rheumatoid arthritis P Sidiropoulos' ${ }^{1}$, G Kakavouli', DT Boumpas' ${ }^{2}$, K Voudouris'}

${ }^{1}$ First General Hospital of Thessaloniki, Thessaloniki, Greece

2 University of Crete, Heraklion, Greece

Arthritis Res Ther 2003, 5 (suppl 1):57

Background and objectives: Although treatment with anti-TNF therapy is effective in controlling disease activity in patients with refrac- tory rheumatoid arthritis (RA), approximately 30\% of patients do not respond. Moreover, in certain patients, adjustments in therapy are needed after an initial response. We sought to better delineate this in a cohort of RA patients receiving anti-TNF therapy.

Patients and methods: Sixty-four patients ( 50 females and 14 males, mean age 52.6 years and mean disease duration 10.3 years), with active rheumatoid arthritis despite treatment with disease-modifying antirheumatic drugs (DMARDs) received infliximab. In these patients, treatment with a mean of 2.9 DMARDs had previously failed. Treatment with methotrexate was continued in 48 patients (mean dose $10.1 \mathrm{mg} / \mathrm{wk}$ ) and with various DMARDs in 6 . Concomitant prednisolone (mean dose $8.5 \mathrm{mg} / \mathrm{d}$ ) was used in $43(67.2 \%)$. The DAS index (44 joints) was applied to assess clinical efficacy. The dose of infliximab was $3 \mathrm{mg} / \mathrm{kg}$ per infusion administered every 8 weeks after the third dose on week 6 .

Results: In this cohort, 19 (29.7\%) patients discontinued therapy ( $42 \%$ for lack of insurance coverage, $26 \%$ because of inefficacy, $21 \%$ because of infections and $11 \%$ because of allergic reactions). No patient discontinued therapy for any reason after the 30th week. All clinical parameters were significantly improved $(P<0.01)$ after the fourth infusion. Forty-five patients completed 6 infliximab infusions (mean 30 weeks) and 29 of them 12 infusions (mean 75 weeks of treatment). In the last group, clinical response was sustained throughout the 75 weeks of treatment and the dose of prednisolone was significantly decreased $(P<0.0001)$ while $24 \%$ (6 of 25$)$ of patients discontinued steroids. To achieve clinical response, the frequency of infliximab infusions was increased to every 6 weeks in $31 \%$ of patients, while methotrexate was significantly increased in $38 \%$ of patients (21 patients, mean dose from 10.1 to $12.3 \mathrm{mg} / \mathrm{wk}, P<0.04$ ).

Conclusion: The clinical response of RA patients treated with infliximab is sustained during 75 weeks of treatment. However, in approximately one-third of patients, the frequency of infliximab infusions has to increase after initial response in order to sustain it.

\section{8}

\section{Infliximab treatment reduces synovial cellularity as early as $\mathbf{4 8}$ hours after initiation of treatment, but not by induction of apoptosis TJM Smeets, MC Kraan, PP Tak}

Division of Clinical Immunology and Rheumatology, Academic Medical Center/University of Amsterdam, Amsterdam, The Netherlands Arthritis Res Ther 2003, 5 (suppl 1):58

Background: The mechanism of action of TNF- $\alpha$-targeted therapies, which may have a beneficial effect soon after initiation of treatment in rheumatoid arthritis (RA) patients, is as yet not completely understood. Previous work has shown that TNF- $\alpha$ blockade results in decreased cellularity in the synovium, which can be explained in part by reduced cell migration. In the present study we investigated whether treatment with the chimeric anti-TNF- $\alpha$ antibody infliximab could also reduce cellularity by induction of apoptosis in the RA synovium.

Methods: Twenty-four RA patients with active disease (DAS 4.8 or higher), who had failed at least 2 DMARDs, were randomized to receive either infliximab $(3 \mathrm{mg} / \mathrm{kg})(n=12)$ or placebo $(n=12)$ intravenously. All 24 patients were subjected to an arthroscopic synovial biopsy directly before initiation of treatment. In all 24 patients, a second arthroscopic synovial biopsy of the same index joint was performed 48 hours after the first procedure. After the second arthroscopy, the patients who had initially received placebo were also treated with infliximab $(3 \mathrm{mg} / \mathrm{kg})$ in an extension study. A third arthroscopy was performed in all 24 patients on day 28. Immunohistologic analysis was performed using monoclonal antibodies (mAbs) against CD3 (T cells), CD22 (B cells), CD38 (plasma cells), CD68 (macrophages), CD55 (fibroblast-like synoviocytes [FLS]), and granzyme B. In situ detection of apoptosis was performed by TUNEL (transferase-mediated UTP end labeling) assay. Sections were analysed by computer-assisted image analysis. For statistical analysis, the Wilcoxon signed-rank test and the Mann-Whitney $U$ test were used. 
Results: As early as 48 hours after initiation of infliximab treatment, there was a significant reduction in the number of intimal macrophages ( -49 cells $/ \mathrm{mm}^{2} \pm 67$ [median \pm SEM]; $P=0.009$ ), which was not observed in the placebo group $(+10 \pm 54)$. The number of $T$ cells tended to be decreased in patients treated with infliximab $(-52 \pm 32)$ but not in the placebo group $(+10 \pm 25)$; this difference did not reach statistical significance. The numbers of $B$ cells, plasma cells, and granzyme $\mathrm{B}^{+}$cells were unchanged 48 hours after treatment with either infliximab or placebo.

Of interest, the TUNEL assay did not reveal any increase in the number of apoptotic cells after infliximab treatment $(-0.7 \pm 13.6$ in the infliximab group; $+6.9 \pm 10.8$ in the placebo group; both not significant). Similarly, the extension study in 24 patients revealed that there was no increase in apoptosis in the synovium on day 28.

Conclusion: Infliximab therapy may reduce the number of inflammatory cells in rheumatoid synovial tissue as early as $\mathbf{4 8}$ hours after initiation of treatment, but apparently not by induction of apoptosis. Presumably, decreased cell infiltration primarily results from early inhibition of cell migration.

\section{9}

\section{Secreted IL-1Ra exerts a protective effect on atherosclerotic lesion development in apolipoprotein-E-deficient mice \\ F Soussi ${ }^{1}$,, BR Kwak ${ }^{2}$, G Pelli' ${ }^{2}$, F Mach ${ }^{2}$, C Gabay ${ }^{1,2}$}

${ }^{1}$ Division of Rheumatology, University Hospital and Department of Pathology, School of Medicine, University of Geneva, Geneva, Switzerland

2Division of Cardiology, University Hospital, Geneva, Switzerland Arthritis Res Ther 2003, 5 (suppl 1):59

Background: A large body of evidence implicates interleukin (IL)-1, a proinflammatory cytokine, in the pathogenesis of a variety of human inflammatory disorders such as rheumatoid arthritis (RA). RA patients experience a markedly increased frequency of cardiovascular disease. $\mathrm{IL}-1$ is expressed within the endothelium of atherosclerotic plaques and may participate in inflammatory mechanisms of atherogenesis. IL-1 receptor antagonist (IL-1Ra) is a natural IL-1 inhibitor. The term 'IL-1 Ra' refers to four different isoforms, one of which is secreted (sIL-1Ra) and the other three of which are intracellular (iclL-1Ra1, 2, 3). slL-1Ra competitively inhibits receptor binding of IL-1. In patients with RA, the administration of recombinant human slL-1Ra ameliorates the clinical parameters of disease activity and decreases the progression of joint damage.

Objective: The purpose of this study was to determine whether slL-1Ra influences the formation of atherosclerotic plaques in vivo.

Methods: Transgenic mice expressing high amounts of human slL-1Ra were crossed with apolipoprotein-E-deficient mice $\left(\mathrm{ApoE}^{-l-}\right)$, which develop atherosclerotic lesions when fed a high-cholesterol diet, in order to obtain $\mathrm{ApoE}^{-/-}$IL-1Ra-wild-type and $\mathrm{ApoE}^{-/-} \mathrm{IL}-1 \mathrm{Ra}$-transgenic mice of identical genetic background. Twelve-week-old males of both groups ( $n=6$ per group) were fed a cholesterol-rich diet (1.25\%) for 10 weeks. Increase in serum lipid profiles (total cholesterol, triglycerides) did not differ between both groups. Development of atherosclerotic lesions was measured as the extent of sudanophilic lesions, by computer image analysis.

Results: The average lesion area within aortic roots was significantly decreased $(47 \%, P<0.001)$ in transgenic mice $\left(0.49 \pm 0.06 \mathrm{~mm}^{2}\right)$ as compared with controls $\left(0.93 \pm 0.05 \mathrm{~mm}^{2}\right)$. The extent of sudanophilic lesions was also reduced within the thoracoabdominal aorta in transgenic mice $(-36 \%)$. Preliminary analysis of the cellular composition of atherosclerotic plaques showed a decrease in the percentage of macrophage-positive areas (-49\%) in IL-1Ra transgenic mice as compared with control mice.

Conclusion: Our results show that sIL-1Ra exerts a protective effect on the progression of atherosclerosis in mice. These findings suggest that the administration of IL-1Ra may also exert beneficial effects on cardiovascular complications in patients with RA.
60

\section{Anti CD4 antibodies directly suppress TNF- $\alpha$ production in human Th1 T-cell clones but not IL-4 production in Th2 clones}

\section{S Tschiedel, Y Schwitalle, F Emmrich}

Institute for Clinical Immunology and Transfusion Medicine, University of Leipzig, Germany

Arthritis Res Ther 2003, 5 (suppl 1):60

Background: Anti-CD4 antibodies have been described for treatment of certain autoimmune diseases. In vitro experiments have shown that anti-CD4 antibodies are able to inhibit immune responses mediated by Thelper cells.

Objective: However, it became unclear whether or not these experiments performed in bulk cultures represent merely regulatory effects or cell biological differences between functionally different populations of Thelper cells.

Methods: Therefore, we established human Th1 T-cell and Th2 T-cell clones, which were treated with anti-human CD4 antibodies. The T-cell clones were stimulated via the T-cell receptor and the CD28 molecule, and cytokine production was determined for TNF- $\alpha$, IFN- $\gamma$ and IL-4.

Results: TNF- $\alpha$ and Interferon- $\gamma$ are produced exclusively by Th1-T cells and inhibition of cytokine production by anti-CD4 was nearly total for TNF- $\alpha$ production but much less pronounced for IFN- $\gamma$. No effect of antiCD4 on IL-4 production in human Th2 T-cell clones was observed.

Conclusion: Our data may help us to understand the mechanisms of anti-CD4-mediated modulation of immune responses.

\section{1}

\section{A GATA-3 binding site in the first intron of the interleukin-4 gene defines a critical element for the memory expression of interleukin-4 in Th lymphocytes \\ L Tykocinski, P Hajkova, T Stamm, O Sözeri, M Löhning, B Friedrich, J Hu-Li, C Pannetier, WE Paul, G Grütz, J Walter, A Radbruch}

Deutsches Rheumaforschungszentrum, Berlin, Germany Arthritis Res Ther 2003, 5 (suppl 1):61

T lymphocytes can become imprinted for the expression of particular cytokines. This functional memory may be an essential and basic component in the control of rheumatic inflammation. We have shown before that epigenetic modification of cytokine genes is involved in the establishment of a cytokine memory for IL-4.

Here we report identification of a region of the first intron of the interleukin-4 (IL-4) gene that is methylated in naive Th cells and in Th1 cells, but demethylated in IL-4 expressing Th2 cells. This intron sequence (CIS) is conserved in the IL-4 genes of all species analysed so far. The CIS contains two GATA-binding sites. Both binding sites, their orientation and distance are required for specific binding of GATA-3 from Th2 cells. Th cells in which part of the IL-4 gene, including the CIS, is replaced by a gfp-gene, are impaired in their memory for IL-4.

The CIS thus provides a GATA-3 specific nucleus of epigenetic modification of the IL-4 gene, imprinting it for memory expression upon restimulation of the $\mathrm{T}$ cell by antigen alone.

\section{2}

\section{A polymorphism in the IL-10 promoter affects autoantibody production and subsequent joint destruction in rheumatoid arthritis}

FA van Gaalen, L Lard, J Schonkeren, E Pieterman, G Stoeken, $\mathbf{K}$ Vos, $\mathbf{R}$ Nelissen, $\mathbf{R}$ Westendorp, $\mathbf{R}$ Hoeben, FC Breedveld, R Toes, TWJ Huizinga

Department of Rheumatology, Leiden University Medical Center, Leiden, The Netherlands

Arthritis Res Ther 2003, 5 (suppl 1):62

Background: Rheumatoid arthritis (RA) is a multifactorial, polygenic disease, in which the relevant pathways involved in its various stages 
are poorly understood. Interleukin-10 (IL-10) is known for its wide range of both anti-inflammatory and inflammatory effects on various cell types involved in RA.

Objective: To gain a better understanding of the role of IL-10 in RA, we analyzed in a prospective cohort of RA patients $(n=283)$ the -2849 A/G IL-10 promoter polymorphism, as this polymorphism is highly associated with high (AG/GG variants) or low (AA variant) IL-10 production. Results: In our cohort, the IL-10 genotype was, in comparison with controls, not a risk factor for RA. But,RA patients with the -2849 genotypes associated with high IL-10 production, had, at baseline, significantly higher titers of $\lg G$ autoantibody (anti-CCP and $\lg$ G rheumatoid factor), but not of IgM autoantibody (IgM rheumatoid factor). Moreover, a higher rate of joint destruction was observed in RA with genotypes associated with high IL-10 production. However, invasiveness of fibroblast-like synoviocytes, which are thought to be important effectors of joint destruction, was not correlated with IL-10 genotypes.

Conclusion: The $-2849 \mathrm{IL}-10$ promoter polymorphims associated with high IL-10 production were found in RA patients with high IgG autoantibody titers and an increased rate of joint destruction. As IL-10 is crucially involved in class-switching and function of B-cells, we propose that genetically determined differences in IL-10 production mediate their effect on joint destruction via increased autoantibody production by B cells.

\section{3}

\section{Association of single nucleotide polymorphisms within cytokine genes to juvenile idiopathic arthritis in Czech children}

J Vavrinec ${ }^{1}$, O Cinek1, P Vavrincova ${ }^{1}$, T Slavcev², H Malcova1, S Radova ${ }^{1}$

${ }_{12 n d}$ Department of Pediatrics, Prague, Czech Republic

2Institute of Clinical and Experimental Medicine, Prague, Czech Republic Arthritis Res Ther 2003, 5 (suppl 1):63

Objective: We tested the association of certain cytokine gene polymorphisms with juvenile idiopathic arthritis (JIA) in Czech Caucasians. Methods: In a case-control study, genotypes of 130 patients with JIA (63 males, 67 females; age at onset $7.6 \pm 4.4$ years; 43 oligoarticular, 72 polyarticular, 15 systemic form) were compared with those of 102 healthy unrelated blood donors. Using polymerase chain reaction with sequence-specific primers designed by J Mytilineos, 24 singlenucleotide polymorphisms were tested within 13 different genes for cytokines (IL-1 $\alpha$, IL-1 $\beta$, IL-2, IL-4, IL-6, IL-10, IL-12, TNF- $\alpha$, TGF-1 $\beta$, INF- $\gamma$ ) and related molecules (IL-1R, IL-1RA, IL-4R $\alpha$ ). Risk was expressed using OR calculated from allelic, genotypic, and phenotypic frequencies, and the $P$ values were corrected for 13 tested molecules. Results: Two polymorphisms were significantly associated with JIA. The IL4 -1098 G phenotype was present in $10 \%$ of cases and $25 \%$ of controls $(\mathrm{OR}=0.32, \mathrm{Cl} 95 \% 0.16-0.67, P$ corrected=0.039). The IL-1 $\beta+3962 \mathrm{C}$ phenotype was present in $96 \%$ of cases and $84 \%$ of controls $(\mathrm{OR}=4.65, \mathrm{Cl} 95 \%$ 1.64-13.2, P corrected=0.05). There was also a tendency towards a lower prevalence of the TNF- $\alpha-238$ A phenotype in cases (5\%) than in controls (16\%), but it became insignificant after correction for the number of tested molecules.

Conclusions: Our associations with IL-1 $\beta$ or with IL-4 have not been yet reported from other populations.

Acknowledgement: Supported by grant MSMT CR 111300003 and MZ CR 00006042.

\section{4}

\section{Molecular cross-talk between the TRAIL and TGF- $\beta$ pathways in human lung fibroblasts \\ VV Yurovsky}

University of Maryland School of Medicine, Baltimore, MD, USA Arthritis Res Ther 2003, 5 (suppl 1):64

Tumor-necrosis-factor-related apoptosis-inducing ligand (TRAIL) has been closely associated with regulation of the immune response and pathogenesis of autoimmune diseases. The expression of TRAIL was found in CD8 T cells that had undergone oligoclonal expansion in the lungs of patients with systemic sclerosis and were able to stimulate collagen production in lung fibroblasts. Soluble, multimerized TRAIL and normal human lung fibroblasts were used as a model of selective TRAIL influence on fibroblasts. TRAIL was found to increase both $\alpha 2$ (I) collagen mRNA expression and total soluble collagen secretion, with peak response at $1 \mathrm{ng} / \mathrm{ml}$ TRAIL. DNA microarray analysis suggested that fibroblast response to TRAIL might be mediated by c-Jun $\mathrm{N}$-terminal kinase (JNK). The increase in JNK1 expression and phosphorylation as well as phosphorylation of its specific substrate were confirmed by Western blotting. The treatment of fibroblasts with TRAIL also enhanced the expression of a number of genes involved in tissue remodeling, including those related to the transforming growth factor (TGF) beta pathway. The increase in TGF- $\beta 1$ mRNA level was confirmed by Northern blotting and by measurements of active TGF- $\beta 1$ in culture supernatants. In addition, antibody-mediated blocking of TGF- $\beta$ was shown to abrogate TRAIL-induced collagen synthesis. These data suggest that TRAIL can enhance extracellular matrix production in fibroblasts by triggering expression of TGF- $\beta$, which acts in an autocrine manner. If this process continues uncontrolled, it may contribute to the development of fibrosis, particularly in the lungs of patients with systemic sclerosis.

65

Isolated and combined inhibition of TNF-, IL-1 and RANKL-pathways in TNF-induced arthritis: effects on synovial inflammation, bone erosion and cartilage destruction

\section{J Zwerina', S Hayer', K Redlich', U Feige ${ }^{2}$, C Dunstan'2, H Bergmeister ${ }^{3}$, G Kollias ${ }^{4}$, G Steiner', J Smolen ${ }^{1}$, G Schett ${ }^{1}$}

${ }^{1}$ Division of Rheumatology, Department of Internal Medicine III, University of Vienna, Vienna, Austria

2Department of Pathology, Amgen, Inc., Thousand Oaks, CA, USA ${ }^{3}$ Center for Biomedical Research, University of Vienna, Vienna, Austria ${ }^{4}$ Institute of Immunology, Alexander Fleming Biomedical Sciences Research Center, Vari, Greece Arthritis Res Ther 2003, 5 (suppl 1):65

To investigate the efficacy of isolated and combined blockade of TNF-, IL-1- and RANKL-pathways on synovial inflammation, bone erosion and cartilage destruction in a TNF-driven arthritis model, human TNF transgenic (hTNFtg) mice were treated with anti-TNF (infliximab), IL-1 receptor antagonist (IL-1Ra) or osteoprotegerin (OPG). In addition, each of three possible double combination therapies and a triple combination therapy was applied. Therapy was followed by histological assessment of synovial inflammation, bone erosion and cartilage damage.

Synovial inflammation was inhibited by anti-TNF $(-51 \%)$, but not IL-1Ra or OPG monotherapy. Combinations of anti-TNF with IL-1Ra (-91\%) or OPG $(-81 \%)$ were additive and almost completely blocked inflammation. Bone erosion was effectively blocked by anti-TNF $(-79 \%)$ and also by OPG $(-60 \%)$, but not by IL-1Ra monotherapy. Combination of anti-TNF and IL-1Ra, however, completely blocked bone erosion $(-98 \%)$. The effects on inhibition of bone erosion were accompanied by reduction of osteoclast numbers within synovial tissue. Cartilage destruction was inhibited by anti-TNF $(-43 \%)$, weakly, but not significantly by IL-1Ra, and not at all by OPG monotherapy. Combination of anti-TNF with IL-1Ra was the most effective double combination therapy in preventing cartilage destruction $(-80 \%)$. In all analyses, a triple combination of anti-TNF, IL-1Ra and OPG was not superior to double combination therapy with anti-TNF and IL-1Ra. Articular changes caused by chronic TNF overexpression are not completely blockable by monotherapies, which target TNF, IL-1 or RANKL. However, combined approaches that reduce TNF load and block IL-1 or RANKL as downstream mediators of TNF can lead to a complete remission. Differences in their efficacy to block synovial inflammation, bone erosion and cartilage destruction further strengthen the rationale for combined blockade of more than one proinflammatory pathway. 


\section{MHC and autoimmune disease}

\section{6}

\section{Interaction between hsp73 and rheumatoid-arthritis- associated HLA-DR alleles}

\section{Auger, J Roudier}

INSERM E9940-Faculté de Médecine, Marseille, France Arthritis Res Ther 2003, 5 (suppl 1):66

Background: The OKRAA amino acid motif of HLA-DRB1*0401 helps the development of rheumatoid arthritis by an unknown mechanism. In human B cells, we have observed that the QKRAA motif carries original properties. The constitutive 70-kDa heat-shock protein hsp73 binds HLA-DRB $1{ }^{*} 0401$ and targets it directly from endoplasmic reticulum to lysosomes, bypassing the normal route through golgi and endosomes. Objective: To evaluate how well different HLA-DRB1 alleles bound hsp73, we developed quantitative assays.

Results: By precipitation assay using total and lysosomal protein extracts, we found that alleles associated with rheumatoid arthritis bound hsp73 better than alleles not associated with rheumatoid arthritis. HLA-DRB $1{ }^{*} 0401$ is the best hsp73 binder. By a direct binding assay with purified protein, we confirmed that HLA-DRB $1{ }^{*} 0401$ that carries the QKRAA motif is the best hsp73 binder.

Conclusion: These properties may help particular antigen processing and presentation by HLA-DRB $1{ }^{*} 0401$, potentially leading to autoimmunity.

\section{7}

The presentation of the immunodominant epitope of HC gp-39 in the context of the RA-associated HLA class II molecules is specific for RA synovium D Baeten', P Steenbakkers², A Boots², EM Veys', F De Keyser'

${ }^{1}$ Rheumatology, Ghent University Hospital, Ghent, Belgium

${ }^{2}$ Pharmacology, NV Organon, Oss, The Netherlands

Arthritis Res Ther 2003, 5 (suppl 1):67

Objective: Peptide 263-275 is the immunodominant epitope of $\mathrm{HC}$ gp-39, a candidate autoantigen in rheumatoid arthritis (RA). The present aim is to analyse HLA-DR SE/HC gp-39263-275 complexes in synovium of RA patients versus inflammatory controls.

Methods: Synovial biopies were obtained from swollen knee joints in 65 RA patients and 67 controls ( 30 with spondylarthropathy, 16 with psoriatic arthritis, 10 with crystal-induced arthritis, 7 with osteoarthritis, and 4 with PMR), and from knee joints without synovitis in 9 RA patients. Synovial sections were stained with $\mathrm{mAb} 12 \mathrm{~A}$, which recognizes specifically HLA-DR SE/HC gp-39263-275 complexes.

Results: mAb 12A revealed mononuclear cells located near lympoid aggregates and positive for CD1a, a marker of dendritic cells. Positive cells were found in 40 of $65(61.5 \%)$ inflamed RA synovia but only in 2 of 30 with spondylarthropathy and 0 of 37 other controls $(3.0 \%)(P<0.001)$. In RA, there were no differences between the $12 \mathrm{~A}^{+}$and $12 \mathrm{~A}^{-}$patients for disease duration, rheumatoid factor, $\mathrm{SE}, \mathrm{C}$-reactive protein, erythrocyte sedimentation rate, nonsteroidal anti-inflammatory drugs, disease-modifying antirheumatic drugs, and corticosteroid. Histological analysis of $12 \mathrm{~A}^{+}$ versus $12 A^{-}$RA synovia indicated a higher score for global inflammation $(P=0.025), \mathrm{CD} 3(P=0.013), \mathrm{CD} 1 \mathrm{a}(P=0.032)$ and a trend for $\mathrm{CD} 20$ $(P=0.066)$. Accordingly, no $12 \mathrm{~A}^{+}$cells were detected in the nine RA knee joints without effusion $\left(6\right.$ were $\left.\mathrm{SE}^{+}\right)$. $\mathrm{HC}$ gp-39 expression was higher in $12 \mathrm{~A}^{+}$versus $12 \mathrm{~A}^{-}$samples $(P=0.001)$. Finally, intracellular citrullinated peptides, which are another specific histological marker for RA synovium, were found in only half of the $12 \mathrm{~A}^{+}$samples but also in some $12 \mathrm{~A}^{-}$ samples, indicating that the two markers are independent.

Conclusion: HLA-DR SE/HC gp-39263-275 complexes are frequently detected in inflamed RA synovia but not in inflamed control samples and in noninflamed RA samples. This suggests that dendritic cells actively present the immunodominant epitope of $\mathrm{HCgp}-39$ at the primary site of inflammation in RA. Moreover, the specificity of the staining offers a new and independent tool for the histopathological diagnosis of rheumatoid arthritis.
68

Localisation of MHC Class II/HC gp-39 complexes in synovia of rheumatoid arthritis patients using complex-specific monoclonal antibodies

D Baeten ${ }^{1}$, PGA Steenbakkers ${ }^{2}$, E Rovers ${ }^{2}$, EM Veys ${ }^{1}$, AMW Rijnders' ${ }^{2}$, J Meijerink², F De Keyser', A Boots ${ }^{2}$

${ }^{1}$ Rheumatology, Ghent University Hospital, Ghent, Belgium 2Pharmacology, NV Organon, Oss, The Netherlands Arthritis Res Ther 2003, 5 (suppl 1):68

Objective: Recently HC gp-39 was identified as a candidate autoantigen in RA. The aim of this study is to generate and validate monoclonal antibodies (mAbs) to HLA DR $\alpha \beta{ }^{*} 0401 / \mathrm{HC}$ gp-39263-275 complexes to further investigate the relevance of this antigen in RA.

Methods: Spleen cells from mice immunised with HLA $\mathrm{DR} \alpha \beta 1^{*} 0401 / \mathrm{HC}$ gp-39263-275 complexes were selected and submitted to a B-cell culture and minielectrofusion procedures. The resulting set of mAbs were characterised for their specificity by ELISA and FACS. Functionally, they were tested for inhibition of HC gp-39263-275. specific $D R \alpha \beta 1^{*} 0401$-restricted T-cell hybridomas. Finally, one of the mAbs was used for staining of specific complexes in RA synovium.

Results: We have generated a set of five mAbs to a combination epitope of the specific MHC/peptide complexes. FACS studies revealed that these mAbs recognize specific complexes on homozygous $D R \alpha \beta 1{ }^{*} 0401$ positive BLCL pulsed with $\mathrm{HC}$ gp-39263-275. The best mAb, 12A, was further characterized using a set of irrelevant $D R \alpha \beta 1{ }^{*} 0401$-binding peptides, and truncated/elongated versions of $\mathrm{HC} \mathrm{gp}-39263-275$ itself. The minimal epitope recognized in combination with $\mathrm{DR} \alpha \beta 1^{*} 0401$ was HC gp-39263-273. Peptides not encompassing HC gp-39263-273 were not recognized. Three out of five mAbs were able to inhibit (up to 90\%) the response of $\mathrm{HC}$ gp-39263-275-specific DR $\alpha \beta 1^{*} 0401$-restricted T-cell hybridomas to peptide-pulsed antigen-presenting cells or purified complexes. Moreover, mAb 12A localised and identified dendritic cells that present $\mathrm{DR} \alpha \beta 1^{*} 0401 / \mathrm{HC}$ gp-39263-275 complexes in synovial tissue of $\mathrm{DR} \alpha \beta 1^{*} 0401$-positive RA patients.

Conclusions: These data indicate local presentation of the $\mathrm{HC}$ gp-39263-275 epitope in the inflamed target tissue by professional antigen-presenting cells and support a role of $\mathrm{HC} \mathrm{gp-39}$ in the local autoimmune response that leads to chronic inflammation and joint destruction.

\section{9}

Impaired T-cell stimulation by antigen-presenting cells results from defective accessory cell function in HLA-B27 transgenic rat

G Falgarone, C Hacquard-Bouder, A Bosquet, D Monnet, M Breban

Rhumatologie, Hôpital Avicenne, Bobigny, France

Arthritis Res Ther 2003, 5 (suppl 1):69

HLA-B27/hb2-microglobulin transgenic rats spontaneously develop a multisystem inflammatory disease resembling the human spondyloarthropathies. This disease in rats is dependent on the presence of a bacterial flora and mediated by T cells, but antigen-presenting cells (APCs) may also play a critical role. Splenic dendritic cells (DCs) have been reported to be defective in allogeneic $\mathrm{mIR}$ in this model.

Here, we investigated the functional defect of APCs. We observed a defective stimulation of allogeneic and syngeneic CD4 $4^{+}$, and $\mathrm{CD} 8^{+} \mathrm{LN}$ T lymphocytes, by DC and B cells, from disease-prone 33-3 HLA-B27 transgenic, but not from healthy homozygous 120-4 HLA-B7 transgenic rats, even if stimulation was driven in the presence of Con $A$ or anti-TCR mAbs. Pretreatment of HLA-B27 DCs with lipopolysaccharide or IFN- $\gamma$ did not enhance their stimulatory capacity. In competitive culture, and transwell assay, we found no evidence for an inhibitory factor or a lack of diffusible factor produced by HLA-B27 DCs. When comparing class II MHC, CD2, B7, ICAM1, and LFA-1 molecules at the surface of DC from 33-3, 120-4, and nontransgenic rats, we found no difference. However, the proportion of conjugates formed between 
33-3 DC and allogeneic or syngeneic T cells was decreased, which could account for a defective stimulation of those T cells. We have confirmed a defective stimulation of T cells by APCs in disease-prone 33-3 rats, the mechanism of which appears to implicate APC/T-cell contact, independently of TCR engagement. It must involve accessory cell function, and could explain a loss of tolerance towards microbial flora in this model of spondyloarthropathy.

\section{0}

\section{HLA DRB1*01 and macrophagic myofasciitis}

S Guis', JF Pellissier'2, F Nicoli ${ }^{3}$, D Reviron ${ }^{4}$, JP Mattei', RK Gherardi ${ }^{5}$, J Pelletier ${ }^{2}$, G Kaplanski', D Figarella-Branger ${ }^{2}$, J Roudier ${ }^{1}$

${ }^{1}$ Service de Rhumatologie, Hôpital de La Conception, Marseille, France

${ }^{2}$ Service d'Anatomie-Pathologie et de Neuropathologie, Hôpital de la Timone, Marseille, France

${ }^{3}$ Service de Neurologie, Hôpital Sainte Marguerite, Marseille, France

${ }^{4}$ Laboratoire d'Immunogénétique, Etablissement Français du Sang

'Alpes-Méditerranée', Marseille, France

${ }^{5}$ Service de Médecine Interne, Hôpital Henri Mondor, Créteil, France Arthritis Res Ther 2003, 5 (suppl 1):70

Background: Macrophagic myofasciitis (MMF) is characterised by specific myopathological alterations with inflammatory infiltrates of the monocyte/macrophage lineage containing aluminic inclusions.

Objective: The aim of this study was to analyse the HLA-DRB1 polymorphism in determining genetic susceptibility to MMF.

Methods: HLA-DRB1 alleles were defined by polymerase chain reaction SSOP/SSP genotyping in 10 European Mediterranean MMF patients and 230 unrelated healthy controls.

Results: An increased frequency of HLA-DRB1 ${ }^{*} 01$ was observed in MMF patients (66\%) in comparison with controls (17\%) (OR 9.8, Cl 2.0-62.2) $\left(P<0.002, P_{\mathrm{c}}<0.03\right)$. There was no significant difference in the distribution of the remaining HLA-DRB1 alleles frequencies between MMF and controls.

Conclusion: In Southern France, HLA-DRB1*01 is significantly associated with MMF.

\section{1}

\section{Influence of HLA-DRB1 P4 binding pocket electric charge on rheumatoid arthritis (RA) susceptibility}

L Michou ${ }^{1,2}$, S Tezenas du Montcel ${ }^{3}$, E Petit-Texeira2 ${ }^{2}$, C Pierlot ${ }^{2}$, I Lemaire ${ }^{4}$, J Osorio' ${ }^{2}$, W Frigui ${ }^{2}$, S Lasbleiz', P Quillet', T Bardin 1 , F Clerget $^{3}$, B Prum ${ }^{5}$, F Cornélis ${ }^{1},{ }^{2}$ for ECRAF

1 Unité de Génétique Clinique, Hôpital Lariboisière, Paris, France ${ }^{2}$ GenHotel/Laboratoire de Recherche Européen pour la Polyarthrite Rhumatoïde, ECRAF-Universités d'Evry et de Paris VII, Evry-Genopole, France

3INSERM U535, Le Kremlin Bicêtre, France

${ }^{4}$ Laboratoire de Biologie, Centre Hospitalier Sud Francilien, Corbeil Essonne, France

${ }^{5}$ Laboratoire Statistique et Génome, Genopole, Evry, France

Arthritis Res Ther 2003, 5 (suppl 1):71

Background: HLA-DRB1 alleles coding for the shared epitope (SE), an amino acid motif in the third hypervariable region of the beta 1 chain of HLA-DR, are associated with RA. The underlying biological mechanism is unknown. A model was recently proposed (Reviron et al. Arthritis Rheum 2001; 44:535-540), based on the electric charge (EC) of the fourth antigenic peptide-binding pocket (P4) of the HLA-DR molecule. SE alleles carrying a strong positive EC at P4, the model postulates that the negative EC of the P4 has a protective effect for RA that modulates the effect of the SE.

Objective: To test that model, taking advantage of familial-based association analysis.

Methods: The DNA of 100 Caucasian French families with one RA patient and both parents were genotyped for HLA-DRB1. Genotypes were stratified in susceptible $(\mathrm{S})$, neutral $(\mathrm{N})$ and protective $(\mathrm{P})$ groups: $\mathrm{S}$ for the genotype SE/SE and the genotype SE/EC+ (non SE allele with a positive $\mathrm{EC}$ ); $\mathrm{N}$ for the genotype $\mathrm{SE} / \mathrm{EC}^{-}$(non SE allele with a negative $\mathrm{EC}$ ) and the genotype $\mathrm{EC}^{+} / \mathrm{EC}^{+} ; \mathrm{P}$ for the genotype $\mathrm{EC}^{-} / \mathrm{EC}^{-}$ and the genotype $\mathrm{EC}^{-} / \mathrm{EC}^{+}$.

The analysis was performed with a genotype relative-risk method comparing the RA patient genotypes with the virtual control genotypes reconstructed from parental untransmitted alleles. The expectations from the model were: S genotype more frequent in RA, N genotype with similar frequency in RA and controls and P genotype more frequent in controls.

Results: The S genotype was more frequent in RA (55\% versus $29 \%$, $\left.P=1.9 \times 10^{-4}\right)$, the $\mathrm{N}$ genotype had similar frequencies (33\% in RA versus $29 \%$ in controls, not significant) and the $P$ genotype was more frequent in controls $\left(42 \%\right.$ versus $\left.12 \%, P=1.8 \times 10^{-6}\right)$.

Conclusion: Our results are in keeping with a protective effect of the negative EC of the P4 HLA-DR pocket modulating the SE effect on RA susceptibility.

\section{2}

\section{CD25+ regulatory cells from HLA-DQ8 transgenic mice are capable of modulating collagen-induced arthritis}

\section{ME Morgan, R Sutmuller, HJ Witteveen, RRP de Vries, REM Toes}

Leiden University Medical Center, Leiden, The Netherlands Arthritis Res Ther 2003, 5 (suppl 1):72

Background: In mice, CD25+ CD4+ T regulatory cells have been implicated in the control of immune responses and may have the potential to be used in therapies for autoimmune diseases, such as rheumatoid arthritis.

Objective: In order to evaluate their involvement in chronic arthritis, we depleted $\mathrm{CD}_{2} 5^{+}$cells in DBA/1 mice, which are susceptible to collagen-induced arthritis (CIA).

Results: Significant increases in severity and collagen-specific antibodies were seen in mice that were depleted before immunization with collagen. In vitro tests with splenocytes from depleted mice also showed increased proliferation of collagen-specific T cells, indicating that $\mathrm{CD}_{25} 5^{+}$regulatory cells are involved in CIA. In humans, the HLA-DQ8 molecule is strongly associated with rheumatoid arthritis. Since CD25 ${ }^{+} \mathrm{CD}_{4}{ }^{+}$Tregulatory cells are probably selected in the thymus, specific MHC class II molecules could hinder their development, which could explain the association between HLA and disease susceptibility. In order to explore this possibility, we performed similar experiments in HLA-DQ8 transgenic mice. We found that depletion of $\mathrm{CD} 25^{+}$cells had the same effect on CIA as seen in the DBA/1 mice. Furthermore, DQ8-restricted CD25+ CD4 ${ }^{+} \mathrm{T}$ cells were found to be as capable of suppressing the proliferation of PHA stimulated splenocytes as $\mathrm{CD} 25^{+} \mathrm{CD} 4^{+} \mathrm{T}$ regulatory cells isolated from DBA/1 mice.

Conclusion: These findings indicate that $\mathrm{CD} 25^{+}$regulatory cells can modulate arthritis and that HLA-DQ8 does not interfere in the generation of functional $\mathrm{CD} 25^{+} \mathrm{CD} 4^{+} \mathrm{T}$ regulatory cells.

\section{Gene and cell therapy}

73

Effect of synovial fluid on adeno-associated virus mediated gene transfer to chondrocytes

V Cottard ${ }^{1}$, G Falgarone ${ }^{1,2}$, D Lutomski ${ }^{1}$, MC Boissier $^{\mathbf{1}, 2}$, N Bessis ${ }^{1}$

${ }^{1}$ UPRES EA -3408 and Rheumatology Department, Université Paris

XIII, Paris, France

${ }^{2}$ Avicenne Hospital, Bobigny, France

Arthritis Res Ther 2003, 5 (suppl 1):73

Background: Direct intra-articular gene tranfer with adeno-associated virus (AAV) vectors is a promising strategy to allow efficient therapeutic transgene expression within the joint. However, over $90 \%$ of humans 
demonstrate antibodies against AAV which could alter AAV transduction efficiency in vivo.

Objective: Our objective was to determine the influence of synovial fluid (SF) and serum from arthritic patients on AAV-mediated gene transfer to chondrocytes in vitro.

Methods: SF and sera derived from 21 patients suffering from various (inflammatory or mechanical) origins were collected. Neutralizing activity against AAV/LL-4 was determined by assessing the ability of SF or serum to inhibit transduction of AAV/LL-4 into the C20A4 human chondrocyte cell line. Total IgGs were purified from SF by salt-dependent chromatography.

Results: In SF and sera, inhibition of AAV-mediated gene transfer to chondrocytes was observed in all arthritic patients. Purified IgG from SF exhibited inhibition patterns similar to those seen with unfractionated SF. A correlation was observed between levels of inhibition by the $\mathrm{SF}$ and the serum $(P<0.0001, r=0.813)$. Lastly, we have shown that the inhibition of AAV/IL-4 infection on C20A4 cells by SF and sera could be reversed by increasing the number of AAV/IL- 4 particles, with a dose-dependent effect.

Conclusion: SF and sera from all patients show a neutralizing activity against $A A V$ infection on chondrocytes. Neutralizing factors were lgG antibodies present in the SF. This inhibition can be reversed by increasing AAV doses. In the future, these data might be useful to adapt intraarticular AAV gene therapy to each individual patient.

\section{4}

\section{Tetracycline transcriptional silencer (tTS) tightly controls transgene expression in the skeletal muscle: in vivo intramuscular IL-10 DNA electrotransfer application to arthritis}

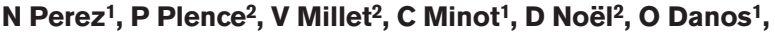 C Jorgensen ${ }^{2,3}$, F Apparailly ${ }^{2}$}

1 Genethon III CNRS URA 1923, Evry, France

2 INSERM U475, Immunopathologie des maladies tumorales et autoimmunes, Montpellier, France

${ }^{3}$ Service d'Immuno-rhumatologie, Centre Hospitalier Universitaire Lapeyronie, Montpellier, France

Arthritis Res Ther 2003, 5 (suppl 1):74

Background: The Dox-inducible reverse tetracycline transactivator (rtTA) is often used to control gene activity in cells and transgenic animals. However, the Tet-on system is limited by the high levels of transgene expression in the absence of doxycycline administration.

Objective and methods: To overcome this unregulated expression, we used the tetracycline-dependent transcriptional silencer (tTS) that binds the tet $\mathrm{O}$ inducible promoter in the absence of Dox. Controlled gene expression was analyzed in vivo by delivering combinations of the Dox-regulated luciferase reporter construct, the rtTA and the tTS expression plasmids into the tibialis anterior muscles of adult mice, using electrotransfer.

Results: Elevated luciferase expression levels were observed in the absence of doxycycline, and a 10-fold induction was obtained after drug administration. In contrast, when tTS was added, background expression was dramatically lowered, by three to four orders of magnitude, and induction was maintained. The tTS system was then used to control expression of a therapeutic gene in experimental arthritis. The tibialis anterior muscle of DBA1 mice was coinjected with plasmids encoding the anti-inflammatory cytokine viral interleukin-10 (vIL-10) under the control of the tetO promoter, the rtTA and tTS. Electroporation of injected muscles resulted in a dose-dependent increase in vlL-10 expression, maintained over a 3-month period. The Dox-regulated vIL-10 secretion showed significant inhibitory effects on collageninduced arthritis, as paw swelling was reduced and the onset of disease was delayed in the Dox-treated group in comparison with the control group without Dox.

Conclusion: The use of tTS significantly improves the utility of the rtTA system for somatic gene transfer by reducing background activity.
75

Immunotherapy through injection of immature dendritic cells prevents collagen-induced arthritis P Plence, R Pfannes, D Noël, F Apparailly, J Sany, C Jorgensen

Immuno Rheumatology, University Hospital Montpellier, France Arthritis Res Ther 2003, 5 (suppl 1):75

Background: Dendritic cells (DCa) play an important role for initiation and regulation of immune response in arthritis. Immature DCs with a low expression of MHC class II and of coactivation molecules CD86 have a tolerigenic potential in vivo. Previous studies have shown that genetically modified DCs and TNF- $\alpha$-matured DCs may prevent autoimmune diseases or allograft rejection.

Objective: Therefore, we explored the immunological effects of differentially matured DCs on the development of collagen-induced arthritis in mice.

Methods: Murine bone-marrow-derived DCs where cultured in the presence of granulocyte/macrophage-colony-stimulating factor and IL-4 and incubated with collagen type II (CII). Maturation of the DCs was blocked with IL-10, or induced with TNF- $\alpha$ or lipopolysaccharide (LPS). The DC differentiation and maturation steps were controlled by CD11c and CD86 expression, which was assessed by flow cytometry. Seven days before immunisation with bovine Cll, mice were injected intraperitoneally with 500,000 DCs obtained at different stages of maturation. Mice were boosted on day 21 after arthritis induction and the disease course was monitored until day 43. DC function was assessed through $\mathrm{mIR}$ assays.

Results: While injection with IL-10-blocked or LPS-matured DCs had no significant influence on the onset and development of arthritis, administration of TNF-matured DCs resulted in a reduction of arthritis severity in comparison with the control group. In contrast, mice treated with immature DCs showed a delayed arthritis onset and a decrease in the arthritis clinical score.

Conclusions: Collagen-induced arthritis may be prevented by pretreatment with antigen-specific immature DCs or TNF-matured DCs. Furthermore, the principle of DC-mediated tolerance may have promising immunotherapeutic potential in arthritis.

\section{6}

\section{Gene therapy of destructive arthritis in SCID mice} U Sack', A Hirth', A Moessner1, M Grapenthin', F Kahlenberg1, J Lehmann' ${ }^{2}$, U Anderegg ${ }^{3}$, K Ueberla ${ }^{4}$, F Emmrich ${ }^{1}$

${ }^{1}$ Institute of Clinical Immunology and Transfusion Medicine, University of Leipzig, Leipzig, Germany

2Institute of Veterinary Immunology, University of Leipzig, Leipzig, Germany

${ }^{3}$ Clinic of Dermatology, University of Leipzig, Leipzig, Germany ${ }^{4}$ Department of Molecular and Medical Virology, University of Bochum, Bochum, Germany

Arthritis Res Ther 2003, 5 (suppl 1):76

Background and objective: Synovial membrane fibroblasts in rheumatoid arthritis induce the destruction of cartilage and bone. We have isolated a fibroblast cell line which induces a rapid destruction of articular cartilage following intraarticular instillation in SCID mice and in vitro. Both approaches can be modulated by gene transfer.

Methods: As a cytokine with functions directed to inflammatory and immune cells as well as fibroblasts, interleukin-11 was selected to modulate invasive behaviour of fibroblasts. For transduction, a retroviral vector system, particle-mediated transfer (gene gun), and a lentiviral vector based on simian immunodeficiency virus were investigated. Cells $(500,000)$ were injected directly into the knee joinst of mice with severe combined immunodeficiency (SCID). Mice were monitored for joint swelling, serological parameters and by radiological methods. In vitro, cells were coincubated with cartilage for 1 week. Finally, the histology of cartilage destruction and signs of apoptosis were studied. Results: The efficacy of gene transfer was $<10 \%$ for retroviral transfer or gene gun but $>85 \%$ for lentiviral transfer. Therefore, animal testing 
and in vitro assays were performed with lentiviral-transfected cells in comparison with nontransfected invasive fibroblasts and control cells. Cartilage destruction within 10 days was induced by instillation of nontransfected cells. Morphology revealed invasion of fibroblast-like cells into the articular cartilage. Transfection with interleukin-11 did not act on swelling but slightly reduced cartilage invasion. In vitro, this effect was caused by reduction of apoptosis in chondrocytes.

Conclusion: Induction of cartilage destruction by intraarticular application of fibroblast like cells into SCID mice can be modulated by gene transfer. Lentiviral vectors systems offer a novel approach for highly efficient transduction of these cells. This model provides the opportunity to check novel therapeutic strategies for reduction of cartilage erosion.

\section{7}

\section{Treatment with OPG and cellular gene therapy with IL-4 decrease bone resorption-associated inflammation in collagen-induced arthritis}

\author{
N Saidenberg-Kermanac'h', N Bessis', M-C de Vernejoul'2, \\ MC Boissier ${ }^{1}$, M Cohen-Solal ${ }^{2}$ \\ ${ }^{1}$ Department of Rheumatology, Avicenne Hospital and University of \\ Paris 13, Bobigny, France \\ 2INSERM U348, Lariboisier Hospital, Paris, France \\ Arthritis Res Ther 2003, 5 (suppl 1):77
}

Background: Interleukin-4 (IL-4) has anti-inflammatory effects in collagen-induced arthritis (CIA). Osteoprotegerin (OPG) inhibits bone resorption by binding the receptor activator of nuclear factor $\mathrm{KB}$ ligand (RANKL) and thereby inhibits binding of RANKL to RANK (receptor activator of nuclear factor $\mathrm{KB}$ ) receptors of osteoclast precursors.

Objectives: To evaluate the action of OPG and IL-4 on the inflammatory process and the bone resorption associated with the inflammation. Methods: CIA was induced in DBA/1 mice by immunization with bovine type II collagen (CII). Mice were treated by subcutaneous injections of OPG-Fc or with IL-4 DBA/1-transfected fibroblasts or both OPG-Fc+IL-4. Control groups received DBA/Tst or I1gG or saline. In one group CIA was not induced. Urinary deoxypyridinolin levels and total-body bone mineral density (BMD, Piximus Lunar) were measured at baseline and at sacrifice, allowing the measure of bone gain (BMD). Spleen cells were cultured after stimulation with Cll, and cytokines were measured in the supernatants using ELISA techniques.

Results: CIA significantly improved in the IL-4 groups. OPG had no effect on arthritis clinical scores but histologic scores were reduced in OPG, IL-4 and OPG+IL-4 groups versus nontreated CIA mice. Treatment with OPG significantly increased BMD in the total body. Moreover, the combination of IL-4 and OPG exerted an additive effect of BMD. D-pyridinolin levels decreased by $45 \%$ in OPG-treated mice and by $68 \%$ when mice were treated with both OPG and IL-4. INF- $\gamma$ production was inhibited in IL-4 treated mice in comparison with controls. Interestingly, OPG also had a moderate effect on IFN- $\gamma$ but potentiated the inhibitory effect observed in IL-4-treated mice.

Conclusion: OPG and IL-4 prevent bone loss in CIA in the mouse model and could have additive effects.

\section{8}

\section{Gene transfer using artificial chromosomes containing a marker gene in primary cells and rat adjuvant arthritis}

\section{MJBM Vervoordeldonk', J Adriaansen', S Vanderbyl'2, PP Tak ${ }^{1}$}

${ }^{1}$ Division of Clinical Immunology and Rheumatology, Academic Medical Center, Amsterdam, The Netherlands

${ }^{2}$ Chromos Molecular Systems Inc., Burnaby, BC, Canada

Arthritis Res Ther 2003, 5 (suppl 1):78

Background and objective: Most antirheumatic therapies are given systemically, which may result in complications because of the high dosage needed to achieve therapeutic levels in the joints. Gene therapy might provide a more efficient system to deliver therapeutic compounds at the site of inflammation. The artificial chromosome expression system ( $A C$ es) is a unique, nonintegrating, nonviral gene-expression system, which functions like a natural chromosome. This technology offers advantages over current expression systems because it allows stable expression of genes producing single or multiple proteins over long periods. We are developing ex vivo gene therapy using artificial chromosomes containing reporter genes (LacZ or RFP) for local delivery of genes in rats with adjuvant arthritis. The aim of this study was to evaluate the transfection efficiency in cell lines or primary cells, including rat skin fibroblasts (RSFs) and fibroblast-like synoviocytes (FLSs). Furthermore, we investigated the feasibility of local delivery of a marker gene to the joints of rats with adjuvant arthritis (AA) by ex vivo gene therapy.

Methods: Transfer efficiency and optimal dose of transfection agent were determined using iododeoxyuridine (IdUrd)-incorporated ACes complexed to Superfect (Qiagen) (Cytometry Vol 44:100-105, 2001). Following transfection, $A C$ es were antibody-labeled and cells were analyzed by flow cytometry and fluorescent photomicroscopy. Using optimized transfection conditions and after growing the cells under selection, we expanded the colonies and determined reporter gene expression. Cell lines or primary cells transfected with Aces containing the LacZ gene or control cells were injected into the right ankle joints of rats with adjuvant arthritis on day 12 after adjuvant immunization. Joints were harvested 2 and 7 days later and assayed for beta-gal activity.

Results: The delivery of intact artificial chromosomes was detected within $24 \mathrm{~h}$ post transfection. Maximum delivery rates of $27 \%$ were observed. Flow cytometry data correlated well with microscopic analysis. After growing cell lines and primary cells under selection, clones expressing LacZ and RFP were identified. Ex vivo transfer of the LacZ gene to the ankle joints of rats with AA resulted in expression of the marker gene in the synovium. In the other organs, LacZ expression was not detected two days after injection of the cells.

Conclusion: The results demonstrate that IdUrd-labelled ACes can be detected $24 \mathrm{~h}$ after transfection. Both cell lines and primary cells can be efficiently transfected with $A C$ es and express the transgene. In addition, we show successful local ex vivo gene transfer in a rat AA model using $A C e s$ containing a marker gene. This work demonstrates the potential feasibility of treating arthritis and other connective tissue diseases utilizing $A C$ es as nonviral vectors for gene therapy.

\section{Genetics}

\section{9}

The mutation P392L of the sequestosome 1 gene in Paget's disease of bone is frequent in the French population

L Michou' ${ }^{1}$, JL Laplanche ${ }^{2}$, P Orcel ${ }^{3}$, P Hilliquin', N Philip 6 , J Roudier ${ }^{7}$, P Quillet ${ }^{5}$, T Bardin 1,3, JM Launay², F Cornélis'

${ }^{1}$ Unité de Génétique Clinique, Hôpital Lariboisière, Paris, France ${ }^{2}$ Service de Biochimie, Hôpital Lariboisière, Paris, France

${ }^{3}$ Fédération de Rhumatologie, Hôpital Lariboisière, Paris, France

${ }^{4}$ Service de Rhumatologie, Centre Hospitalier Sud Francilien, Corbeil

Essonne, France

${ }^{5}$ Laboratoire de Biologie, Centre Hospitalier Sud Francilien, Corbeil

Essonne, France

'Service de Génétique, Hôpital de la Timone, Marseille, France

7INSERM E 9940, Faculté de médecine, Marseille, France

Arthritis Res Ther 2003, 5 (suppl 1):79

Background: Paget's disease of bone (PDB) is a chronic disease of the skeleton that affects $3 \%$ of the Caucasian population aged over 40 years. PDB often segregates as an autosomal dominant trait. Genetic heterogeneity has been demonstrated, with at least 2 PDB loci, on chromosomes 18 (18q23) and 5 (5q35-qter). At the chromosome 5 locus, (Laurin et al. Am J Hum Genet 2002; 70:1582-1588) identified in the sequestosome 1 (SOSTM1) gene, involved in the RANK (recep- 
tor activator of NF-кB) pathway, a recurrent mutation (P392L) present in $16 \%$ of the sporadic PDB patients in the French Canadian population. Genetic testing is clinically relevant, as it could lead, in families carrying the mutation, to early diagnosis at the clinically asymptomatic stage, when early treatment could be attempted to prevent complications. However, it is not known whether this mutation is specific to the Canadian population or is frequent in other Caucasian populations.

Objective: To evaluate the frequency of the SOSTM1 P392L mutation in the French Caucasian population.

Methods: Nineteen French Caucasian patients with sporadic PDB underwent genetic testing. The search for the mutation relied on a PCR-RFLP assay.

Results: The P392L mutation of SOSTM1 was detected in 2 patients out of $19(11 \%)$

Conclusion: The P392L mutation of the SOSTM1 gene in PDB is frequent in the French Caucasian population. Investigation of other European populations would be of interest. Genetic testing of PDB patients in France is indicated, aiming at early diagnosis in relatives of patients carrying the mutation.

\section{0}

\section{A novel juvenile idiopathic arthritis (JIA) susceptibility gene in HLA class I region marked by microsatellite D6S265}

\section{A Smerdel, BA Lie, C Finholt, R Ploski, Ø Førre, DE Undlien, E Thorsby}

Institute of Immunology, Department of Rheumatology, Rikshospitalet University Hospital, Oslo, Norway

Arthritis Res Ther 2003, 5 (suppl 1):80

Objective: Juvenile idiopathic arthritis (JIA), a chronic inflammatory joint disease, is associated with particular alleles at three different HLA loci: HLA-A, DR-DQ, and DP. We have recently found that a gene in the vicinity of microsatellite (MS) marker D6S265 in the HLA class I region may contribute to a predisposition to JIA. To further evaluate the implicated region containing marker D6S265, we analyzed a denser set of polymorphic markers covering $\sim 1.8 \mathrm{Mb}$ of the HLA region around D6S265.

Methods: We investigated 102 patients with JIA classified according to the ACR criteria. As controls we selected 207 healthy, unrelated individuals. Only patients and controls carrying the DR8-DQ4 haplotype were included in this study. We used $13 \mathrm{MS}$ markers covering a region $\sim 1 \mathrm{Mb}$ and $\sim 0.8 \mathrm{Mb}$ centromeric and telomeric, respectively, to D6S265. An EM- algorithm was used to estimate haplotypes, and the distribution of MS alleles on the DR8-DQ4 haplotype was compared between patients and controls, in order to exclude associations secondary to linkage disequilibrium (LD) with this high-risk haplotype.

Results: The strongest association with JIA was observed for allele 5 at D6S265 (OR=3.1; $\left.P_{\mathrm{c}}<10^{-4}\right)(\sim 100 \mathrm{~kb}$ centromeric to HLA-A). LD and haplotype analyses showed that the D6S265 5 association was not secondary to an association to $\mathrm{HLA}-\mathrm{A}^{*} 0201$, previously reported to be associated with JIA. Positive associations with JIA showed also: allele 7 at D6S2704 $\left(P_{c}<0.05\right)(\sim 160 \mathrm{~kb}$ centromeric to D6S265) and allele 11 at D6S2707 $\left(P_{\mathrm{c}}<0.005\right)(\sim 300 \mathrm{~kb}$ telomeric to D6S265). This strongly suggests that our initially observed association to D6S265*5 is not a false positive result, but reflects the presence of a true disease-susceptibility gene in this region. Furthermore, the analysis of three-marker rolling haplotypes demonstrated a peak of association close to D6S265.

Conclusion: This hitherto unidentified gene in the HLA class I region, marked by D6S265*5 and distinct from HLA-A2, influences the risk for JIA conferred by the DR8-DQ4 haplotype. The gene in question remains to be identified.
81

\section{RA-specific expression profiles and new candidate genes}

U Ungethüm 1,4, T Häupl2, D Koczan³ ${ }^{3}$ H Huber2, T v Helversen2, P Ruiz ${ }^{4}$, H Witt ${ }^{4}$, M Drungowski ${ }^{4}$, HJ Zacher ${ }^{5}$, C Seyfert ${ }^{6}$, J Neidel ${ }^{7}$, V Krenn ${ }^{8}$, GR Burmester ${ }^{2}$, HJ Thiesen ${ }^{3}$, H Lehrach ${ }^{4}$, S Bläß ${ }^{2}$

${ }^{1}$ Core Facility GeneExpression, Charité University Clinic, Berlin, Germany ${ }^{2}$ Rheumatology and Clinical Immunology, Charité University Clinic, Berlin, Germany

${ }^{3}$ Proteome Center, Rostock, Germany

${ }_{4}^{4}$ Max-Planck Institute for Molecular Genetics, Berlin, Germany

${ }^{5}$ Helios Kliniken, Berlin, Germany

${ }^{6}$ Department of Orthopedics, KMG Kliniken, Kyritz, Germany

${ }^{7}$ Department of Orthopedics, Charité University Clinic, Berlin, Germany

8Institute of Pathology, Charité University Clinic, Berlin, Germany

Arthritis Res Ther 2003, 5 (suppl 1):81

Objective: To identify rheumatoid arthritis- (RA)-specific profiles of differentially expressed genes.

Methods: Synovial tissues from RA and osteoarthritis $(\mathrm{OA})$ patients and from normal joints were selected according to their disease-characteristic histology. Gene expression was analyzed using DNA microarrays (GeneChip; Unigene-array) and representational difference analysis (RDA). Data were validated on larger cohorts of patients by RT-PCR.

Results: Nine hundred and eighty genes were significantly regulated in RA synovial tissue as compared with non-RA. Specialized cluster analysis identified a set of $\mathbf{3 1 2}$ genes as sufficient of unequivocally discriminating RA from non-RA patterns (class discovery). Genes of highest regulation were associated with leukocyte activation (chemokines, chemokine receptors, B- and T-cell genes), endothelial and angiogenic activation, tissue destruction and remodelling [MMP-3, BMP-4, TIMPs]. Interestingly, a large set of genes was down-regulated in RA (TGF- $\beta$ superfamily, apoptosis-related genes, transcription factors). Osteopontin-like genes $(n=46)$ - up-regulated in RA - and glutathione peroxidase-3-like genes $(n=85)$ - down-regulated in RA - yielded the highest correlation coefficients $(>0.94)$. Megakaryocyte stimulating factor (MSF), down-regulated in a subset of RA, may hold the key to subclassification: a loss-of-function mutation in the MSF-encoding gene leads to synovial hyperplasia in camptodactyly-arthropathy-coxa vara-pericarditis syndrome, and, as in RA, also to pericardial involvement. A further candidate, vitamin-D3-up-regulated protein-1 (VDUP-1), is regulated like MSF and predisposes to premature coronary artery disease when mutated, again a feature of a subset of RA.

Conclusion: RA specific gene profiles were identified and are useful to improve diagnostics of the disease. Novel gene candidates not yet in the focus of RA pathogenesis have been identified that are likely to further the understanding of RA.

\section{2}

Association between ASCA-positivity and carrier of a CARD-15 mutation in patients with Crohn's disease

B van der Cruyssen ${ }^{1}$, F De Keyser ${ }^{1}$, H Peeters', M van den Berghe1, D Marichal', I Hoffman', T Van Oostveldt', D Laukens'2, E Remaut ${ }^{2}$, L Steidler'2, D Elewaut ${ }^{1}$, C Cuvelier $^{1}$, M de Vos', H Mielants', E Veys ${ }^{1}$

${ }^{1}$ Ghent University Hospital Belgium

${ }^{2}$ Department of Molecular Biomedical Research, Ghent, Belgium Arthritis Res Ther 2003, 5 (suppl 1):82

Objective: We investigated whether there is a link between two markers for Crohn's disease (CD): the CD susceptibility mutations in the CARD15 gene and the serologic anti-Saccharomyces cerevisiae (ASCA) antibodies. Both markers may, in some way, also be associated with spondyloarthropathy $(\mathrm{SpA})$, which is known to be related to inflammatory bowel disease.

Methods: Serum samples of $109 \mathrm{CD}$ patients were analysed for IgA and IgG ASCA with a commercial ELISA kit. A RFLP-PCR technique 
was used to genotype all patients for three single-nucleotide polymorphisms (SNPs) in the CARD15 gene: R702W, G908R and 1007fs. Every SNP was verified by direct sequencing.

Results: The overall carrier frequency of a CARD15 mutation in CD was $50.5 \%$. ASCA-positivity for $\lg A$, IgG and $\lg G$ or $\lg A$ was found in respectively $31.2 \%, 31.2 \%$ and $43.1 \%$.

Chi-square testing showed a positive association between CARD15 mutation and ASCA IgA $(P=0.001, \mathrm{OR}=4.167, \mathrm{Cl} 1.709-10.157)$, $\operatorname{lgG}(P=0.005, \mathrm{OR}=3.406, \mathrm{Cl} 1.428-8.124)$ and $\lg \mathrm{A}$ or $\operatorname{lgG}$ $(P=0.005, \mathrm{OR}=3.068, \mathrm{Cl} 1.391-6.764)$.

Conclusion: CARD15 mutations and ASCA are not independent risk factors for $C D$. Instead, they are significantly associated with each other in a population of CD patients (both for ASCA IgA and IgG isotype). This could be interpreted in a double way. CARD15 mutations and ASCA may be both associated with a particular, as-yet-undefined, phenotypic subset of CD. Or CARD15, as an immune-response gene, may in some way modulate humoral immunity, predisposing to the generating of ASCA.

\section{Infection}

\section{3}

\section{Epstein-Barr virus load is higher in rheumatoid arthritis patients than in normal controls}

N Pieri-Balandraud', J Baptiste Meynard', I Auger', H Sovran'1, B Mugnier', D Reviron', J Roudier', C Roudier'

1 INSERM EMI 9940, Hôpital de la Conception

2Etablissement Français du Sang, Marseille, France

Arthritis Res Ther 2003, 5 (suppl 1):83

Objective: For 20 years the Epstein-Barr virus (EBV) has been suspected to contribute to the pathogenesis of rheumatoid arthritis (RA). RA is strongly associated with shared epitope positive HLA-DR alleles. EBV load has been extensively studied in RA patients, using semiquantitative PCR. Inconsistent results reflect the lack of sensitivity and accuracy of this technique. We quantified EBV in peripheral blood mononuclear cells by real time PCR, to determine whether EBV load is higher in RA patients than in controls and to test whether HLA-DR alleles or treatment influences EBV load.

Methods: Eighty-four patients fulfilling the 1987 ACR criteria for RA and 22 patients with rheumatic conditions other than RA were studied. Sixty-nine healthy controls were chosen from bone marrow donors at the Marseille blood transfusion center. HLA-DR genotyping of patients and controls was performed by PCR-SSP. Real-time PCR was performed using a Roche LightCycler. A 214-bp fragment from the highly conserved long internal repeat IR1 was amplified. Two specific hybridization probes were used to recognize adjacent internal sequences within the target. EBV-positive Burkitt's lymphoma cell line was used as an external standard.

Results and conclusion: EBV load is expressed in EBV genome copy number per $500 \mathrm{ng}$ of human genomic DNA $(1.5 \times 105$ cells $)$. We found that patients with RA have a higher EBV load (median 8.84) than non-RA patients (median 1.56) and healthy controls (median 0.6). EBV load is not obviously influenced by disease-modifying antirheumatic drugs nor by HLA-DR and is stable over time.

\section{4}

\section{Fast and sensitive method for the detection of bacteria in synovial fluid by multiplex PCR R Stuhlmeier, H Broell, KM Stuhlmeier}

Ludwig Boltzmann Institute for Rheumatology, Vienna, Austria Arthritis Res Ther 2003, 5 (suppl 1):84

Background: Bacterial infections are common and are known to be involved in many diseases including arthritis. While some methods for detecting bacteria are time-consuming, others are faster but lack specificity and/or sensitivity.
Methods and results: We employed a new method for DNA isolation and compared the results with those of an established method. We show that an equivalent of fewer than 10 bacteria of Staphylococcus aureus (SA), methicillin-resistant Staphylococcus aureus, Staphylococcus epidermitis (SE) or bacteria in general can be detected in less than 2 hours.

We found that lyses in a SDS/ $\beta$-mercaptoethanol buffer and exposure to microwaves is as well suited for detecting fewer than 10 microorganisms per sample as a longer, more elaborate and more expensive method using specific enzymes. We further confirmed the sensitivity of our multiplex PCR method by recovery experiments using known amounts of bacteria. Such experiments showed that bacteria present in single-digit quantities can be detected even in viscous solutions such as synovial fluid. We further showed that the chosen primer pairs are suited for multiplex PCR, the simultaneous testing of samples for the presence of $\mathrm{SA}, \mathrm{SE}$, and/or bacteria in general. We also showed that the assay conditions are suitable for detecting the presence of methicillin-resistant forms of SA. The specificity of the PCR was confirmed by comparison of the actual size with the calculated length of the fragment, and by sequencing of the PCR product.

Conclusion: Taken together, our method of rapid DNA isolation and the optimized PCR program make it possible to confirm the presence or absence of minute amounts of bacteria. Employing real-time PCR would shorten this procedure even further. This method might therefore contribute to more timely and specific interventions.

\section{5}

Increased frequency of T cells specific for EBV gp110 in the synovial fluid of patients with rheumatoid arthritis

\section{E Toussirot 1,3, D Wendling', J Luka ${ }^{2}$, P Tiberghien ${ }^{3}$, J Roudier}

${ }^{1}$ Rheumatology, Hôpital Minjoz, Besançon, France

2Eastern Virginia Medical School, Norfolk, Virginia, USA

3/mmunogenetics, INSERM E0119 UPRES EA 2284, Besançon

France

4Immuno-rheumatology, INSERM EMI 9440, Marseille, France

Arthritis Res Ther 2003, 5 (suppl 1):85

Background: The shared epitope (SE) helps the development of rheumatoid arthritis (RA) by an unknown mechanism. The Epstein-Barr virus (EBV) glycoprotein gp110, a major target in the immune control of EBV replication, contains a copy of the SE. We previously showed that frequencies of T-cell precursors specific to EBV gp110 are influenced by HLA-DR polymorphism and that RA patients have low frequencies of T cells specific for EBV gp110.

Objective: To determine the frequency of $\mathrm{T}$ cells (limiting dilution analysis) specific for EBV gp110 and a control antigen (Escherichia coli protein extract) in the synovial fluid of patients with RA or various forms of arthritis. Methods: Nine RA patients (ACR 1987 criteria; mean age $61.1 \pm 7.3$ years) and 10 controls with inflammatory rheumatic diseases (mean age $42.5 \pm 17.4$ years) were studied. For RA patients, the frequency of both peripheral blood and synovial T cells specific for EBV gp110 was evaluated.

Results: In the synovial fluid, the frequency of T cells specific for EBV gp110 was significantly higher in RA than in non-RA patients (mean \pm SD $2.5 \pm 1.6 \times 10^{-6}$ vs $0.7 \pm 0.9 \times 10^{-6} ; P=0.02$ ) (no difference for the control antigen: $1.9 \pm 3.3 \times 10^{-6}$ vs $2.1 \pm 2.0 \times 10^{-6}$; $P=0.3$ ). In RA patients, the frequency of T cells proliferating to gp110 was higher in the synovial fluid than in peripheral blood, but without achieving statistical significance $\left(2.5 \pm 1.6 \times 10^{-6}\right.$ vs $2.0 \pm 1.8 \times 10^{-6}$; $P=0.7$ ) (no difference for the control antigen).

Conclusion: A high frequency of T cells specific for EBV gp110 can be detected in the synovial fluid of RA patients, providing further support for the argument that EBV is involved in RA pathogenesis. 


\section{Muscle disease}

\section{6}

\section{Covariation of MHC class I and CD163 positive macrophages in skeletal muscle tissue of polymyositis and dermatomyositis patients after treatment with high-dose intravenous immunoglobulin (IVIg)}

\section{S Barbasso, M Dastmalchi, H Alexandersson, IE Lundberg}

Rheumatology Unit, Department of Medicine, Karolinska Institutet, Stockholm, Sweden

Arthritis Res Ther 2003, 5 (suppl 1):86

Background: Polymyositis (PM) and dermatomyositis (DM) are characterised by symmetrical muscle weakness, inflammatory infiltrates in skeletal muscle tissue and skin rash (DM).

Objective: Our aim was to investigate the effects of high-dose intravenous immunoglobulin (IVlg) treatment of PM/DM patients on expression of various immunological markers in skeletal muscle tissue, e.g. major histocompatibility complex (MHC) class I and macrophages; on clinical signs; and on muscle status.

Methods: Six PM and four DM patients were treated intravenously with high-dose IVlg. Skeletal muscle biopsies were collected from these patients on three occasions: before treatment, and 24-48 hours and 3 months after treatment. Consecutive sections immunohistochemically stained for HLA-ABC and CD163 were analysed both manually by conventional microscope and by computerized image analysis. The percentage of positively stained areas and the number of cells per $\mathrm{mm}^{2}$ were assessed.

Results: The skeletal muscle tissue of IVlg-treated PM/DM patients revealed a heterogeneous change and covariation in expression of MHC class I and macrophages. Correlations with clinical parameters and muscle function will be determined.

Conclusions: IVIg treatment affects the expression of MHC class I and CD163 positive macrophages in skeletal muscle tissue of PM/DM patients in a heterogenous and covarying fashion.

\section{7}

HMGB1, a new proinflammatory molecule of interest in polymyositis and dermatomyositis patients

C Grundtman, A-K Ulfgren, K Borg, U Andersson, H ErlandssonHarris, IE Lundberg

Rheumatology Unit, Department of Medicine, Karolinska Institutet, Stockholm, Sweden

Arthritis Res Ther 2003, 5 (suppl 1):87

Background: Polymyositis (PM) and dermatomyositis (DM) are chronic inflammatory muscle disorders of unknown origin. The ubiquitously expressed nuclear protein high mobility group box chromosomal protein 1 (H MGB1) will, when released extracellularly, act as a potent proinflammatory molecule.

Objective: To investigate H MGB1 expression in muscle tissue from $\mathrm{PM}$ and DM patients with and without inflammatory infiltrates present in their muscle biopsy.

Methods: Muscle biopsy specimens from 10 patients (6PM, 4DM) with and 14 patients (8PM, 6DM) without inflammatory cell infiltrates and 8 healthy controls were investigated. HMGB1 expression was studied by immunohistochemical staining.

Results: Patients with inflammatory cell infiltrates show HMGB1 staining mainly with a cytoplasmic localization in vascular endothelial cells, infiltrating rounded mononuclear cells of macrophage-like morphology for all patients and in muscle fibres in 6 of 10 patients. In patients without inflammatory infiltrates, HMGB1 was detected in 3 of 14 patients, all with $\mathrm{DM}$, in endothelial cells with a cytoplasmic manner, there was no HMGB1 expression in the muscle fibres. No cytoplasmic or nuclear HMGB1 expression was found in the muscle tissue specimens from healthy controls.
Conclusion: HMGB1 was detected in muscle biopsies from PM and DM patients with inflammatory cell infiltrates. HMGB1 could play a role in maintaining the chronic inflammation. The major cell source of HMGB1 production in myositis seems to be the mononuclear inflammatory cells. HMGB1 could be a molecule of potential interest for new targeted therapy in myositis.

88

Rhabdomyolysis and myalgia associated with anticholesterolemic treatment as potential signs of susceptibility to malignant hyperthermia

S Guis', D Bendahan', JP Mattei', G Kozak-Ribbens', D Figarella-Branger ${ }^{2}$, S Trefouret ${ }^{3}$, V Bernard $^{4}$, A Lando4, J Cozzone ${ }^{1}$

${ }^{1}$ Centre de Résonance Magnétique Biologique et Médicale, UMR CNRS 6612, Faculté de Médecine, Marseille, France

${ }^{2}$ Service d'Anatomie-Pathologie et de Neuropatholgie, Hôpital de la Timone, Marseille, France

${ }^{3}$ Service de Neurologie, Hôpital de la Timone, Marseille, France ${ }^{4}$ Département d'Anesthésie-Réanimation, Hôpital Nord, Marseille,

France

Arthritis Res Ther 2003, 5 (suppl 1):88

Background: Antilipemic agents such as statins are extensively used for the acute and long-term treatment of cardiovasular disease. Adverse muscle effects commonly include myalgias and elevated serum creatine kinase whereas a few fatal cases associated with myoglobinuria and renal failure have been described recently.

Objective: The purpose of the present study was to investigate muscle contraction using in vitro contracture tests (IVCT) in patients with adverse effects from anticholesterolemic treatment.

Methods: Two patients with statin-therapy-induced mylagias and rhabdomyolysis were included in the study. They were investigated 6 months after discontinuation of statin treatment, when signs of rhabdomyolysis had disappeared. In vitro contracture tests in the presence of halothane or caffeine were performed in accordance with the guidelines to the European Malignant Hyperpyrexia Group.

Results: Histological and immunohistochemical analyses showed signs of rhabdomyolysis. Abnormal muscle contracture was measured with both halothane and caffeine in the first patient. For the second patient, muscle samples developed abnormal contracture with halothane only. Both patients were diagnosed as having malignant hyperthermia syndrome.

Conclusion: Our results further confirm the myotoxic effects of treatment with statins. We report for the first time these effects in patients with malignant hyperthermia syndrome for whom calcium homeostasis is impaired in skeletal muscle. This impairment is commonly attributed to a genetic defect affecting the ryanodine receptor, one of the calcium channels in the sarcoplasmic reticulum membrane. Our result suggest that toxic rhabdomyolysis could be a sign of susceptibility to malignant hyperthermia and that muscle contraction should be investigated, using IVCT, in subjects who develop myalgia with rhabdomyolysis during treatment with statins.

\section{Miscellaneous}

\section{9}

The diagnostic value of synovial histopathology in undifferentiated inflammatory arthritis: a prospective study in 154 consecutive patients

D Baeten, E Kruithof, IEA Hoffman, L De Rycke, B Vandooren, EM Veys, F De Keyser

Department of Rheumatology, Ghent University Hospital, Ghent, Belgium Arthritis Res Ther 2003, 5 (suppl 1):89

Objective: To explore prospectively the diagnostic value of synovial histopathology in undifferentiated inflammatory arthritis by analysing the 
positive predictive value (PPV) of single histological markers and the additive value of multiparameter models.

Methods: Synovial biopsies were obtained in 154 consecutive patients presenting for diagnostic work-out: 67 were clinically classified as rheumatoid arthritis (RA), spondyloarthropathy $(\mathrm{SpA})$, or other disease at time of arthroscopy (cohort 1). Patients with undifferentiated arthritis $(n=87)$ were re-evaluated after 6 months, yielding a diagnosis in 53 (cohort 2). Macroscopic, histological, and immunohistochemical synovial parameters with diagnostic value were identified in cohort 1 . Subsequently, the PPV of single parameters and multiparameter models was tested in cohort 2.

Results: Four single parameters yielded PPVs of more than $95 \%$ in cohort 1: anticitrulline staining, mAb 12A staining (recognising a specific $\mathrm{MHC} /$ peptide complex), and lining layer hyperplasia of more than five cell layers for RA and crystal depositions for other diseases. In undifferentiated arthritis, only anticitrulline staining, mAb 12A staining, and crystal depositions had a PPV of more than $90 \%$. Using these parameters, $39.6 \%$ of the undifferentiated patients were classified, with a PPV of $90.5 \%$.

Using cohort 1 as a learning file, two decision trees were developed which made a prediction in $74.6 \%$ and $67.2 \%$ of the patients, with PPVs of $88.0 \%$ and $86.7 \%$, respectively. When this was applied to cohort 2, a diagnostic prediction was made in $79.2 \%$ and $71.7 \%$ of the patients, with a PPV of $81.0 \%$ and $86.8 \%$, respectively.

Conclusion: This study supports the idea that synovial histopathology can be used for the early diagnosis of undifferentiated arthritis and that multiparameter models have an additive value compared with single parameters.

Acknowledgments: The authors thank Annemieke Boots and Peter Steenbakkers, Organon NV, for providing mAb 12A.

\section{0}

\section{Local production of soluble CD163 in the spondyloarthropathic joint}

\section{Baeten', HJ Møller', J Delanghe ${ }^{3}$, EM Veys', SK Moestrup ${ }^{4}$, F De Keyser ${ }^{1}$}

${ }^{1}$ Rheumatology, Ghent University Hospital, Ghent, Belgium

${ }^{2}$ Clinical Biochemistry, Aarhus University Hospital, Aarhus, Denmark

${ }^{3}$ Clinical Biochemistry, Ghent University Hospital, Ghent, Belgium

${ }^{3}$ Medical Biochemistry, University of Aarhus, Aarhus, Denmark

Arthritis Res Ther 2003, 5 (suppl 1):90

Objective: We recently described an increase of macrophages expressing the scavenger receptor CD163 in synovium and gut of SpA patients. CD163 is a receptor for haemoglobin-haptoglobin $(\mathrm{Hp}) \mathrm{com}$ plexes with highest affinity for the multimeric $2-2 \mathrm{Hp}$ phenotype. CD163 can be shed from the macrophage membrane as a soluble protein ( $s C D 163)$, which has been shown to inhibit lymphocyte proliferation in vitro. The present aim is to find out if the increased presence of CD163+ macrophages in SpA is associated with $\mathrm{Hp}$ polymorphism and/or local production of SCD163 in the joint.

Methods: $\mathrm{CD}_{163^{+}}$macrophages in synovium and SCD163 in synovial fluid (SF) (normalized for albumin levels) were assessed by immunohistochemistry and ELISA, respectively, in $26 \mathrm{SpA}$ and 23 RA patients. Serum sCD163 was analysed in 100 SpA patients, 23 RA patients, and 20 healthy controls (HCs). Serum SCD163 was reassessed after 12 weeks of treatment with infliximab in $20 \mathrm{SpA}$ patients. Finally, $\mathrm{Hp}$ polymorphisms were determined in $130 \mathrm{SpA}$ and $23 \mathrm{RA}$ patients.

Results: The number of $\mathrm{CD}_{163^{+}}$macrophages was increased in both synovial lining $(P<0.001)$ and sublining $(P<0.001)$ in SpA patients versus RA patients. Within the SpA group, HLA-B27+ patients had higher scores than HLA-B27- $(P=0.022$ and $P=0.016$ for lining and sublining, respectively). SF median sCD163 levels were high in both $\mathrm{SpA}(8.04 \mathrm{mg} / \mathrm{l})$ and RA $(8.79 \mathrm{mg} / \mathrm{l})$, and approximately three times higher than the corresponding serum levels. Interestingly, in SpA, SCD163 in SF correlated with that in the synovial lining $(r=0.43$, $P=0.034)$ and in serum $(r=0.33, P=0.002)$. Serum sCD163 was increased in SpA $(2.2 \mathrm{mg} / \mathrm{l})(P=0.008)$ and $\mathrm{RA}(3.0 \mathrm{mg} / \mathrm{l})(P<0.001)$ versus HCs. In SpA, serum sCD163 correlated weakly with CRP and ESR, but was unaffected by infliximab treatment. Finally, Hp polymorphisms in SpA were characterised by a slight underrepresentation of the 1-1 and overrepresentation of the 2-1 phenotype. Hp polymorphisms were not associated with serum or SF sCD163 levels.

Conclusion: These data confirm an increased presence of $\mathrm{CD} 163^{+}$ macrophages in the SpA joint and indicate local production of sCD163. The increased levels of sCD163 may contribute to local impairment of T-cell proliferation and activation in SpA.

\section{1}

\section{The use of neural network algorithms for the classification of undifferentiated arthritis by synovial histopathology}

\author{
D Baeten', B Wyns², I Hoffman', S Sette², L Boullart²,
} F De Keyser ${ }^{1}$

${ }^{1}$ Department of Rheumatology, Ghent University Hospital, Ghent, Belgium

${ }^{2}$ Department of Electrical Energy, Systems and Automation, Ghent University, Ghent, Belgium

Arthritis Res Ther 2003, 5 (suppl 1):91

Objective: We indicated recently that synovial histopathology can be used for early diagnosis of undifferentiated arthritis (UA), with multiparameter models such as decision trees being superior to single parameters. The present aim is to build a prediction method based on a neural network approach and to compare this to the decision tree algorithm.

Methods: Synovial histopathology (including14 parameters) was performed on 120 synovia of patients with knee synovitis presenting for diagnostic workout. In 67 patients, a definite diagnosis was made at the time of arthroscopy (32 RA, $22 \mathrm{SpA}, 13$ other diseases); this cohort was used as learning file for the algorithms. The remaining 53 patients had real undifferentiated arthritis (UA) at presentation and a definite diagnosis was obtained by clinical follow-up (19 RA, 21 SpA, 13 other diseases) 6 months later; this cohort was used as test file to validate the models. A self-organizing neural network was developed using modified Kohonen mapping in combination with a case-based learning evaluation criterion.

Results: Classifying all $53 \mathrm{UA}$, the global positive predictive value (PPV) of the neural network was $64.2 \%$, including a PPV of $78.9 \%$ for RA, $57.9 \%$ for $\mathrm{SpA}$, and $63.2 \%$ for other diseases. Using the decision tree model on the same cohort, the global PPV was $69.8 \%$, with a PPV of $66.7 \%$ for RA, $70.0 \%$ for SpA, and $77.8 \%$ for other diseases. Since it is clinically more important to classify a subset of UA with a high PPV $(>80 \%)$ than to classify all patients (resulting in a lower overall PPV), a distance criterion was placed on top of the case-based learning evaluation algorithm, resulting in the classification of $50.9 \%$ of the samples with a PPV of $81.5 \%$. Using the same PPV requirement for the decision tree, $79.2 \%$ of the samples were classified with a PPV of $81.0 \%$.

Conclusion: Although the global performance of the neural network was slightly inferior to the decision tree model, the neural network was superior for the classification of RA. These results warrant further research in the neural network approach, especially for classification systems using a high number of parameters.

\section{2}

\section{CXCL13 and CCL21 play a key role in ectopic lymphoneogenesis in Sjögren's syndrome}

F Barone, M Blades, A Manzo, P Morgan, M Montecucco, G Valesini, C Pitzalis

GKT School of Medicine, London, UK

Arthritis Res Ther 2003, 5 (suppl 1):92

Objective: The aim of this study was to characterise the organisation of neolymphoid structures in glands of patients with Sjögren's syndrome and to correlate their maturation with CXCL13 and CCL21 expression. Methods: Salivary-gland biopsies from 28 patients with SS and 12 with sialoadenitis were examined using immunohistochemistry (IHC). Infil- 
trates were characterised according to the score (grade $1,<50$ periductal lymphocytes; grade 2, $>50$ lymphocytes; grade $3=$ grade 1 or 2 plus $\mathrm{GC})$. Follicular maturation was assessed with respect to T/B-cell segregation, CD45RO and CD45RA, CD21+ FDCs, GC and MECA79+ HEVs. CXCL13 and CCL21 expression was also assessed.

Results: Grade 1 showed predominance of $\mathrm{CD}^{+} / \mathrm{CD} 45 \mathrm{RO}^{+}$infiltrating lymphocytes. Grade 2 showed increased number of $\mathrm{CD}_{2} \mathrm{O}^{+}$ $\mathrm{CD}_{45 \mathrm{RA}}{ }^{+}$and a variable degree of organization $(54.55 \%$ not segregated, $21.21 \%$ atypically segregated, $24.24 \%$ segregated). Grade 3 showed $\mathrm{CD}^{2} \mathrm{0}^{+} / \mathrm{CD} 45 \mathrm{RA}{ }^{+}$predominance with typical segregation. Within grades 2 and 3 , we detected CD21+ FDC clusters. MECA79+ vessels were detected on the edge of the aggregates. CXCL13 expression was detected in $4.07 \%$ of grade $1,46.16 \%$ of grade 2 and $100 \%$ of grade 3 aggregate and in some infiltrated ducts. CCL21 expression was detected in $2.5 \%$ of grade $1,17.85 \%$ of grade 2 and $47.62 \%$ of grade 3 aggregates.

Conclusions: The presence of fully formed lymphoid follicles characterized by GC, B/T segregation, HEVs and FDCs within the target organs for SS, and the association of these structures with chemokines acting as regulator of lymphoneogenesis, suggest a key role of these molecules in the pathogenesis and evolution of the disease process.

\section{3}

\section{Delayed resolution of acute inflammation during zymosan-induced arthritis in leptin-deficient mice E Bernotiene ${ }^{1,2}$, G Palmer ${ }^{1,2}$, D Talabot-Ayer ${ }^{1,2}$, I Szalay- Quinodoz ${ }^{2}$, C Gabay ${ }^{1,2}$ \\ ${ }^{1}$ Division of Rheumatology, University Hospital, and Department of Pathology, University of Geneva School of Medicine, Geneva, Switzerland \\ 2Division of Clinical Pathology, University Hospital, Geneva, Switzerland \\ Arthritis Res Ther 2003, 5 (suppl 1):93}

Background: Proinflammatory or anti-inflammatory roles have been ascribed to leptin, depending on the experimental model investigated. We recently observed decreased severity of antigen-induced arthritis (AIA) in leptin-deficient ob/ob mice. However, joint inflammation in AIA depends on the immune response to an exogenous antigen, which is impaired in ob/ob mice.

Objective: The aim of the present study was to investigate potential effects of leptin in zymosan-induced arthritis (ZIA), a model of acute inflammatory arthritis, which is not dependent on the adaptive immune response.

Methods and results: Arthritis was induced in ob/ob and control $+/$ ? C57BL/6 mice by injection of zymosan A (Zy) into the knee joint cavity. Increased blood flow, reflecting the severity of joint inflammation, was quantified by uptake of technetium $99 \mathrm{~m}$. It was similar 6 and 24 hours after Zy injection in ob/ob and control mice. However, it persisted on day 3 in ob/ob animals, while subsiding in controls. Histology repeatedly showed similar severity of arthritis in ob/ob mice and controls on day 3 , but arthritis always tended to be more severe in ob/ob than in $+/$ ? mice at later time points (days 14 and 21). Similar observations were made using leptin-receptor-deficient $d b / d b$ mice, suggesting that the effects of leptin are mediated via the $\mathrm{Ob}-\mathrm{Rb}$ receptor. The acutephase response was examined in ob/ob and control mice after injection of $Z y$ by measuring circulating levels of interleukin (IL)- 6 and serum amyloid A (SAA). Serum IL- 6 increased in all animals during the first 24 hours after Zy injection, but IL-6 levels were significantly higher in ob/ob mice than in controls. SAA increased in all animals during the first 3 days after $Z y$ injection, but SAA levels were significantly higher on days 1 and 3 in ob/ob animals than in controls. The acute-phase response thus appeared to be more pronounced in ob/ob mice, although corticosterone levels were significantly elevated in these animals at baseline and throughout the experiment

Conclusion: These data suggest that the resolution of acute inflamma- leptin thus appears to display anti-inflammatory properties, limiting the acute phase response and the chronicity of arthritis.

\section{4}

Chondrocyte number and proteoglycan synthesis in the ageing and osteoarthritic human articular cartilage K Bobacz, A Soleiman, L Erlacher, J Smolen, WB Graninger

Department of Rheumatology, Internal Medicine III, University of Vienna, Vienna, Austria

Arthritis Res Ther 2003, 5 (suppl 1):94

Objective: To correlate the number of chondrocytes in healthy and osteoarthritic human articular cartilage with age and to evaluate the influence of senescence on total proteoglycan synthesis.

Methods: Chondrocytes were isolated from human articular cartilage derived from hip joints with and without osteoarthritic lesions. Cell number was assessed by light microscopy and normalized to cartilage sample wet weight. Chondrocytes were grown as monolayer cultures for 7 days in a chemically defined serum-free basal medium. Total proteoglycan synthesis was measured by $\left[{ }^{35} \mathrm{~S}\right]$ sulfate incorporation into newly synthesized macromolecules.

Results: Chondrocyte numbers in healthy cartilage decreased significantly with advancing age $(r=-0.69, P<0.0001)$. In contrast to healthy specimens, chondrocyte numbers were decreased in OA cartilage irrespective of and unrelated to age and differed markedly, by an average of $38 \%$, from the cell numbers found in healthy cartilaginous tissue $(P<0.0001)$. Regarding proteoglycan synthesis, no dependence on patient's age, either in healthy or in OA specimens, were observed in our culture settings.

Conclusions: Chondrocytes from healthy and OA joints synthesized comparable amounts of $P G$, independent of age or underlying OA disease. As the cell count in our monolayer cultures was constant, we conclude that the decreased chondrocyte number found in the ageing and OA joints could be a crucial factor in limiting tissue replenishment in vivo.

\section{5}

Expression and regulation of discoidin domain receptor 1 (DDR1) - a novel receptor for collagen - in normal human renal cells and patients with lupus nephritis DT Boumpas ${ }^{1}$, T Kuroiwa ${ }^{2}$

${ }^{1}$ University of Crete, Medical School, Heraklion, Greece

${ }^{2}$ Gunma University, Medical School, Kuroiwa, Japan

Arthritis Res Ther 2003, 5 (suppl 1):95

Background and objective: Pathogenic accumulation of extracellular matrix $(E C M)$ is a common feature of progressive renal diseases. Cytokines such as TGF- $\beta$ as well as aberrant communication of renal cells with ECM via specific cell-surface receptors are thought to play a pivotal role in this process. Recently, a novel receptor tyrosine kinase subfamily has been identified and designated as discoidin domain receptor tyrosine kinase type 1 (DDR1) and type 2 (DDR2). These are functional collagen receptors, whose tyrosine kinase is activated upon binding to collagen. We sought to explore the expression and regulation of DDR1 in the human kidney in both normal and diseased states. Methods: We used cultured human mesangial and tubular cells and renal biopsies from patients with lupus nephritis or normal kidneys obtained from nephrectomies. DDR1 expression was studied by immunohistochemistry and Northern and Western blot analyses. Tyrosine phosphorylation was detected by immunoblotting using antiphosphotyrosine blots.

Results: High levels of DDR1 expression were detected by immunohistochemistry in glomerular epithelial and mesangial cells (MCs) of normal human kidney specimens. DDR1 was also expressed in renal tubular epithelial cells, albeit at lower levels. As compared with normal controls, DDR1 expression was significantly decreased in mesangial areas obtained from patients with proliferative lupus nephritis $(n=7)$, while it was up-regulated in tubular epithelial cells surrounded by significant interstitial fibrosis. Cultured human MCs expressed DDR1 in vitro, 
a finding verified by Western and Northern blot analysis. Stimulation of MCs with collagen induced tyrosine phosphorylation of DDR1, indicating that mesangial DDR1 is a functional collagen receptor. Interestingly, platelet-derived growth factor and basic fibroblast growth factor, both of which are potent mitogens for MCs, significantly decreased the expression of DDR1 both in mRNA and protein levels. TGF- $\beta$ did not exert such an effect.

Conclusion: DDR1 participates in the interaction of MCs with mesangial ECM. Decreased expression of DDR1 in MCs may represent an important process for mesangial proliferation.

\section{6}

\section{Human platelets stimulate mesangial cells to produce monocyte chemoattractant protein-1 via the CD40/CD40-ligand pathway and may amplify glomerular injury DT Boumpas ${ }^{1}$, T Kuroiwa ${ }^{2}$}

1 University of Crete, Medical School, Heraklion, Greece ${ }^{2}$ Gunma University, Medical School, Kuroiwa, Japan Arthritis Res Ther 2003, 5 (suppl 1):96

Background and objective: Depletion of platelets reduces influx of hemopoietic cells into the glomeruli, decreases resident cell proliferation and improves renal function in animal models of glomerulonephritis. However, the precise mechanisms by which platelets promote glomerular injury are poorly understood. We explored whether platelets induce production of monocyte chemoattractant protein-1 (MCP-1) by cultured human mesangial cells (MCs) and the mechanisms involved.

Methods: Platelets were isolated from normal human donors and cocultured with MCs at various ratios. The contribution of cell-to-cell contact was examined by a double-chamber culture system. MCP-1 synthesis in cocultures was determined by semiquantitative reverse transcription/real-time PCR and ELISA. Signal transduction was studied by mobility gel-shift assays and phosphotyrosine immunoblots. Results: Platelets, at 1:100 ratio (MC: platelets), induced a more than 10-fold increase in mesangial MCP-1 production, both in mRNA and protein levels. Using a double-chamber culture system, we demonstrated that the direct cell-to-cell contact between platelets and $\mathrm{MC}$ is indispensable for MCP-1 production. Importantly, blockade of the CD40-CD40 ligand (CD4OL) pathway with neutralizing antibodies decreased MCP-1 production by approximately $60 \%$. Immunostaining confirmed the expression of CD40 by cultured MCs. When added into MC cultures, recombinant $\mathrm{CD} 40 \mathrm{~L}$ in combination with recombinant IFN- $\gamma$, enhanced MCP-1 production twofold (relative to the basal levels in response to recombinant IFN- $\gamma$ alone), confirming that CD40 was functionally expressed on MCs. Using gel-shift assay and a specific inhibitors, we showed that the contact of MCs with platelets induced $\mathrm{NF}-\mathrm{KB}$ activation, which was essential for MCP-1 synthesis. In additional experiments, we found that activation of $\mathrm{p} 38$ mitogen-activated protein kinase (MAPK) and protein tyrosine kinases (PTKs) are involved in platelet-mediated MCP-1 induction by MCs.

Conclusion: Platelet/MC contact stimulates the production of MCP-1 and may contribute to glomerular inflammatory responses by recruiting leukocytes from the peripheral blood.

\section{7}

\section{Activation of respiratory burst in polymorphonuclear leukocytes upon contact with stimulated $\mathbf{T}$ cells and inhibition by high-density lipoproteins (HDLs) \\ P Cettour-Rose, J-M Dayer, D Burger, P Roux-Lombard}

Immunology and Allergy Division, University Hospital, Geneva, Switzerland

Arthritis Res Ther 2003, 5 (suppl 1):97

Background: Polymorphonuclear neutrophils (PMNs) are attracted early at sites of inflammation, where they are in close proximity with other types of immune cells. Cellular contact with stimulated T cells are known to prime PMNs for respiratory burst, and direct cell-cell contact between T cells and monocytes is a major mechanism that triggers the production of inflammatory cytokines.

Methods: We analysed the direct induction of the respiratory burst in human PMNs upon contact with stimulated T cells. The production of reactive oxygen species (ROS) by PMNs was monitored in vitro by the luminol-enhanced chemiluminescence assay.

Results: Membrane from PHA/PMA-stimulated human Tlymphocytes and from T-cell line HUT-78 induced a dose-dependent ROS production by $\mathrm{PMNs}$, demonstrating that stimulated T-cells are able to stimulate PMN respiratory burst by direct cell-cell contact. Neither TNF soluble receptors nor IL-1 receptor antagonist interfered with ROS production induced by T-cell membranes. Monoclonal antibodies directed toward CD-18 inhibited 60\% of PMN respiratory burst induced by stimulated T-cell membrane, while antibodies to CD11a,b,c and CD69 had no effect. These results suggest a partial role for $\beta$-2-integrin CD18 in PMN activation. Furthermore, HDL inhibited stimulated T-cell induced PMN respiratory burst in a dose-dependent manner, allowing a complete inhibition for $200 \mu \mathrm{g} / \mathrm{ml}$. Similar inhibitory effects of HDL have previously been described in activation of monocytes by direct cell-contact.

Conclusion: These results emphasize the importance of direct cell-cell contact in inflammatory processes and strongly suggest that at the surface of $\mathrm{T}$ cells, similar molecules, although affected by different coactivators, are involved in the activation of both monocytesmacrophages and PMNs.

\section{8}

\section{TNF suppresses CD4+ T-CELL responses by attenuating calcium/NFAT-dependent but not ERK- dependent signal transduction pathways}

\section{JM Clark, K Aleksiyadis, N Panesar, AP Cope}

The Kennedy Institute of Rheumatology Division, Faculty of Medicine, Imperial College, London, UK

Arthritis Res Ther 2003, 5 (suppl 1):98

Background: Chronic exposure of $\mathrm{CD}^{+} \mathrm{T}$ cells to picomolar concentrations of tumour necrosis factor alpha (TNF) induces a hyporesponsive phenotype, as measured by T-cell-receptor-(TCR)-stimulated proliferation and cytokine production, which is similar to that of T cells recovered from inflamed rheumatoid synovial joints. We have reported previously that chronic exposure to TNF impairs assembly of the TCR/CD3 complex at the cell surface by down-regulating expression of the signal amplification module TCR zeta (TCR- $\zeta$ ). TCR-induced tyrosine phosphorylation of ZAP-70, LAT and PLC- $\gamma 1$ are attenuated in TNF-treated cells as a consequence.

Objective and results: Here we report studies of the effects of TNF on downstream signalling pathways using a murine T-cell hybridoma. We show that signalling from the TCR via the extracellular signal-regulated kinase (ERK) pathway is similar in control and TNF-treated cells, as determined by induction of GTP-bound Ras, by phosphorylation on ERK1/2 and the ERK substrate Elk-1, and by ERK-dependent expression of c-fos and CD69. By contrast, TCR-induced calcium flux is greatly attenuated in TNF-treated cells. Despite preservation of ERK signalling, induction of cytokine mRNA transcripts, whose expression depends upon calcium signals and the generation of NFAT (functional nuclear factor of activated T cells) or NFAT/AP-1 complexes, is markedly suppressed in TNF-treated T cells. Further experiments reveal that TNF alters signalling through the calcium/NFAT pathway independently of its effects on receptor-proximal events. For example, we find that whereas calcium responses induced by ionomycin or thapsigargin are similar in control and TNF-treated cells, IL-2 production is greatly reduced in TNF-treated cells as compared with controls after stimulation with phorbol ester and ionomycin. As is the case for stimulation via TCR, activation of the Ras/ERK pathway by phorbol ester is preserved in TNF-treated T cells.

Conclusion: These data are consistent with a model in which TNF alters NFAT function through effects on nuclear translocation, DNA binding or transcriptional activation. The model also predicts that TNF 
may promote T-cell effector responses indirectly by suppressing NFATdependent genes whose expression is required for immunoregulation and peripheral tolerance.

\section{9}

\section{Myeloid-related protein (MRP) 8 and MRP 14 in rheumatoid arthritis and spondyloarthropathy L De Rycke', D Baeten', D Foell², EM Veys'1, F De Keyser'1,} J Roth ${ }^{2}$

${ }^{1}$ Department of Rheumatology, Ghent University Hospital, Ghent, Belgium

${ }^{2}$ Department of Pediatrics, University of Münster, Münster, Germany Arthritis Res Ther 2003, 5 (suppl 1):99

Background: Myeloid-related protein (MRP) 8 (S100A8) and MRP 14 (S100A9) are calcium-binding proteins belonging to the $\mathrm{S} 100$ family. Their expression in leukocytes is restricted to neutrophils and early differentiation stages of monocytes. In several inflammatory diseases, serum concentrations and expression of MRP 8 and MRP 14 by infiltrating myelomonocytic cells correlate with disease activity, indicating that both proteins are released during inflammatory processes.

Objective: To analyze MRP 8/14 concentrations in serum and synovial fluid (SF), and expression of MRP 8 and MRP 14 in synovial tissue in $\mathrm{RA}$ and SpA.

Methods: Paired serum, SF and synovial tissue samples of $20 \mathrm{RA}$ and 20 SpA patients and sera of 20 healthy controls (HCs) were analyzed. Concentrations of MRP 8/14 in serum and SF were determined by ELISA. The expression of MRP 8 and MRP 14 in synovium was investigated using immunohistochemistry on frozen sections. Sections were scored on a semiquantitative 4-point scale. For statistical analysis, the Mann-Whitney test and Spearman's Rho correlations were performed. $P$ values $\leq 0.05$ were considered significant. Bonferroni corrections were applied when necessary.

Results: Serum concentrations of MRP 8/14 were significantly higher in RA (medians $1285 \mathrm{ng} / \mathrm{ml}$ [210-11390]) and SpA (medians $570 \mathrm{ng} / \mathrm{ml}$ [230-2730]) than in HCs (medians $280 \mathrm{ng} / \mathrm{ml}$ [130-680]) (RA versus HCs: $P<0.001$; SpA versus HCs: $P=0.002$ ). Moreover, MRP 8/14 serum concentrations in RA were increased, in comparison with SpA $(P=0.036)$. Also for SF concentrations, MRP 8/14 levels were significantly higher in RA than in SpA (medians $11,720 \mathrm{ng} / \mathrm{ml}$ [0-95,000] versus $2445 \mathrm{ng} / \mathrm{ml}$ [0-33,250], $P=0.049$ ). MRP 8 staining in the lining layer was more prominent in RA than in SpA (medians 2 [0-3] versus 1 [0-3], $P=0.019$ ), and MRP 14 staining in the sublining layer was more abundant in RA than in $\mathrm{SpA}$ (medians 2 [0-3] versus 1 [0-2], $P=0.026$ ). In RA, MRP 8/14 concentrations in serum correlated well with SF concentrations $(r=0.650, P=0.002)$.

Conclusion: We found significantly higher MRP 8 and 14 serum concentrations, MRP 8 and 14 SF concentrations, and MRP 8 and 14 expression in synovial tissue in RA than in SpA. In both diseases, MRP 8 and 14 serum levels were higher than in HCs.

\section{0}

\section{Human chondrocytes, reactive oxygen species production and Nox}

\section{Grange, MJ Stasia, S Vergnaud, JS Lu, C Trocme, P Gaudin, F Morel}

GREPI EA 2938 UJF, Enzymology Laboratory and Rheumatology Department, Centre Hospitalier Universitaire A Michallon, Grenoble, France

Arthritis Res Ther 2003, 5 (suppl 1):100

Joint destruction is a key point in many inflammatory and degenerative diseases. This is mainly mediated by inflammation cells and resident cells such as chondrocytes. Matrix metalloproteinases and reactive oxygen species are widely involved.
This work shows that three different human immortalized chondrocyte (HIC) cell lines (a gift from M Goldring) and native chondrocytes can generate superoxide anions $\left(\mathrm{O}^{2-}\right)$ constitutively and after activation with PMA or ionomycin. The $\mathrm{O}^{2-}$ produced by chondrocyte NADPH oxidase is about $0.1 \%$ of the respiratory burst measured in phagocytic cells such as neutrophils. All the components of NADPH oxidase were detected by Western blot analysis: the cytosolic factors p47phox, p67phox and p40phox and the two subunits of the cytochrome $b_{558}$, gp91phox (Nox2) and p22phox. The presence of cytochrome $b_{558}$ was also demonstrated by reduced minus oxidized differential spectra in $1 \%$ Triton X-100-soluble extract from the three HIC cell lines. The cytochrome $b_{558}$ content in chondrocytes was about $10 \mathrm{pmol} / \mathrm{mg}$ of proteins: this amount is lower than in neutrophils $(200 \mathrm{pmol} / \mathrm{mg}$ of proteins). The presence of Nox4 and Nox2 mRNA in the three HIC cell lines was demonstrated by RT-PCR and Northern blot analysis.

The three $\mathrm{HIC}$ cell lines and native chondrocytes contain phagocyte NADPH oxidase components, and Nox2 (gp91phox) analogs as Nox4 and Nox5. The low level of superoxide anions $\mathrm{O}^{2-}$ produced by chondrocytes in comparison with neutrophils may be involved in signal transduction and may be implicated in the structural and functional alterations of cartilage matrix observed in arthritis and osteoarthritis.

\section{1}

Predictive markers of disease outcome in synovial tissue: T cells, synovial fibroblasts, and granzyme B $^{+}$ cytotoxic cells predict unfavorable outcome in patients with recent-onset rheumatoid arthritis MC Kraan', J Haringman1, EC Barg 1,2, MD Smith³, MJ Ahern³, TJM Smeets ${ }^{1}$, FC Breedveld², PP Tak1

${ }^{1}$ Division of Clinical Immunology and Rheumatology, Department of Internal Medicine, Academic Medical Center/University of Amsterdam, Amsterdam, The Netherlands

2Department of Rheumatology, Leiden University Medical Center,

Leiden, The Netherlands

3Department of Rheumatology, Repatriation General Hospital,

Adelaide, South Australia

Arthritis Res Ther 2003, 5 (suppl 1):101

Objective: To determine immunohistological markers in synovial tissue of early rheumatoid arthritis (RA) patients, which could be used as predictors for disease outcome.

Methods: Synovial tissue was obtained from 36 RA patients within 1 year after the initial symptoms and before the initiation of treatment with any disease-modifying antirheumatic drug. Clinical, laboratory, and radiological assessment (Larsen score) was performed at the time of the biopsy and at the end of follow-up (mean 58 months, range 38-72 months). Immunohistological analysis was performed to detect T cells, B cells, plasma cells, fibroblast-like synoviocytes (FLS), macrophages, and granzyme $\mathrm{B}^{+}$cytotoxic cells. The sections were evaluated by digital image analysis.

Results: Patients were divided into two groups based upon the radiological progression per year of follow-up: group I with moderate progression $(n=20)$ (by $<2$ points/year, Larsen score) and group II with pronounced progression ( $n=16$ ) (by $\geq 2$ points/year, Larsen score). Regression analysis with a univariate model revealed that female gender $(\mathrm{RR}=10.7, P=0.015)$ and numbers of granzyme $\mathrm{B}^{+}$cytotoxic cells $(\mathrm{RR}=12, P=0.003)$, T cells $(\mathrm{RR}=10.1, P=0.013)$, and FLS (RR $=10, P=0.020)$ discriminated between groups I and II. A multivariate model demonstrated that female gender $(\mathrm{RR}=78.42, P=0.017)$ and numbers of $\mathrm{T}$ cells $(\mathrm{RR}=1.2, P=0.015)$ and $\mathrm{FLS}(\mathrm{RR}=1.4$ $P=0.013$ ) were independent discriminators between groups I and II. Conclusion: The numbers of granzyme $\mathrm{B}^{+}$cytotoxic cells, T cells, and FLS in synovial tissue of RA patients are related to the severity of joint damage and therefore may be useful prognostic markers of disease outcome in patients with recent-onset RA. In addition, the observations suggest a pathogenic role of these cells in the process of joint damage. 
102

OPG and RANKL in serum and synovial fluids of patients with rheumatoid arthritis, osteoarthritis and spondylarthropathy

O Krystufkova', J Niederlova', V Senolt', M Hladikova², S Ruzickova', J Vencovsky'

${ }^{1}$ Institute of Rheumatology, Prague, Czech Republic

2Institute of Medical Informatics, 2nd Medical Faculty, Charles

University, Prague, Czech Republic

Arthritis Res Ther 2003, 5 (suppl 1):102

Background: Osteoprotegerin (OPG) and receptor activator of nuclear factor $\mathrm{KB}$ ligand (RANKL) are the key regulators of osteoclastogenesis in inflammatory diseases, such as RA. OPG binds to RANKL, prevents its ligation to receptor activator of nuclear factor $\mathrm{KB}$ (RANK) and inhibits differentiation and activation of osteoclasts. The imbalance of this system results in the predominance of osteoresorption and bone erosions.

Objective: The aim of study was to compare the levels of OPG and soluble RANKL (sRANKL) in serum (S) and synovial fluid (SF) in rheumatoid arthritis (RA), osteoarthritis (OA) and spondylartropathies $(\mathrm{SpA})$ and to correlate these levels with inflammatory parameters. We hypothesized that there is a higher local synthesis of both factors and positive correlation of SRANKL in synovial fluid with the disease activity in RA.

Methods: The paired $S$ and knee SF samples were collected from 105 patients with RA $(n=45), \mathrm{OA}(n=46)$ and SpA $(n=14)$. The OPG and sRANKL levels were measured by sandwich ELISA (Biomedica).

Results: Concentrations of OPG and SRANKL were significantly higher in SF than in $S$ in all groups (Table 1). RA and SpA groups had S-OPG and SF-OPG lower than OA. RA and OA groups differed significantly. S-sRANKL was negative in most cases in all groups. The significant negative correlation with serum CRP and SF leukocyte count was found in S-OPG, SF-OPG and SF-sRANKL.

Table 1

The mean OPG and SRANKL levels in patient cohorts

\begin{tabular}{lrrr}
\hline & \multicolumn{1}{c}{ RA } & \multicolumn{1}{c}{ OA } & \multicolumn{1}{l}{ SpA } \\
\hline S-OPG (pmol/l) & $1.9(1.6 ; 2.3)$ & $2.4(2.2 ; 2.7)$ & $1.8(0.9 ; 2.7)$ \\
SF-OPG $(\mathrm{pmol} / \mathrm{l})$ & $3.8(3.1 ; 4.4)$ & $8.4(7.5 ; 9.3)$ & $3.5(2.1 ; 4.8)$ \\
SF-sRANKL $(\mathrm{pmol} / \mathrm{l})$ & $3.36(2.5 ; 4.2)$ & $3.41(2.9 ; 3.8)$ & $1.9(1.5 ; 2.5)$
\end{tabular}

Values are means ( $95 \%$ confidence interval).

Conclusion: The increased local production of OPG and SRANKL in active joints reflects the production by inflammatory cells. Lower local and systemic concentrations of OPG in RA and SpA, but not in OA, are in agreement with the theory that OPG is insufficiently protective in inflammatory arthritis. The finding that there is no difference in SF sRANKL in RA and OA suggests that the local osteoresorption results from cell-bound RANKL rather than from the activity of the soluble form. Acknowledgement: Supported by grant NK/7293-3 MH CR.

\section{3}

\section{Identification of homing peptides specific for human synovium by in vivo phage display selection}

\section{Lee, C Buckley, M Blades, G Panayi, AJ George, C Pitzalis}

Department of Rheumatology, GKT School of Medicine, London, UK Arthritis Res Ther 2003, 5 (suppl 1):103

Background: The microvascular endothelium (MVE) plays a major role in the pathogenesis of rheumatoid arthritis (RA). There is evidence to suggest that tissue-specific MVE determinants are involved in selective recruitment of pathogenic immune cells to sites of inflammation.
Objective: The aim of this work was to target the synovial MVE in tissue grafts transplanted into mice with SCID (severe combined immunodeficiency), using phage display.

Methods: Human synovium and skin were transplanted into SCID mice. A disulfide-constrained seven-amino-acid peptide phage library was injected intravenously into the animals and synovial homing phage was recovered from grafts. DNA sequencing of homing phage clones allowed the identification of specific peptides.

Results: Synovial homing phages that distinctively bind to synovial but not skin or mouse MVE were isolated. They retained their tissue homing specificity in vivo independently from the phage component, the original pathology of the transplanted tissue and the degree of human/murine graft vascularisation. One such peptide (CKSTHDRLC) maintained synovial homing specificity both when presented by the phage or as a free synthetic peptide. The synthetic peptide also competed and inhibited in vivo the binding of the parent phage to the cognate synovial MVE ligand.

Conclusions: We report the isolation of peptides with homing properties specific for human synovial MVE. The identification of such peptides opens the possibility of using these sequences to construct joint-specific drug delivery systems that may have a considerable impact in the treatment of arthritic conditions.

\section{4}

Increased susceptibility of osteoarthritis tenocytes to FasL-induced apoptosis is associated with elevated expression of Fas receptor but no alterations in the expression of Sentrin-1/SUMO-1

A Machner1, A Baier1,2, A Drynda², S Drynda², G Pap¹, S Gay³, W Neumann', T Pap ${ }^{2,3}$

${ }^{1}$ Department of Orthopedic Surgery, Otto-von-Guericke-University, Magdeburg, Germany

2Division of Experimental Rheumatology, Otto-von-Guericke-University, Magdeburg, Germany

${ }^{3}$ Center of Experimental Rheumatology, University Hospital Zürich,

Zürich, Switzerland

Arthritis Res Ther 2003, 5 (suppl 1):104

Background and objective: Alterations in periarticular tendons have been described in osteoarthritis (OA), but the specific properties of OA tenocytes and particularly the regulation of apoptosis in these cells remain poorly understood. Therefore, we analyzed the expression of Fas and sentrin-1/SUMO-1, a small ubiquitin-like modulator of Fas signaling, in tenocytes of patients with knee OA and studied the susceptibility of these cells to FasL-induced apoptosis.

Methods: Tenocyte cultures were established from tendon specimens of the quadriceps femoris muscle of OA patients and characterized by FACS analysis with antibodies against fibroblast markers (AS02, 5B5) and monocyte markers (CD45, CD68). Expression levels of Fas and sentrin-1/SUMO-1 were determined by quantitative real-time PCR (TaqMan, Applied Biosystems). Levels of soluble Fas (sFas), and soluble TNF receptor I (sTNFRI) were measured by ELISA. To induce apoptosis, tenocytes were stimulated with $100 \mathrm{ng} / \mathrm{ml} \mathrm{rhFasL}$ for 16 hours. Apoptosis was determined through the detection of cytoplasmatic mononucleosomes and oligonucleosomes (Cell Death ELISA, Roche). The effects of TNF- $\alpha$ were studied by stimulation with 1,10 or $100 \mathrm{ng} / \mathrm{ml} \mathrm{TNF-} \alpha$ alone or 24 hours prior to the induction of apoptosis. Tenocytes from non-OA patients were used as controls.

Results: FACS analysis confirmed the fibroblast-like nature of tenocytes and excluded the presence of monocyte-derived cells in the cultures. Quantitative PCR showed significantly higher levels of Fas mRNA in OA tenocytes in comparison with healthy controls. As demonstrated by ELISA, tenocytes from OA patients produced lower levels of apoptosis-inhibiting sFas. No differences were seen in the expression of sentrin-1/SUMO-1 and STNFRI. After stimulation with rhFasL, tenocytes from OA patients exhibited higher rates of apoptosis than control cells. TNF- $\alpha$ prevented FasL-induced apoptosis in OA tenocytes but had no effects in normal tenocytes. 
Conclusion: The data suggest an association between knee OA and higher susceptibility of periarticular tenocytes to FasL-induced apoptosis. Increased expression of Fas receptor and lower levels of sFas may provide the basis for these alterations that in turn may promote the rupture of tendons. The antiapoptotic effects of TNF- $\alpha$ in OA tenocytes but not in normal cells most likely reflect regenerative attempts. They should be considered when anti-TNF- $\alpha$ strategies are discussed for the treatment of OA.

\section{5}

BCA-1 (CXCL13) and SLC (CCL21) production and lymphoid neogenesis in rheumatoid synovitis

A Manzo, M Carulli, S Paoletti, M Blades, F Barone, G Yanni, R Caporali, C Montecucco, M Uguccioni, C Pitzalis

GKT School of Medicine, London, UK

Arthritis Res Ther 2003, 5 (suppl 1):105

Objective: To relate the production of BCA-1 and SLC to lymphoid neogenesis in the rheumatoid arthritis (RA) synovium, in order to analyse their expression in relationship to the development of lymphoid features (T/B cell segregation, follicular dendritic cells [FDC] and expression of peripheral node addressin [PNAd]).

Methods: Fifty synovial-membrane samples from 20 RA patients were studied using immunohystochemistry and in situ hybridization. Samples were stained for T, B and FDC, PNAd, BCA-1 and SLC. In situ hybridisation was performed for BCA-1 and SLC. Grading analysis was assessed according to the radial cell count from the central blood vessel to the point of widest infiltration: grade 1 ( $2-5$ cells), grade 2 $(6-10)$ and grade $3(>10)$. The percentage of aggregates positive for each factor within each grading group was calculated.

Results: Samples from 17 patients showed the presence of grade 2 and/or 3 aggregates; in three cases only perivascular cuffing was demonstrated. Fully formed follicular-like structures, with centrally located CD21+ FDC and T/B segregation, were seen in 7 of the 20 patients (35\%). BCA-1 and SLC were expressed within lymphocytic clusters in 18 of 20 and 15 of 20 patients, respectively. BCA-1 and SLC expression was associated with mature follicular organisations. However they were detected also in the absence of fully formed lymphoid-like structures. Production of BCA-1 and SLC was established by in situ hybridisation to localize within lymphocytic clusters but even in the absence of mature follicles.

Conclusions: This study confirms that the expression of BCA-1 and SLC is associated with the ectopic lymphoid organisation seen in RA. Furthermore, it demonstrates by in situ hybridisation the precise site of production of these chemokines. Finally, grading analysis indicates a relationship between their expression and the progressive enlargement and organisation of infiltrating cell.

\section{6}

\section{Modulation of VCAM-1 expression with antisense oligonucleotides targeting signalling molecules \\ J Morel, CC Park, B Combe, K Zhu, AE Koch}

Centre Hospitalier Universitaire Montpellier, Montpellier, France Arthritis Res Ther 2003, 5 (suppl 1):106

In a recent report, we implicated a PI3-kinase and nuclear-factor- $\mathrm{kB}$ (NF-KB)-dependent pathway in IL-18-induced expression of vascular cell adhesion molecule-1 (VCAM-1) expression in RA synovial fibroblasts. We showed that IL-18 activates PI3 kinase/Akt, NF-אB, c-Src and Erk 1/2.

Here, we tested various oligonucleotides (ODNs) targeting signalling molecules induced by IL-18 signalling pathways. We also tested these antisense ODNs on IL-18-induced VCAM-1 expression. We evaluated IL-18-activated signalling molecules by Western blot and VCAM-1 expression by flow cytometry. Treatment with antisense c-Src ODN reduced IL-18-induced Erk 1/2 expression by $32 \%$ in comparison with control treatment, suggesting the upstream role of src in Erk $1 / 2$ activation. In addition, antisense c-Src ODN treatment also inhibited Akt expression by $74 \%$ in comparison with that in controls. Blocking PI3kinase through treatment with antisense PI3-kinase ODN almost com- pathway, inhibition of IRAK with antisense ODN to IRAK reduced IL-18induced expression of the transcription factor NF- $\mathrm{KB}$, which was not affected by inhibition of c-Src by antisense ODN. Finally, the IL-18induced expression of VCAM-1 was inhibited by treatment with antisense ODN to c-Src, NF-KB, PI3-kinase and Erk 1/2 to 43\%, 57\%, 59\% and $68 \%$ versus control treatment with the respective sense ODNs.

Conclusion: These data support the role of IL-18 in the activation of two novel pathways during RA synovial fibroblast stimulation, in addition to signalling through NF-KB. They suggest that these two novel pathways are controlled by Src kinase. The potential benefit of antisense ODN as selective inhibitors in down-regulating signalling events is also supported by the real decrease in IL-18-induced VCAM-1 expression seen after treatment of the RA synovial fibroblasts with antisense ODNs. Antisense ODNs constitute an interesting approach to block intracellular signalling pathways.

\section{7}

\section{Inhibition of MMP1, MMP2 and MMP8 by mepacrine C Pollaschek, KM Stuhlmeier}

Ludwig Boltzmann Institute for Rheumatology, Vienna, Austria Arthritis Res Ther 2003, 5 (suppl 1):107

Background: Matrix metalloproteinases (MMPs) play a pivotal role in many diseases. Inhibition of these enzymes is therefore also an important therapeutic target in rheumatoid arthritis and osteoarthritis, in which elevated levels of MMPs contribute to joint destruction. We reported earlier that mepacrine may effect MMPs by interfering with the activation of the transcription factor AP-1. Here we demonstrate that mepacrine may exert certain beneficial effects by suppressing MMP up-regulation in mononuclear cells.

Objective and methods: THP-1 and blood cells freshly isolated by density-gradient centrifugation were used. This cell population was pretreated with mepacrine and was subsequently stimulated with PMA for 4 hours to induce MMPs. RT-PCR was used to monitor the effect of mepacrine on cytokine- and PMA-induced MMP1, MMP2, MMP3 and MMP8 up-regulation.

Mepacrine has been used successfully to tether certain forms of rheumatic diseases. In order to account for these findings, we investigated possible effects of mepacrine on TNF as well as PMA-induced MMP up-regulation.

Results: Mepacrine dose-dependently inhibited the PMA-induced upregulation of MMP1, MMP2 and MMP8. The observed effects are specific, since mepacrine did not interfere with MMP3 activation. Western blot and RT-PCR experiments showed that treatment of mononuclear cells (MNCs) with mepacrine blocked the MMP up-regulation at the transcriptional level. Furthermore, electrophoretic mobility shift assays, using the AP-1 consensus element and MNC nuclear extract, demonstrated that, similar to human synovial fibroblast-like cells, mepacrine blocked AP-1-DNA interactions.

Conclusion: These effects of mepacrine on MMP up-regulation in MNCs may contribute to the beneficial effects of this drug seen in the past. To what degree events upstream of AP-1 are affected by mepacrine is currently under investigation.

\section{8}

The new B-cell-specific exon 1B of the CD5 mRNA favors autoimmunity by preventing the membrane expression of CD5

\section{Y Renaudineau, N Haget, P Le Goff, P Youinou}

Brest University Medical School, Laboratory of Immunology and Department of Rheumatology, Brest, France

Arthritis Res Ther 2003, 5 (suppl 1):108

Background and objective: The B-cell population comprises B1 and $B 2$; the $B 1$ population is subdivided into $B 1 a$, which express $C D 5$, and $\mathrm{B} 1 \mathrm{~b}$, which do not. B1 cells contribute to autoimmune disease, and a negative regulation has been ascribed to CD5. We recently described an alternative exon1 (referred as exon1B) and pursued the issue of the interplay of two exons 1 in the pathogenesis of lupus. 
Methods: B cells, including the B1a, B1b and B2 subpopulations, and T cells, were sorted from periperal blood (PB), tonsils, cord blood (CB) and CLL samples. Jurkat and Daudi cells were used as positive and negative controls, respectively. Conventional, nested and real-time PCR, in situ hybridization and EBV transformation were used, and CD5 molecules were counted.

Results: Exon 1B was shown to encode an additional mRNA in B cells and to be functional. It was never found in T cells, including those activated by anti-CD3 plus IL-2 or PMA. There was a gradient expression of exon 1A: PB T cells >B CLL >tonsil B $(\mathrm{B} 1 \mathrm{a}>\mathrm{B} 1 \mathrm{~b}>\mathrm{B} 2),>\mathrm{PB} \mathrm{B}>\mathrm{CB}$ $B$ cells. This correlated with the CD5 molecule at the membrane. In situ hybridization of cytospan cells and germinal center sections confirmed this statement. Exon $1 \mathrm{~A}$ substituted to exon 1B in activated (anti- $\mu$ plus IL-2), but not in further advanced (anti- $\mu$ plus IL-4) B cells. The leader peptide of exon-1B-induced protein was hydrophilic (not expressed) while that of exon-1A-induced protein was hydrophobic (expressed).

Conclusion: An aberrant exon 1B usage prevents transportation of CD5 to the membrane. Given the negative control exerted by CD5 in the vicinity of the BCR, B-cell-mediated autoimmune disease might thus occur as a failure to express CD5.

\section{9}

\section{Pro-MMP levels and severity of RA}

\section{Tchetverikov, L Lard, R Hanemaaijer, TWJ Huizinga}

Leiden University Medical Center, TNO, Leiden, The Netherlands Arthritis Res Ther 2003, 5 (suppl 1):109

Objective: The aim of the present study was to analyze the relationship between systemic levels of proMMP3, MMP8, and MMP9 and MMP activity in $\alpha 2 \mathrm{M} / \mathrm{MMP}$ complexes and the progression of joint destruction in patients with early rheumatoid arthritis (RA).

Methods: One hundred and nine patients diagnosed with probable or definite RA of recent onset were entered in this study. The patients were followed up for 2 years; clinical data, blood samples and radiographs were obtained at baseline, at 1 year and at 2 years. MMP levels were quantified using ELISA and MMP activity assays.

Results: During the 2-year study, joint damage progressed from 0 to 10 (median Sharp score, $P<0.001$ ) and the Disease Activity Score (DAS) decreased from 3.4 to $2.5(P<0.001)$. Stable levels of proMMP3 and $\alpha 2 \mathrm{M} / \mathrm{MMP}$ and a significant decrease in proMMP8 and proMMP9 levels was observed throughout the 2 years. Regression analysis showed that serum proMMP3 levels at the disease onset were independently associated with the progression of joint damage (B: $0.37,95 \% \mathrm{Cl} 0.13-0.61, P=0.003$ ).

On the basis of the rate of joint destruction, the patients were divided into two subgroups: according to whether the progression of joint damage was mild or severe. The proMMP3 levels were significantly higher in the severe vs mild group at all time points. Mild progressors showed a decrease in the levels of proMMP8, proMMP9 and $\alpha 2 \mathrm{M} / \mathrm{MMP}$ complexes $(P=0.01$ and $P<0.001, P=0.009$, respectively), whereas no changes in proMMP8, proMMP 9 and $\alpha 2 \mathrm{M} / \mathrm{MMP}$ levels were found in the severe group.

Conclusion: ProMMP3 levels at the onset of disease are predictive of joint damage progression.

\section{0}

\section{Fibroblast-like synoviocytes obtained from different joints at different times from one patient show similar invasiveness in vitro}

\section{TCA Tolboom ${ }^{1}$, R Nelissen'², REM Toes', TWJ Huizinga'}

${ }^{1}$ Department of Rheumatology, Leiden University Medical Center, Leiden, The Netherlands

${ }^{2}$ Department of Orthopedic Surgery, Leiden University Medical Center, Leiden, The Netherlands

Arthritis Res Ther 2003, 5 (suppl 1):110

Background: In rheumatoid arthritis (RA), fibroblast-like synoviocytes (FLSs) have an aberrant behaviour. We have shown that FLSs from
Figure 1

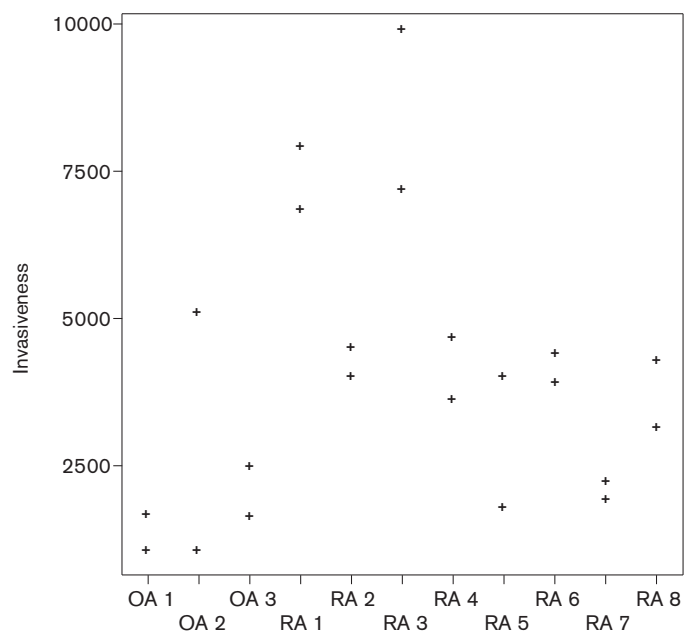

Invasiveness of FLSs (in Matrigel) of two different joints from one patient.

patients with RA display a different expression profile of matrix metalloproteinases, a different rate of proliferation and a different behaviour in an in vitro invasion model as compared with FLS from patients with osteoarthritis $(\mathrm{OA})$ or fractures. Others have shown that FLSs in patients with RA show characteristics of transformation, such as an increased rate of proliferation, anchorage-independent growth and invasiveness in a SCID mouse invasion model. Interestingly, microdissection studies recently showed that RA synovial tissue sections from different regions of the synovium were characterised by different $p 53$ transition mutations, suggesting that oxidative stress leads to different mutations and can lead to different behaviour of FLSs. This observation suggests that even within a joint, the inflammatory stress can lead to differences in FLS behaviour.

Objective: We therefore wished to evaluate the differences between FLS populations obtained from different joints of the same patient, to gain a better understanding of the potential differences in invasive behaviour of FLSs within one patient. To do this, we analysed the invasiveness of FLSs obtained from different joints from one patient in an in vitro model.

Methods: Synovium was obtained from 11 patients ( 8 with RA and 3 with OA) at joint replacement surgery and FLSs were isolated from the tissue using enzymatic digestion. When the cells had grown to confluence, invasion was tested in transwells coated with Matrigel.

Results: The results show that the variation within one patient is smaller than the variation between patients (Fig. 1). These data suggest that the inflammatory process that drives the transition of synoviocytes to invasive FLSs is similar in different joints taken from the same patient.

\section{1}

Serum cartilage oligomer proteins in psoriatic arthritis I Ujfalussy', M Brózik², J Kelemen', Z Tarján', É Koó1

${ }^{1}$ Polyclinic of the Hospitaler Brothers of St John of God, Budapest, Hungary

${ }^{2}$ National Institue of Rheumatology and Physiotherapy, Budapest,

Hungary

Arthritis Res Ther 2003, 5 (suppl 1):111

Background: In the cartilage of the joint, the matrix proteins are very pronounced in relation to the scattered chondrocytes in the tissue. In recent years, many different small molecules have been described with close relation to the collagen fibers and with activities that could be important in protecting the collagen fiber structure. One of these proteins is cartilage oligometric protein (COMP). 
Objective: The aim of our study was to investigate the serum level of COMP in psoriatic arthritis, to determine whether cartilage destruction is taking place.

Methods: Thirty-six psoriatic arthritis patients (22 women, 14 men), with an avarage disease duration of 7 years, were examined. For every patient, the disease activity on a visual analogue scale, the number of painful and swollen joints and the Ritchie index were recorded, as well as the sedimenation rate and CRP. The level of COMP was measured. Correlations between the activity parameters and the level of COMP were evaluated. Results: A good correlation was found between the Ritchie index and the serum level of COMP $(r=0.4)$. Low correlation was seen between the level of COMP and the number of painful joints $(r=0.1)$. No correlation was found between COMP and any of CRP, sedimentation rate or number of swollen joints.

Conclusion: The serum level of COMP can be used as one of the activity indicators of arthritis activity, though the correlation with other activity parameters in PsA is not so strong as in rheumatoid arthritis. The reasons for this difference may lie in the additional activity of the skin disease.

112

The inhibitory receptor FcyRII reduces joint inflammation in immune complex arthritis not only by inhibition of activatory FcyR but also by efficient clearance of immune complexes

\section{PL van Lent ${ }^{1}, K_{\text {Nabbe }}{ }^{1}$, AB Blom ${ }^{1}$, AE Holthuysen ${ }^{1}$,} $S$ Verbeek ${ }^{2}$, WB van den Berg' ${ }^{1}$

${ }^{1}$ Department of Experimental Rheumatology and Advanced

Therapeutics, University Medical Center, Nijmegen, The Netherlands

${ }^{2}$ Department of Human Genetics, University Medical Center,

Nijmegen, The Netherlands

Arthritis Res Ther 2003, 5 (suppl 1):112

Background: In earlier studies, we found that using Fc $\gamma \mathrm{RII}{ }^{-/-}$mice, the inhibiting FcyRll is an important regulator of joint inflammation and cartilage destruction during immune-complex arthritis (ICA) and that this receptor probably acts by down-regulating activatory FcyR functions. Objective: In the present study, we investigated the in vivo role of FcyRII during ICA in the absence of activatory Fc $\gamma \mathrm{R}$, using FcyRI/III-/and $\mathrm{Fc} \gamma \mathrm{RI} / \mathrm{II} / \mathrm{III}{ }^{-/-}$mice.

Results: At day 3 after ICA induction, a strongly elevated inflammation (exudate and infiltrate respectively $2200 \%$ and $270 \%$ ) was found in knee joints of $\mathrm{Fc \gamma RI/II/III-/-}$ as determined by histology whereas inflammation was almost absent in knee joints of $\mathrm{Fc} \gamma \mathrm{RI} / \mathrm{III}^{-/}$. Eight hours after injection of heat-aggregated $\lg G$, significantly more $\lg G$ was detected in knee joints of $\mathrm{Fc} \gamma \mathrm{RI} / \mathrm{II} /\left.\mathrm{III}\right|^{-/}$in comparison with wild-type controls which was mainly associated with the lining layer. Although inflammation was much higher in knee joints of $\mathrm{Fc} \gamma \mathrm{RI} / \mathrm{II} / \mathrm{III}^{-/-}$and the inflammatory cells still expressed an inflammatory phenotype, severe cartilage destruction (matrix-metalloproteinase-mediated neoepitopes in the matrix and chondrocyte death) was completely prevented, in contrast to the marked destruction observed in the wild type.

Conclusion: Our study indicates that FcyRll reduces joint inflammation in the absence of activating FcyR by promoting clearance of immune complexes from the joint. Infiltrating cells that fail to express FcyR, although they still become activated, are no longer able to induce cartilage destruction.

\section{3}

\section{The molecular chaperone BiP (GRP 78) inhibits the differentiation of normal human monocytes into immature dendritic cells}

\section{O Vittecoq, V Corrigall, M Bodman-Smith, G Panayi}

Department of Rheumatology, King's College London, Guy's Hospital, London, UK

Arthritis Res Ther 2003, 5 (suppl 1):113

Objective: To evaluate the effects of BiP, which has recently been shown to prevent collagen-induced arthritis, on the differentiation of monocytes into immature dendritic cells (IDCs).
Methods: Monocytes from healthy blood donors were cultured for 3 days with GM-CSF and IL-4 to generate IDCs, either alone or in the presence of $\mathrm{BiP}(20 \mu \mathrm{g} / \mathrm{ml})$ or $\beta$-galactosidase $(20 \mu \mathrm{g} / \mathrm{ml})$ as a control. TNF- $\alpha$ and IL-10 levels were measured by ELISA from the culture supernatants collected at 24 and 72 hours. Neutralisation experiments with IL-10 blockers were performed. Immunoflurescent staining and FACS analysis were carried out on cells harvested at day 3. Mixed leukocyte reactions were performed by coculturing the different monocyte populations with purified allogenic T cells (ratio 1:10) for 5 days. Results: Addition of BiP to monocytes cultured with GM-CSF and IL-4 i) significantly inhibited down-regulation of CD14 and up-regulation of HLA-DR, CD80, CD86 and CD1a, the pattern of surface markers usually consistent with IDC differentition, ii) induced a significantly higher production of IL-10 within the supernatants and iii) strongly inhibited the proliferation of allogeneic T cells. Many of the effects mediated by BiP can be reversed by the addition of anti-IL10 antibody. Conclusion: These findings support the concept that BiP may have immunomodulatory properties that could have therapeutic benefit in rheumatoid arthritis.

\section{4}

A subset of memory effector $T$ cells in peripheral blood defined by differential expression of the TCR- $\zeta$ chain Z Zhang, N Panesar, AP Cope

Kennedy Institute of Rheumatology Division, Faculty of Medicine, Imperial College, London, UK Arthritis Res Ther 2003, 5 (suppl 1):114

Background: The T-cell receptor zeta (TCR- $\zeta$ ) chain plays an important role not only in the assembly of the TCR/CD3 complex but also in coupling cell surface receptors to downstream intracellular signalling pathways. We have recently identified a subset of T cells in the peripheral blood that expresses low levels of TCR zeta (TCR- $\zeta$-dim). Since several groups have documented reduced expression of TCR- $\zeta$ chain in synovial-joint $T$ cells from patients with rheumatoid arthritis, we set out to test the hypothesis that peripheral blood TCR- $\zeta$-dim T cells represent a subset of circulating memory effector $T$ cells.

Objective: To characterise the cell surface markers and cytokine-producing capacity of the TCR- $\zeta$-dim T cells.

Methods: Three-colour staining and flow cytometry (FACS) were performed on fixed and permeabilised cells to study cell-surface markers and the expression of intracellular TCR- $\zeta$. Intracellular TNF- $\alpha$ and IFN- $\gamma$ expression were also detected by FACS after stimulation with phorbol ester and ionomycin in the presence of monensin, and the expression in TCR- $\zeta$-bright and TCR- $\zeta$-dim populations was compared.

Results: Engagement of TCR on peripheral blood T cells in vitro led to down-regulation of TCR- $\zeta$. Furthermore, levels of TCR- $\zeta$ from inflamed joints were also dramatically reduced in comparison with that from the peripheral blood. As expected, synovial-fluid and membrane Tcells expressed more CD45RO, CD45RB-dull and CD62L-neg than peripheral blood T cells. In comparison with the $\mathrm{CD}^{+}{ }^{+} \mathrm{TCR}-\zeta$-bright population, peripheral blood TCR- $\zeta$-dim T cells were also enriched for CD45RO expression, and expressed the CD45RB-dull and CD62Lneg markers of memory T cells. A significant proportion of TCR- $\zeta$-dim $T$ cells were found to be CD28-negative. After stimulation in vitro, TCR- $\zeta$-dim cells were found to be enriched for TNF- $\alpha$ and IFN- $\gamma$ producers in comparison with the TCR- $\zeta$-bright T-cell subset from the sample individual. Preliminary data suggest that TCR- $\zeta$-bright and TCR- $\zeta$-dim T-cell subsets can be distinguished on the basis of their relative expression of CD52.

Conclusion: $\mathrm{CD}^{+}{ }^{+} \mathrm{TCR}-\zeta$-dim cells are characteristic of T cells activated through the TCR and are enriched for cells capable of expressing TNF- $\alpha$ and IFN- $\gamma$. We postulate that this T-cell subset may represent circulating effector cells that may play a role in promoting the chronic inflammatory process. 
115

\section{Methotrexate (MTX) inhibition of cytokine production: relationship with clinical outcome and genetic polymorphisms}

\section{Pascual-Salcedo', P Sabina ${ }^{1}$, A Balsa', ME Miranda'1, J} Martin', M Pascual'2 ${ }^{2}$ E Martín Mola'

${ }^{1}$ Servicios de Inmunología y Reumatologia Hospital La Paz, Spain ${ }^{2} \mathrm{CSIC}$, Granada, Spain

Arthritis Res Ther 2003, 5 (suppl 1):115

Introduction: Downregulation of TNF- $\alpha$ levels in synovial fluid of rheumatoid arthritis (RA) has been described following treatment with methotrexate (MTX). Although the mechanism of action of MTX is unknown, inhibition of methylenetetrahydrofolate reductase (MTHFR) could be implicated. Polymorphisms in MHTFR have been described (A1298T and C677T) that may condition clinical response.

Aim: To determine whether MHTFR genotype is related to the 'in vitro' cytokine inhibition and 'in vivo' clinical response to MTX.

Materials and methods: Twenty-three patients with early RA were studies along with 23 healthy donors. Blood (1/10 diluted in LPS-free Iscove's) was cultured in the presence of $1 \mu \mathrm{g} / \mathrm{ml}$ anti-CD3 and $1 \mu \mathrm{g} / \mathrm{ml}$ anti-CD28, with or without MTX $(0.152$ to $625 \mathrm{ng} / \mathrm{ml}$; L. Aarden, personal communication). The effect of MTX was reverted with folinic acid $(3 \mu \mathrm{g} / \mathrm{ml})$. TNF- $\alpha$, IFN- $\gamma$ and IL- 6 concentrations were measured by ELISA in sera and culture supernatants after 72 hours. MTHFR polymorphisms were determined by PCR-RFLP. DAS was used to evaluate the clinical effect of MTX at 6 months.

Results: 1) Basal and stimulated cytokine production was similar in controls and patients. 2) $40 \mathrm{ng} / \mathrm{ml}$ of MTX significantly inhibited IFN- $\gamma$, TNF- $\alpha$ and IL- 6 production of T cells stimulated by anti-CD3 ${ }^{+}$antiCD28 $(P<0.001)$. 3) A statistically significant correlation $(P<0.05)$ was found between ID-50 for TNF- $\alpha$ and clinical improvement as assessed by DAS (\% decrease of DAS score). ID-50 for TNF- $\alpha$ was not related to MHTFR polymorphisms $(P=0.076)$. Median ID-50 was 27.13 for TNF- $\alpha$ (25th percentile $=18.5 ; 75$ th percentile $=34.16)$ and 19.74 for IFN- $\gamma(25$ th percentile $=13.08 ; 75$ th percentile $=24.00)$. 4) ID-50 for IFN- $\gamma$ was lower in homozygous individuals $A 1298 \mathrm{~A}$ $(P<05)$, but was not associated with clinical outcome. No statistical differences were associated to the C677T mutation.

Conclusions: MTX inhibits stimulated T cell cytokine production. Individual susceptibility for MTX inhibition of cytokine production could help predict clinical response to the drug. Mutations in the MHTFR gene were associated with a lower response to MTX 'in vitro'.

\section{6}

\section{Combination of cellular imaging and molecular analysis for evaluation of cellular gene therapy of RA IH Tarner1, E Neumann', M Judex'1, J Schölmerich', S Gay², U Müller-Ladner ${ }^{1}$}

${ }^{1}$ Department of Internal Medicine I, University Hospital Regensburg, Regensburg, Germany

${ }^{2}$ Center of Experimental Rheumatology, Department of Rheumatology, University Hospital Zurich, Zurich, Switzerland

Arthritis Res Ther 2003, 5 (suppl 1):116

Objective: Gene therapy has been developed as a promising tool for the treatment of autoimmune diseases such as rheumatoid arthritis (RA). In order to achieve the goal of establishing a targeted delivery of potentially immune-modulating gene products to inflamed joints in RA, the concept of adoptive cellular gene therapy was developed in an animal model of RA, collagen-induced arthritis (CIA). Adoptive cellular gene therapy utilizes immune cells with specific homing capacity as "vehicle cells" to deliver therapeutic gene products locally after ex vivo retroviral transduction. For the evaluation of adoptive cellular gene therapy two goals have to be achieved. One is the monitoring of cellular trafficking and homing to areas of inflammation. The other is the analysis of molecular effects in the synovium of inflamed target joints. In order to approach these goals, we have tested two analysis powerful techniques on animal and human specimens. For in vivo, real-time visualization of cellular trafficking, bioluminescence imaging has been developed in animal models. For the analysis of compartment-specific analysis of gene expression in human RA synovium, we established the combination of laser-mediated microdissection and differential display to analyze distinct gene expression profiles of histologically defined areas in RA synovium.

Methods: In the CIA model, antigen-specific T-cell hybridomas and dendritic cells (DC) were adoptively transferred into recipient animals after ex-vivo retroviral transduction to express luciferase. Repeated injection with the substrate luciferin and bioluminescence imaging on consecutive days allowed in vivo tracking of the adoptively transferred cells. For development of compartment-specific molecular analysis, cryosections derived from RA synovial tissues were used to obtain cells samples from synovial lining and sublining using a microbeam laser microscope. RNA was isolated and analyzed using nested RAPPCR for differential display fingerprinting. Differentially expressed bands were cut out, PCR products were eluted, cloned and sequenced. Differential expression of identified sequences was confirmed by in situ hybridization and immunohistochemistry.

Results: It could be demonstrated that adoptively transferred T-cell hybridomas and DC homed to and accumulated in inflamed joints of CIA mice. In addition, microdissected RA synovial tissue sections containing about 600 cells were shown to yield sufficient RNA for a stable, reproducible RNA fingerprint. This method allowed us to identify several known and unknown genes as being expressed differentially between the synovial lining and sublining layers, including thrombospondin in the linig, Ciz/cip-1 in the sublining and fibronectin in both layers of RA synovium. All three molecules could be confirmed on the mRNA and protein level.

Conclusion: We tested two novel analysis techniques on animal and human specimens. Bioluminescence imaging allowed in vivo monitoring of the migration pattern of therapeutic "vehicle cells" in adoptive cellular gene therapy of CIA, an animal model of RA. Laser microdissection and subsequent RAP-PCR reliably enabled us to obtain novel insights into the area-dependent differential regulation of gene expression in human RA synovium and distinction between different cell types. In combination, these methods present a powerful tool for the evaluation of cellular gene therapy of RA. 